\title{
Itinerário terapêutico de pacientes com artrite reumatoide em uso de medicamentos modificadores do curso da doença biológicos
}

Silvia Coimbra de Oliveira

Dissertação de Mestrado apresentada ao Programa de Pós-Graduação em Saúde Pública, como exigência para obtenção do título de Mestre em Ciências.

Área de Concentração: Serviços de Saúde Pública

Orientadora: Prof ${ }^{\mathrm{a}} \mathrm{Dr}^{\mathrm{a}}$ Aylene Emilia Moraes Bousquat

Versão Revisada

São Paulo

2017 
É expressamente proibida a comercialização deste documento, tanto na sua forma impressa como eletrônica. Sua reprodução total ou parcial é permitida exclusivamente para fins acadêmicos, desde que na reprodução figure a identificação do autor, título, instituição e ano da dissertação.

Catalogação da Publicação

Biblioteca/CIR: Centro de Informação e Referência em Saúde Pública Faculdade de Saúde Pública da Universidade de São Paulo Dados fornecidos pela autora

Oliveira, Silvia Coimbra de

Itinerário terapêutico de pacientes com artrite reumatoide em uso de medicamentos modificadores do curso da doença biológicos / Silvia Coimbra de Oliveira; orientadora Profa Dra Aylene Emilia Moraes Bousquat. -- São Paulo, 2017.

$100 \mathrm{p}$.

Dissertação (Mestrado) -- Faculdade de Saúde Pública da Universidade de São Paulo, 2017.

1. itinerário terapêutico. 2 . artrite reumatoide. 3. medicamento modificador do curso da doença. 4. medicamento biológico 
Dedico o resultado deste estudo

À minha mãe, eterna companheira e entusiasta das minhas pequenas vitórias.

À minha amiga Paula e a seu pai Sérgio, que me ajudaram a entender que era o momento de dar o primeiro passo.

Aos meus amigos mais íntimos, pela compreensão da ausência nos últimos tempos e pelo incentivo de sempre.

À minha orientadora Aylene, por sua simplicidade e acolhimento, tão necessários.

Aos pacientes que nos doaram seu tempo e suas histórias,

e por eles. 


\section{AGRADECIMENTOS}

À minha professora, a Dra Aylene Bousquat, que acolheu minha proposta de estudo, contribuiu grandemente na formação do olhar humano sobre o sistema de saúde, e foi sempre uma parceira.

À professora Dra Nicolina Silvana Romano Lieber, pelas suas sábias observações e sugestões na banca de qualificação, e por provocar minha admiração e gosto pela saúde pública desde a graduação.

À professora Dra Denise Martin Coviello, por sua disponibilidade e engajamento com o estudo, e por sua participação na banca de qualificação, apoiando-me a construir o olhar para as humanidades.

A professora Dra Elvira Maria Guerra Shinohara, que na iniciação científica me ensinou a relevância social dos projetos de pesquisa.

À minha gestora no hospital, a farmacêutica Débora Mantovani, que em todos os momentos apoiou este estudo, e me permitiu levá-lo a cabo permitindo a flexibilização dos meus horários de trabalho; e à minha colega Patrícia, que comprou comigo este desafio, e muitas vezes me cobriu para que eu pudesse colher e trabalhar os dados. 
A todos os farmacêuticos e atendentes das farmácias do componente especializado Maria Zélia e Várzea do Carmo, que abriram espaço para o estudo, me acolheram e me apoiaram na identificação dos pacientes para o estudo.

Aos meus amigos Isabel, José, João e Livia, por estarem presentes nas fases mais difíceis, e por fazerem parte da minha construção como profissional e como gente.

Aos meus pais, pela educação como valor. 


\section{RESUMO}

OLIVEIRA, S. C. Itinerário terapêutico de pacientes com artrite reumatoide em uso de medicamentos modificadores do curso da doença biológicos. Dissertação - Faculdade de Saúde Pública da USP, São Paulo, 2017.

Introdução - A artrite reumatoide (AR) é uma doença crônica autoimune degenerativa, de alta prevalência e alta morbimortalidade, com difícil diagnóstico em todo o mundo. O seu pronto diagnóstico e o rápido início com medicamentos modificadores do curso da doença (MMCD) impactam de forma relevante o prognóstico do paciente. Para alguns pacientes os MMCD's sintéticos não serão eficazes e este paciente deverá receber então um MMCD biológico, medicamento este de alto custo para o paciente e o sistema de saúde. Objetivo - Explorar as trajetórias percorridas na busca por cuidado por pacientes com AR em uso de MMCD biológico no município de São Paulo. Métodos - Pesquisa qualitativa, de caráter exploratório, com orientação analítico-descritiva, mediante entrevistas semiestruturadas com questões abertas, iniciada após prévia aprovação do Comitê de Ética em Pesquisa e consentimento esclarecido dos entrevistados. Os sujeitos são pacientes em uso de MMCD biológico para tratamento de AR dispensados pelo SUS. Foi utilizada a ferramenta do itinerário terapêutico (IT) para entendimento do caminho escolhido por estes pacientes na busca por cuidado em saúde. Resultados e Discussão - Entre os entrevistados, a busca de cuidado ocorreu tardiamente, normalmente sem a suspeita de que se tratasse de doença reumática degenerativa. Os primeiros profissionais acessados foram o médico clínico geral ou o ortopedista, que raras vezes investigaram com atenção os sintomas relatados para em seguida proceder o encaminhamento adequado e rápido do paciente para o reumatologista. Nos IT's descritos, os tratamentos na sua maioria são constituídos apenas pelos medicamentos, e sem a participação de outros profissionais no acompanhamento além do reumatologista. Os pacientes entrevistados chegaram até o MMCD biológico após tentativa de controle da doença com 
os MMCD's sintéticos, conforme descreve o protocolo de tratamento do Ministério da Saúde. Há nos IT's descritos diversos atores representantes da iniciativa privada, que apoiam e influenciam estes pacientes na escolha dos seus caminhos por cuidado de saúde, que devem ser melhor compreendidos em estudos futuros.

Descritores: Itinerário Terapêutico; Artrite Reumatoide; Medicamento Biológico; Medicamento Modificador do Curso da Doença. 


\section{ABSTRACT}

OLIVEIRA, S. C. Therapeutic itinerary of patients with rheumatoid arthritis using biologic disease-modifying antirheumatic drugs. [Master dissertation] Faculdade de Saúde Pública da USP, São Paulo, 2017.

Introduction - Rheumatoid arthritis (RA) is a chronic degenerative autoimmune disease of high prevalence and with high morbidity and mortality, worldwide difficult to diagnose. Its prompt diagnosis and rapid onset with disease modifying drugs (DMARD) have a relevant impact on the patient's prognosis. For some patients, the synthetic DMARD's will not be effective so these patients should receive a biological DMARD - a high cost medication both to the patient and the health system. Objective - To explore the trajectories performed by patients with RA using biological DMARD in the search for care in the city of São Paulo. Methods - Qualitative research, with an exploratory character, with analytical-descriptive orientation, through semi-structured interviews with open questions, initiated after prior approval of the Committee on Ethics in Research and informed consent of the interviewees. The subjects are patients using biological DMARD to treat RA that were dispensed by SUS. The therapeutic itinerary tool (TI) was used to understand the path chosen by these patients in the search for health care. Results and Discussion - Among those interviewees, the search for care occurred late, usually without the suspicion that there was a degenerative rheumatic disease. The first accessed professionals were the general practitioner or the orthopedist, who rarely ever investigated the reported symptoms with attention to direct the patient to the rheumatologist quickly. In the described TI's, the treatments are mostly composed only by the medicines, and without the participation of other professionals in the follow-up besides the rheumatologist. The patients interviewed reached the biological DMARD's after an attempt to control the disease with synthetic DMARD, as described in the Ministry of Health recommendations. There are several actors representing the private 
sector described in the TI's, who support and influence the patients in the choice of their care pathways, which should be better understood in future studies.

Keywords: Therapeutic Itinerary; Rheumatoid Arthritis; Biological Drugs; Disease-Modifying Antirheumatic Drugs. 


\section{SUMÁRIO}

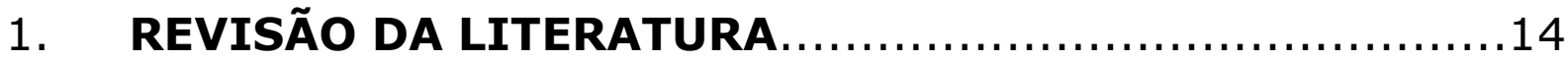

1.1. CARACTERÍSTICA GERAL DA DOENÇA $\ldots \ldots \ldots \ldots \ldots \ldots \ldots 14$

1.2. DIAGNÓSTICO, MONITORAMENTO E IMPACTO DA DOENÇA. 16

1.3. FARMACOTERAPIA E TRATAMENTO NÃO MEDICAMENTOSO: HISTÓRICO NO BRASIL E NO MUNDO......21 1.4. SISTEMA DE SAÚdE NO BRASIL: SUS E SETOR

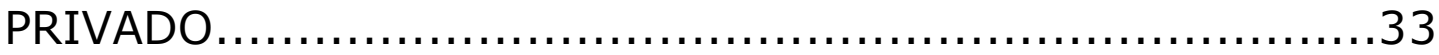

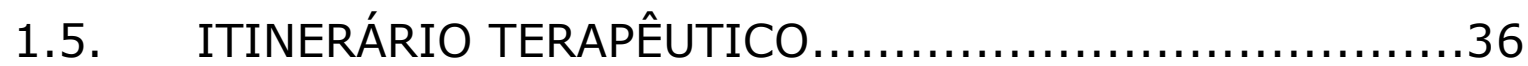

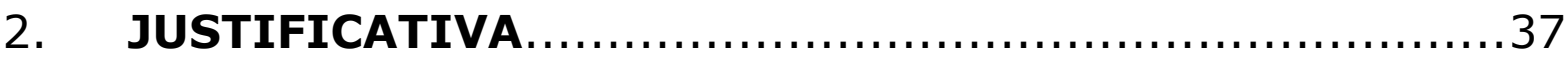

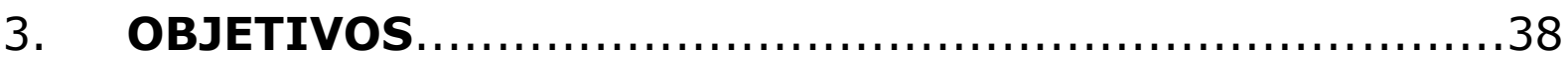

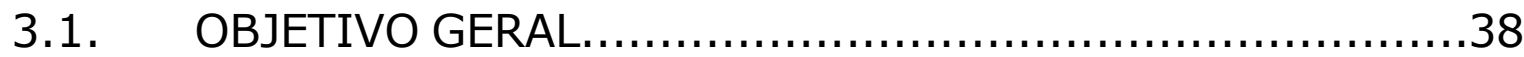

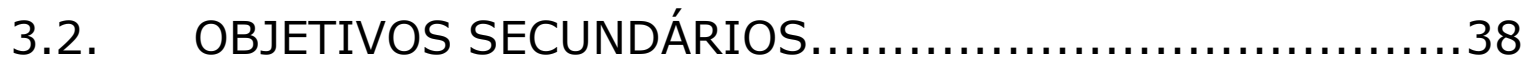

4. METODOLOGIA E ASPECTOS ÉTICOS.........................

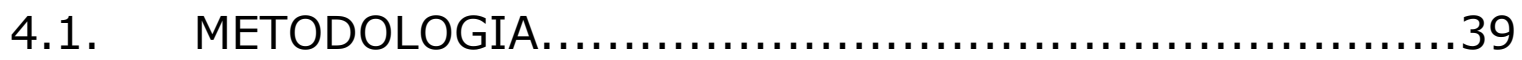

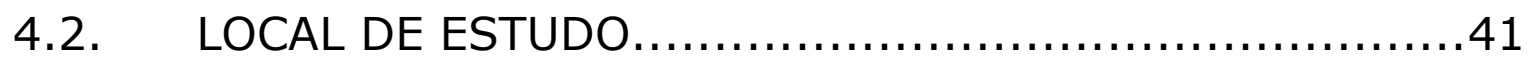

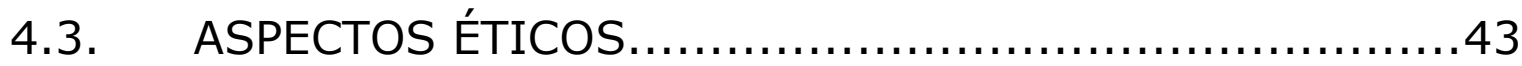

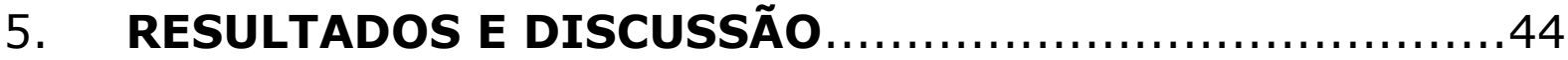

5.1. CARACTERIZAÇÃO DOS ENTREVISTADOS ................44

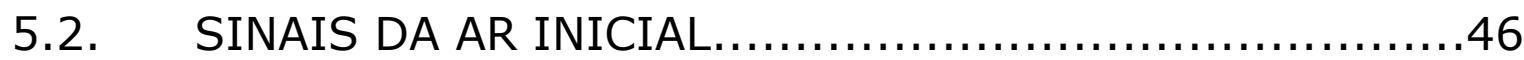


5.3. BUSCA POR CUIDADO - DIAGNÓSTICO ...................52

5.4. EDUCAÇÃO SOBRE A DOENÇA .........................63

5.5. TRATAMENTO NÃO MEDICAMENTOSO INSTITUÍDO......67

5.6. FARMACOTERAPIA INSTITUÍDA...................... 70

5.7. AFASTAMENTOS LABORAIS........................... 81

6. ACHADOS A SEREM MELHOR EXPLORADOS EM OUTROS

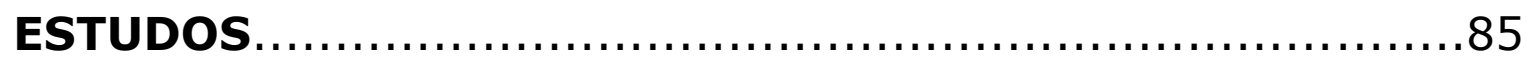

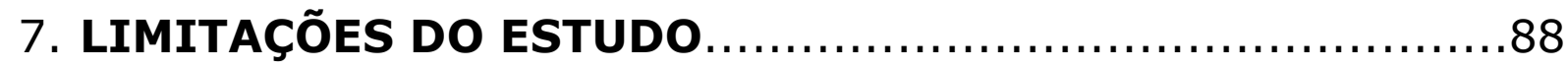

8. CONSIDERAÇÕES FINAIS $\ldots \ldots \ldots \ldots \ldots \ldots \ldots \ldots \ldots \ldots \ldots \ldots \ldots \ldots$

9. REFERÊNCIAS $\ldots \ldots \ldots \ldots \ldots \ldots \ldots \ldots \ldots \ldots \ldots \ldots \ldots \ldots \ldots \ldots \ldots \ldots$

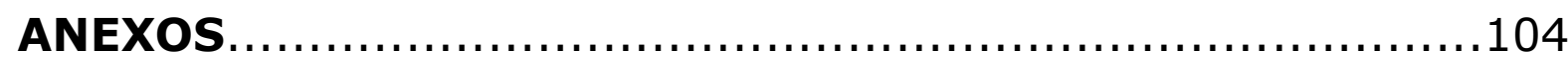

I. Termo de Consentimento Livre e Esclarecido...................104

II. Aprovação do estudo pelo CEP-FSP/USP.....................106

III. Anuência da SES/SP para entrevistas com pacientes.....109 


\section{Lista de abreviaturas e siglas}

\begin{tabular}{|l|l|}
\hline ACR & Colégio Americano de Reumatologia, em inglês \\
\hline AINE & Anti-inflamatório não esteroide \\
\hline Anti-CCP & anticorpo antipeptídeo cíclico citrulinado \\
\hline Anti-TNF & $\begin{array}{l}\text { Medicamentos bloqueadores do fator de necrose } \\
\text { tumoral }\end{array}$ \\
\hline AP & Atenção Primária \\
\hline AR & Artrite reumatoide \\
\hline bDMARD & $\begin{array}{l}\text { Medicamento modificador do curso da doença biológico, } \\
\text { em inglês }\end{array}$ \\
\hline CRA & Associação Canadense de Reumatologia, em inglês \\
\hline DMARD & Medicamento modificador do curso da doença, em inglês \\
\hline EUA & Estados Unidos da América \\
\hline EULAR & Liga Europeia contra Reumatismo, em inglês \\
\hline FAN & Fator antinuclear \\
\hline FR & Fator reumatoide \\
\hline IT & Itinerário terapêutico \\
\hline MMCD & Medicamento modificador do curso da doença \\
\hline MS & Ministério da Saúde \\
\hline MTX & Metotrexato \\
\hline PCDT & Protocolo Clínico e Diretrizes Terapêuticas \\
\hline PIB & Produto interno bruto \\
\hline RA & Artrite reumatoide, em inglês \\
\hline RENAME & Relação Nacional de Medicamentos Essenciais \\
\hline SUS & Sistema Único de Saúde \\
\hline TI & Itinerário Terapêutico, em inglês \\
\hline
\end{tabular}




\section{LISTA DE QUADROS E FIGURAS:}

Quadro 01: Esquemas de tratamento com MMCD's biológicos comparados ao metotrexato e custos anuais. 20

Quadro 02: Linha do tempo com aprovações e indicação dos MMCD biológicos no Brasil e no mundo. .28

Quadro 03: Dados demográficos dos usuários entrevistados

Figura 01: Fases de espera entre os primeiros sintomas de $A R$ e o início com o MMCD, e ações que podem ser realizadas para minimizar o tempo das

etapas .54

Quadro 04: Datas estimadas de diagnóstico e tempos médios de espera dos primeiros sintomas até o diagnóstico

Quadro 05: Datas estimadas de diagnóstico, início com MMCD sintético e biológico, e esquemas terapêuticos utilizados antes dos biológicos. .75

Figura 02: Itinerário terapêutico do usuário A.............................78

Figura 03: Itinerário terapêutico do usuário C............................79 


\section{REVISÃO DA LITERATURA}

\subsection{CARACTERÍSTICA GERAL DA DOENÇA}

A artrite reumatoide (AR) é uma doença crônica, sistêmica, progressiva, que pode ser confundida com outras doenças reumáticas ou lesões ortopédicas agudas, exigindo diagnóstico especializado. Tem elevado impacto para paciente e sociedade devido à sua morbimortalidade, e possui uma janela de oportunidade terapêutica - período de tempo em que se o tratamento adequado é iniciado, pode ser atribuído a importante melhora de 3 a 12 meses após aparecimento dos primeiros sintomas. ${ }^{1-5}$

Sua prevalência média é de 0,5 a $1 \%$ na população mundial, podendo chegar a valores mais altos em algumas populações. ${ }^{6,7}$ No Brasil, dois estudos descreveram de 0,46 a 2 o percentual de pessoas acometidas, a depender da região estudada, o que significa pelo menos 1 milhão de pessoas acometidas considerada estimativa populacional de julho de $2017.8,9$ As mulheres são de 2 a 3 vezes mais afetadas que os homens, e os sintomas aparecem principalmente entre os 31 e 60 anos. ${ }^{1-5}$

A etiologia da AR ainda não é bem definida, relacionando-se a fatores genéticos, epigenéticos e ambientais. ${ }^{1}$ Dentre os ambientais, os principais fatores de risco são o tabagismo, as infecções periodônticas e a composição da flora intestinal. ${ }^{1,10}$ 
Com componentes de doença autoimune, envolve a inflamação da membrana sinovial das articulações. Causa desconforto, dor e edema. Com a persistência da condição inflamatória, pode levar à destruição óssea e cartilaginosa, e eventualmente acometer outros sistemas. Se não controlada, compromete a independência do paciente e sua autonomia para a realização de atividades diárias, de lazer e laborais. ${ }^{1,2,4}$

Além do tecido articular e ósseo, a AR não controlada pode se manifestar em outros órgãos, o que ocorre mais comumente em pacientes com mais tempo de doença, doença articular grave, tabagistas e aqueles com elevados títulos de auto anticorpos como o fator reumatoide (FR), anticorpo antipeptídeo cíclico citrulinado (anti-CCP) e fator antinuclear (FAN), e baixo nível socioeconômico. ${ }^{2,11}$ Os órgãos mais frequentemente afetados são vasos sanguíneos, coração e pulmões, e as possíveis manifestações secundárias: nódulos reumatoides, pericardite, pleurite, doença pulmonar intersticial, hipertensão da artéria pulmonar, síndrome de Caplan, síndrome de Felty, anemia de doença crônica, neuropatia, dentre outras. ${ }^{11}$ Quanto maior for o acometimento extra articular, maior a mortalidade da AR. ${ }^{11}$

Para evitar a evolução dos sintomas e o comprometimento dos tecidos, os pacientes acometidos precisam de diagnóstico e tratamento prontos e especializados. ${ }^{1,2,3}$ 


\subsection{DIAGNÓSTICO, MONITORAMENTO E IMPACTO DA DOENÇA}

O diagnóstico envolve um bom exame clínico, a investigação de história de sintomas, e exames de imagem e laboratoriais. Devem ser considerados: quantidade, localização das articulações afetadas, e duração dos sintomas, presença de nódulos reumatoides, imagens radiográficas, e medida de fatores inflamatórios - proteína C e velocidade de hemossedimentação, e titulação de anticorpos - fator reumatoide, e em caso deste negativo, anti-CCP. ${ }^{2,3,12}$

Tanto no diagnóstico quanto no monitoramento regular da doença, devem ser utilizados instrumentos de avaliação de atividade da doença e de avaliação de capacidade funcional. 2,3,12

O diagnóstico da AR no PCDT brasileiro indica as mesmas orientações do Colégio Americano de Reumatologia (ACR) de 1987 e o consenso entre ACR e Liga Europeia contra Doenças Reumáticas (EULAR) de 201013, descrevendo que a investigação clínica das queixas e história do paciente deve ser complementada por exames laboratoriais e/ou de imagem. Devese diferenciar a AR de outras artrites e neoplasias, e considerar a titulação de anticorpos como FR e anti-CCP, bem como exames de imagem de base e sequenciais não só para efeito diagnóstico como também para avaliação de prognóstico da doença. Como exames de imagem, a depender de cada caso, sugerem-se radiografias das articulações afetadas, ultrassonografia e ressonância magnética. ${ }^{2,13}$ 
Os sintomas clínicos mais presentes descritos são rigidez matinal, artrite simétrica afetando principalmente mãos, punhos, cotovelos, pés, tornozelos, e joelhos e presença de nódulo reumatoide, com duração de pelo menos seis semanas. ${ }^{2,13}$

Inúmeros estudos internacionais demonstram 0 desafio que representa à saúde pública o diagnóstico precoce da $A R^{14-21}$, e diversas estratégias já foram testadas para minimizar o tempo entre a ocorrência dos primeiros e o início do tratamento com medicamento modificador do curso da doença (MMCD), aproveitando a janela de oportunidade terapêutica da doença, e minimizando sua morbimortalidade. ${ }^{22-28}$

O acesso ao médico especialista - reumatologista - constitui um dos gargalos para o diagnóstico precoce. ${ }^{14-21}$ Idealmente, o diagnóstico e o acompanhamento do paciente até alcançar baixo índice de atividade da doença, devem ser feitos pelo reumatologista, ou devem estar sob seu monitoramento. Assim, além de apoiar o correto diagnóstico, o especialista pode avaliar melhor o prognóstico da doença e indicar o tratamento mais adequado, considerando a individualidade do paciente. ${ }^{3}$

Apesar da relevância da presença do especialista no diagnóstico e monitoramento da doença sobretudo nas fases de crise, a equipe de atenção primária (AP) deve ser preparada para rastrear este paciente quando do aparecimento dos primeiros sintomas, direcioná-lo em tempo para o especialista, e recebe-lo de volta após o diagnóstico, apoiando na sua educação e de seus familiares sobre a doença e o tratamento, fornecendo suporte psicossocial, e coordenando a necessidade de cuidados 
suplementares, evitando duplicidades terapêuticas e diagnósticas no sistema. ${ }^{3,29,30}$

Diretrizes internacionais indicam que o tempo ótimo para início de tratamento é em até 3 meses do aparecimento dos sintomas persistentes. ${ }^{3}$

O PCDT brasileiro orienta que se inicie 0 uso de MMCD preferencialmente nos primeiros 12 meses de sintomas, objetivando modificar o curso da doença. ${ }^{2}$

A AR limita o paciente com relação a dor e realização das atividades diárias. Traz importante custo para o portador e sua família - financeiro relacionado a cuidados médicos necessários, e de qualidade de vida, continuidade da sua participação na sociedade, e saúde mental. Para a sociedade também há impacto financeiro da utilização dos sistemas de saúde e previdência social e redução de produtividade. ${ }^{31,32}$

Se os sintomas não forem controlados, ocorrerão afastamentos laborais. No primeiro ano de AR, o paciente fica afastado em média 118 dias, comparados a 46 dias/ano na doença já estabelecida, e 11 da média da população. Cerca de um terço dos pacientes é afastado das atividades laborais 2 anos após o diagnóstico, e após 6 anos, o número sobe para 53\%. Os afastamentos são devidos à debilidade física e psicológica derivada da doença, e relacionam-se à dificuldade para o seu diagnóstico precoce e para o acesso a tratamento e monitoramento da AR. ${ }^{32}$

Os principais fatores que contribuem para o potencial de afastamento são: duração da $A R$, idade, comorbidades, e exercício de trabalhos braçais. ${ }^{32}$ 
Segundo estudo realizado por Buendgens e colaboradores em 2013 com pacientes com AR grave em Santa Catarina, os custos da doença para o sistema de saúde estão sobretudo relacionados à terapia com MMCD's biológicos. O valor médio gasto por um paciente com despesas médicas, incluindo medicamentos, terapias físicas, exercícios e hospitalizações, foi de pouco menos de 20 mil reais por paciente/ano. ${ }^{33}$

O custo anual do tratamento de manutenção, considerando apenas o valor do medicamento, pode variar de pouco menos de $R \$ 100,00$ para o tratamento em monoterapia com o metotrexato (MTX) - medicamento sintético e $1^{\text {a }}$ linha de tratamento, a $\mathrm{R} \$ 88$ mil para o tratamento com um dos MMCD's biológicos, indicados como segunda linha de tratamento após falha ou toxicidade com pelo menos 2 esquemas de tratamento com MMCD's sintéticos. ${ }^{2}$ O quadro 1 apresenta valores de custo dos MMCD's biológicos comparados ao do MTX, considerando apenas o valor dos medicamentos. Os valores são de junho de 2016 da Câmara de Regulação do Mercado de Medicamentos (CMED/ANVISA) ${ }^{34}$, e foi considerado o preço fábrica sem ICMS das apresentações dispensadas pela Secretaria Estadual de Saúde de São Paulo ${ }^{35}$ com os menores valores por mg, e as posologias indicadas nas bulas dos produtos de referência, tendo como referência um paciente de $70 \mathrm{~kg}^{36}$. 
Quadro 01: Esquemas de tratamento com MMCD's biológicos comparados ao metotrexato e custos anuais:

\begin{tabular}{|c|c|c|c|}
\hline Medicamento & $\begin{array}{l}\text { Posologia de } \\
\text { Indução }\end{array}$ & $\begin{array}{l}\text { Posologia de } \\
\text { Manutenção }\end{array}$ & Custo Anual \\
\hline abatacepte & $\begin{array}{c}1 \text { infusão } \\
\text { endovenosa de } 30 \\
\text { minutos nas } \\
\text { semanas } 0,2 \text { e } 6 \\
\text { (dose }=500 \mathrm{mg} \text { se } \\
<60 \mathrm{~kg}, 750 \mathrm{mg} \text { se } \\
60-100 \mathrm{~kg} \text {, e } \\
1000 \mathrm{mg} \text { se } \\
>100 \mathrm{~kg} \text { ) }\end{array}$ & $\begin{array}{c}1 \text { infusão endovenosa } \\
\text { de } 30 \text { minutos a cada } \\
4 \text { semanas } \\
\text { (dose }=500 \mathrm{mg} \text { se } \\
<60 \mathrm{~kg}, 750 \mathrm{mg} \text { se } 60- \\
100 \mathrm{~kg} \text {, e } 1000 \mathrm{mg} \mathrm{se} \\
>100 \mathrm{~kg} \text { ) }\end{array}$ & $R \$ 53.951,82$ \\
\hline adalimumabe & $\begin{array}{c}1 \text { injeção } \\
\text { subcutânea com } \\
40 \mathrm{mg}\end{array}$ & $\begin{array}{c}1 \text { injeção subcutânea } \\
\text { com 40mg a cada 1-2 } \\
\text { semanas }\end{array}$ & $R \$ 79.157,00$ \\
\hline $\begin{array}{c}\text { certolizumabe } \\
\text { pegol }\end{array}$ & $\begin{array}{c}2 \text { injeções } \\
\text { subcutâneas com } \\
\text { 200mg cada por } \\
\text { dia a cada } 2 \\
\text { semanas, por } 6 \\
\text { semanas }\end{array}$ & $\begin{array}{c}1 \text { injeção subcutânea } \\
\text { com 200mg a cada } 2 \\
\text { semanas ou } 2 \\
\text { injeções a cada } 4 \\
\text { semanas }\end{array}$ & $R \$ 20.050,73$ \\
\hline etanercepte & $\begin{array}{c}1 \text { injeção } \\
\text { subcutânea com } \\
50 \mathrm{mg}\end{array}$ & $\begin{array}{c}1 \text { injeção subcutânea } \\
\text { com 50mg } \\
\text { 1x/semana }\end{array}$ & $R \$ 71.954,22$ \\
\hline golimumabe & $\begin{array}{c}1 \text { injeção } \\
\text { subcutânea com } \\
50 \mathrm{mg}\end{array}$ & $\begin{array}{c}1 \text { injeção subcutânea } \\
\text { com 50mg } \\
1 x / \text { semana }\end{array}$ & $R \$ 35.250,36$ \\
\hline infliximabe & $\begin{array}{c}1 \text { infusão } \\
\text { endovenosa de } 1-2 \\
\text { horas com solução } \\
\text { com } 3 \mathrm{mg} / \mathrm{kg} / \text { nas } \\
\text { semanas } 0,2 \text { e } 6\end{array}$ & $\begin{array}{c}1 \text { infusão endovenosa } \\
\text { por } 1-2 \text { horas de } \\
\text { solução com } 3- \\
5 \mathrm{mg} / \mathrm{kg} \text { a cada } 4 \\
\text { semanas, ou com 6- } \\
\text { 10mg/kg a cada } 8 \\
\text { semanas }\end{array}$ & $\begin{array}{c}\mathrm{R} \$ 63.180,00 \mathrm{a} \\
\mathrm{R} \$ 88.452,00\end{array}$ \\
\hline rituximabe & $\begin{array}{c}1 \text { infusão } \\
\text { endovenosa de } \\
3,25-4,25 \text { horas } \\
\text { com } 1000 \mathrm{mg} \text { em } \\
\text { D1 e D15 }\end{array}$ & $\begin{array}{l}1 \text { infusão endovenosa } \\
\text { de } 3,25-4,25 \text { horas } \\
\text { com } 1000 \text { mg em D1 e } \\
\text { D15, em média a } \\
\text { cada } 6-12 \text { meses }\end{array}$ & $\begin{array}{c}\mathrm{R} \$ 25.310,60 \mathrm{a} \\
\mathrm{R} \$ 50.621,20\end{array}$ \\
\hline tocilizumabe & $\begin{array}{l}1 \text { infusão } \\
\text { endovenosa de } 1 \\
\text { hora com solução } \\
\text { com } 3-8 \mathrm{mg} / \mathrm{kg}\end{array}$ & $\begin{array}{c}1 \text { infusão endovenosa } \\
\text { de } 1 \text { hora com } \\
\text { solução com 3- } \\
\text { 8mg/kg a cada } 4 \\
\text { semanas }\end{array}$ & $R \$ 45.239,74$ \\
\hline metotrexato & $\begin{array}{c}3 \mathrm{cps} \text { de } 2,5 \mathrm{mg} \text { por } \\
\text { via oral }\end{array}$ & $\begin{array}{l}3-8 \mathrm{cps} \text { de } \\
2,5 \mathrm{mg} / \mathrm{sem}\end{array}$ & $\begin{array}{l}R \$ 99,68 a \\
R \$ 265,82\end{array}$ \\
\hline
\end{tabular}

Fonte: elaboração própria, com base em dados da CMED de $2016^{34}$ e bulário ANVISA ${ }^{36}$. 


\subsection{FARMACOTERAPIA E TRATAMENTO NÃO MEDICAMENTOSO: HISTÓRICO NO BRASIL E NO MUNDO}

Além do tratamento medicamentoso, a educação ao paciente e seus familiares constitui uma das principais estratégias de abordagem da $A R$, habilitando este paciente a fazer bom uso dos recursos a ele disponíveis, e evitando também desgaste excessivo das articulações através de adaptação da sua rotina de vida. ${ }^{3,37}$

Os sintomas mais presentes são dor e edema nas articulações, fadiga e miastenia. Para reduzir a sua ocorrência e intensidade, o tratamento não medicamentoso envolve exercícios regulares de baixo impacto e/ou aquáticos, técnicas de relaxamento muscular, estratégias para poupar energia, como pequenos descansos ao longo do dia e adaptação para a realização das atividades diárias poupando suas articulações, além do uso de bolsas térmicas. Os profissionais de fisioterapia e terapia ocupacional podem ser muito úteis para orientação destas técnicas e adaptação junto ao paciente. ${ }^{3}$

Acompanhamento psicológico também deve ser incluído no tratamento, e, a depender da evolução do desgaste das articulações, pode ser necessária intervenção cirúrgica. Acupuntura e apoio de outros profissionais de saúde também devem ser avaliados conforme necessidade individual. $2,3,12$ 
O rol farmacoterapêutico disponível para a AR teve importante evolução nas últimas décadas. Os primeiros estudos publicados sobre o uso de cloroquina, sulfassalazina, leflunomida e MTX para tratamento de AR, são, respectivamente, dos anos 50, final de 60, 80 e 90. O manejo da toxicidade com estas alternativas ainda não era muito conhecido, e o tratamento de primeira escolha costumava ser com anti-inflamatórios e analgésicos. Em 1998 o MTX teve registro aprovado nos Estados Unidos da América (EUA) para tratamento de artrite reumatoide. ${ }^{38}$

No final da década de 1990, o infliximabe foi aprovado nos EUA como o primeiro medicamento modificador do curso da doença biológico. ${ }^{38}$ No Brasil, a aprovação para o mesmo medicamento ocorreu no ano de $2000^{39}$, e, após mais 2 anos, em 2002, o mesmo foi incorporado na Relação Nacional de Medicamentos Essenciais (RENAME) ${ }^{40}$, passando a ser dispensado no SUS. Também na década de 2000-2009, outros sete MMCD's biológicos foram aprovados mundialmente, ampliando as alternativas terapêuticas para pacientes sem resposta ou com restrição ao uso de MTX e outros MMCD sintéticos. ${ }^{38}$

Após o infliximabe, passaram a compor também a RENAME em 2006 os MMCD's biológicos etanercepte e adalimumabe ${ }^{41}$, e em 2012, certolizumabe pegol, golimumabe, tocilizumabe, abatacepte e rituximabe ${ }^{42}$.

Os MMCD's biológicos são produzidos através de tecnologia de biologia molecular, com alto custo de desenvolvimento, produção e venda. Os valores destes medicamentos foram comparados ao do MTX no quadro 
1. Conforme PCDT do MS², os MMCD's biológicos devem ser prescritos como terceira opção de tratamento, após a tentativa com doses otimizadas de pelo menos dois esquemas de tratamento (em mono ou poli terapia) com MMCD sintéticos e falha terapêutica, importante reação adversa, ou outra limitação clínica.

Na comunidade científica internacional há uma intensa e fecunda discussão a respeito de qual seria o melhor tratamento de primeira escolha para o paciente com $A R$, e para qual paciente seria custo-efetivo o início com MMCD biológico sem chegar a utilizar os sintéticos. ${ }^{43,44}$ Devido à dúvida ainda existente a respeito de qual perfil de paciente se beneficiaria com o início do tratamento com MMCD biológico como primeira linha, e da ausência de comprovação de custo-efetividade em nível populacional, assim como o PCDT brasileiro, as diretrizes internacionais ainda indicam os MMCD sintéticos como escolha para a primeira linha. 2,3,12

A lista de medicamentos do componente especializado do Sistema Único de Saúde descreve tecnologias medicamentosas semelhantes às diretrizes americanas, canadenses, britânicas e europeias, contemplando todos os medicamentos biológicos nelas descritos. Isto é, o paciente diagnosticado e prescrito em território nacional tem direito ao tratamento medicamentoso, sem restrições, observadas as indicações clínicas. 2,3,12,45,46

Os protocolos europeu, britânico e canadense foram escolhidos como comparativo por terem tradicionalmente uma boa medicina disponível para suas populações, e o americano por ser líder na incorporação de novas 
tecnologias nos seus consensos médicos, ainda que elas não sejam tão acessíveis à sua população. Os autores mais frequentes de estudos sobre artrite provêm de instituições de pesquisa nestes países.

Todos os medicamentos biológicos registrados no Brasil para tratamento da doença estão disponíveis à população pelo SUS, respeitados diagnóstico, sequência racional de linhas de tratamento medicamentoso proposta também pelo ACR e pela EULAR, e exames de monitoramento de função renal, hemograma e colesterol, conforme a toxicidade conhecida do MMCD. $2,3,12$

Desde $2002^{40}$ temos incorporada no PCDT de AR do MS do Brasil a indicação de uso de medicamento de alta tecnologia - o MMCD biológico infliximabe, com reconhecida efetividade para atividade moderada a alta da doença. Em 2006 houve nova incorporação de medicamentos de alta tecnologia - adalimumabe e etanercepte, indicados assim como o infliximabe após 3 esquemas de tratamento com MMCD sintético. ${ }^{41} \mathrm{Em}$ 2013 os demais medicamentos biológicos disponíveis no mundo para AR passaram também a integrar a lista da RENAME: certolizumabe pegol, golimumabe, abatacepte, rituximabe e tocilizumabe. ${ }^{47}$

Em 2012 houve o lançamento mundial do tofacitinibe, MMCD sintético de nova geração, com tecnologia de terapia-alvo, com eficácia comparável aos MMCD's biológicos no tratamento da AR após falha terapêutica com os MMCD's sintético. ${ }^{48,49}$ Em 2014 o medicamento foi aprovado para comercialização no Brasil50, e em 2015 a SBR incluiu-o no seu consenso 
para tratamento de AR como opção para doença em atividade moderada a alta após falha com MMCD biológico. ${ }^{51}$

Em fevereiro de 2017, a Comissão Nacional de Incorporação de Tecnologias (CONITEC) emitiu relatório favorável à incorporação do tofacitinibe pelo SUS, com 180 dias previstos para a disponibilização do medicamento à população. Aguarda-se a publicação de uma atualização no PCDT do MS com as diretrizes de utilização e monitoramento do mesmo. ${ }^{49}$ Ao contrário do PCDT brasileiro para tratamento da $A R^{40}$, os consensos americano, europeu e canadense tenderam a primeiro indicar os MMCD's biológicos como opção equiparada com os MMCD's sintéticos, destacando a ausência de dados robustos sobre segurança no uso em longo prazo. $52,53,54$ Com o passar dos anos, estas recomendações foram se tornando mais restritivas e diretivas para o uso dos MMCD's biológicos, considerando o custo para os sistemas de saúde, e indicando a população que mais se beneficiaria do uso precoce dos mesmos - aqueles com alta atividade da doença e mau prognóstico. ${ }^{55-60}$

Nos EUA, desde 2002 o ACR sugere os medicamentos bloqueadores do fator de necrose tumoral (anti-TNF), uma das classes dos MMCD's biológicos, em associação ao MTX como $2^{\mathrm{a}}$ linha de tratamento após falha com este em monoterapia. ${ }^{53} \mathrm{Em} 2008$ o protocolo americano passou a considerar esta indicação como opção de $1^{a}$ linha de tratamento em casos com alta atividade da doença e presença de mau prognóstico, ou atividade moderada a alta após 2 esquemas com MMCD's sintéticos. ${ }^{55}$ Vale ressaltar que os EUA não possuem um sistema de saúde universal, e as indicações 
de novas tecnologias em protocolos de tratamento ocorrem baseadas em dados de estudos com foco no indivíduo e não na população.

Em 2000 a primeira publicação de um consenso mundial sobre tratamento de $A R$, com participação de reumatologistas de 21 países, incluindo União Europeia, EUA e Canadá, e nele houve a indicação dos anti-TNF como opção associados a um MMCD sintético em doença ativa após tratamento sem sucesso com um esquema de MMCD sintético. ${ }^{61}$

Na Europa, onde os MMCD's biológicos estão presentes no mercado desde 199962, com o infliximabe, temos a EULAR que faz suas recomendações sobre diagnóstico e tratamento para AR. Em 2007, a EULAR indicou os anti-TNF em associação com MTX em caso de doença ativa após MTX em monoterapia. ${ }^{54}$ Em 2010 restringiu esta indicação para uso após um esquema com MMCD's sintéticos apenas para casos com doença ativa e mau prognóstico, ou após 2 esquemas com MMCD's sintéticos. ${ }^{56}$

Nas recomendações canadense, americana, europeia e britânica para tratamento de AR mais antigas localizadas, já estavam presentes os tratamentos medicamentosos e os não medicamentosos. ${ }^{52-54,63}$

A Associação Canadense de Reumatologia (CRA) sugere com ênfase o envolvimento dos profissionais de fisioterapia e terapia ocupacional não só no diagnóstico, como também nos momentos de crise durante o curso da doença, para apoio e estabilização do paciente diante das atividades de vida diária. ${ }^{52}$

O protocolo brasileiro cita os tratamentos adjuvantes ao medicamento como terapia ocupacional, exercícios, fisioterapia, e apoio psicológico, para 
em seguida informar que as evidências na literatura sobre os mesmos são escassas, minimizando seu papel. ${ }^{2}$

As recomendações europeias incluem atividade física e terapia ocupacional como relevantes para o alívio dos sintomas, e ressaltam a importância do controle do tabagismo e obesidade para a melhor resposta do tratamento. Descrevem também como premissa do tratamento a transparência absoluta sobre a doença e as opções terapêuticas e relacionam a aderência ao tratamento à qualidade da informação recebida e da interação entre paciente e equipe de saúde. Cita programas educativos como estratégias adjuvantes para manejo da dor e preservação da capacidade laboral e de participação em atividades sociais, sobretudo no diagnóstico, nas mudanças de tratamento e quando as condições físicas e/ou psicológicas do paciente exigirem. ${ }^{3}$

O protocolo canadense baseia o tratamento nas decisões em conjunto entre paciente e médico, a partir de apropriada educação sobre a doença e discussão clara dos riscos e benefícios presentes. ${ }^{52}$

No quadro 02 há uma linha do tempo com datas do registro brasileiro para cada um dos MMCD's biológicos, e primeiro registro de MMCD biológico nos EUA e Europa. No mesmo quadro estão as datas de incorporação gradual desta tecnologia pelo protocolo brasileiro, e a indicação da mesma feita pela Sociedade Brasileira de Reumatologia, correspondendo, respectivamente, à possibilidade de cobertura pelo SUS do moderno tratamento para $A R$, e a indicação técnico-científica de efetividade dos medicamentos disponíveis. Para efeito de referência, estão também citadas as datas de início de 
indicação desta tecnologia pelos protocolos americano, britânico e europeu. Não foi possível realizar a mesma análise para o evolutivo histórico do cenário canadense devido à indisponibilidade dos protocolos anteriores ao vigente nos sites e bancos de dados pesquisados.

Quadro 02: Linha do tempo com aprovações e indicação dos MMCD biológicos no Brasil e no mundo

\begin{tabular}{|c|c|c|}
\hline ano & local & fato \\
\hline 1998 & EUA & $\begin{array}{l}\text { Aprovação do primeiro MMCD biológico no mundo: } \\
\text { etanercepte }\end{array}$ \\
\hline 1999 & UE & $\begin{array}{l}\text { Aprovação do primeiro MMCD biológico no mercado local: } \\
\text { infliximabe }\end{array}$ \\
\hline 2000 & Brasil & $\begin{array}{l}\text { Aprovação do primeiro MMCD biológico no mercado local: } \\
\text { infliximabe }\end{array}$ \\
\hline 2000 & mundo & $\begin{array}{l}\text { Publicação de consenso entre reumatologistas de } 21 \text { países } \\
\text { sobre tratamento de AR, incluindo EU, EUA e Canadá, } \\
\text { indicando MMCDb anti-TNF como opção associados a MMCD } \\
\text { sintéticos se doença ativa após uso de um esquema de } \\
\text { MMCD sintéticos }\end{array}$ \\
\hline 2002 & EUA & $\begin{array}{l}\text { MMCD biológico (infliximabe e etanercepte) indicado pelo } \\
\text { ACR como possível } 2 a \text { linha de tratamento em associação a } \\
\text { MTX após falha com MTX em monoterapia }\end{array}$ \\
\hline 2002 & Brasil & $\begin{array}{l}\text { Incorporação de infliximabe no PCDT do MS para AR grave } \\
\text { que não respondeu a } 3 \text { esquemas de tratamento com MMCD } \\
\text { sintético }\end{array}$ \\
\hline 2003 & Brasil & Aprovação do adalimumabe \\
\hline 2004 & Brasil & Aprovação do etanercepte \\
\hline 2004 & Brasil & $\begin{array}{l}\text { Consenso SBR - indicação de uso de MMCD biológico } \\
\text { (infliximabe, etanercepte, adalimumabe) se atividade da } \\
\text { doença presente após } 2 \text { esquemas de tratamento com MMCD } \\
\text { sintético }\end{array}$ \\
\hline 2006 & Brasil & $\begin{array}{l}\text { Incorporação de adalimumabe e etanercepte no PCDT do MS } \\
\text { para AR, junto com infliximabe, após } 3 \text { esquemas de } \\
\text { tratamento com MMCD sintético sem resposta terapêutica } \\
\text { adequada, ou se contraindicação a MTX }\end{array}$ \\
\hline 2006 & Brasil & Aprovação do rituximabe \\
\hline 2007 & Brasil & Aprovação do abatacepte \\
\hline 2007 & Brasil & $\begin{array}{l}\text { Consenso SBR - indicação de uso de MMCD biológico anti-TNF } \\
\text { (infliximabe, etanercepte, adalimumabe) se atividade da } \\
\text { doença presente após } 2 \text { esquemas de tratamento com MMCD } \\
\text { sintético; e rituximabe ou abatacepte indicados se presença } \\
\text { de atividade de doença após tratamento com anti-TNF }\end{array}$ \\
\hline
\end{tabular}

continua 
Quadro 02: Linha do tempo com aprovações e indicação dos MMCD biológicos no Brasil e no mundo

continuação

\begin{tabular}{|c|c|c|}
\hline ano & local & fato \\
\hline 2007 & RU & $\begin{array}{l}\text { MMCD biológico anti-TNF (adalimumabe, etanercepte, } \\
\text { infliximabe) indicado em associação ao MTX pelo NICE para } \\
\text { doença ativa após } 2 \text { esquemas de tratamento com MMCD } \\
\text { sintético }\end{array}$ \\
\hline 2007 & UE & $\begin{array}{l}\text { MMCD biológico anti-TNF (adalimumabe, etanercepte, } \\
\text { infliximabe) indicado em associação ao MTX pela EULAR para } \\
\text { doença ativa após tratamento com MTX em monoterapia }\end{array}$ \\
\hline 2008 & EUA & $\begin{array}{l}\text { MMCD biológico anti-TNF (infliximabe, etanercepte, } \\
\text { adalimumabe) indicado em associação ao MTX pelo ACR até } 6 \\
\text { meses de início de doença como opção na } 1 \text { a linha de } \\
\text { tratamento se alta atividade da doença e fatores de mau } \\
\text { prognóstico presentes; MMCD biológico anti-TNF associado a } \\
\text { MTX se na doença estabelecida ( }>6 \mathrm{~m} \text { ) houver moderada } \\
\text { atividade da doença e mau prognóstico após MTX, ou } \\
\text { moderada a alta atividade após terapia combinada com MMCD } \\
\text { sintético ou } 2 \text { esquemas de tratamento com MMCD sintético; } \\
\text { abatacepte se na doença estabelecida ( }>6 \mathrm{~m} \text { ) houver } \\
\text { moderada atividade da doença e mau prognóstico após terapia } \\
\text { combinada com MMCD sintético ou } 2 \text { esquemas de tratamento } \\
\text { com MMCD sintético; rituximabe se na doença estabelecida } \\
\text { (>6m) houver alta atividade da doença e mau prognóstico } \\
\text { após terapia combinada com MMCD sintético ou } 2 \text { esquemas } \\
\text { de tratamento com MMCD sintético }\end{array}$ \\
\hline 2009 & Brasil & Aprovação do tocilizumabe \\
\hline 2009 & RU & $\begin{array}{l}\text { MMCD biológico anti-TNF (adalimumabe, etanercepte, } \\
\text { infliximabe) indicado em associação ao MTX pelo NICE para } \\
\text { doença ativa após } 2 \text { esquemas de tratamento com MMCD } \\
\text { sintético; rituximabe indicado com doença ativa após anti- } \\
\text { TNF; abatacepte indicado para pacientes em uso do produto } \\
\text { (pesquisa) e que o médico considere a continuidade como } \\
\text { benefício }\end{array}$ \\
\hline 2010 & RU & $\begin{array}{l}\text { MMCD biológico anti-TNF (adalimumabe, etanercepte, } \\
\text { infliximabe) indicado em associação ao MTX pelo NICE para } \\
\text { doença ativa após } 2 \text { esquemas de tratamento com MMCD } \\
\text { sintético; rituximabe indicado como } 4 \text { a linha preferencial de } \\
\text { tratamento se anti-TNF não tiver sido efetivo para controle da } \\
\text { doença }\end{array}$ \\
\hline
\end{tabular}


Quadro 02: Linha do tempo com aprovações e indicação dos MMCD biológicos no Brasil e no mundo

continuação

\begin{tabular}{|c|c|c|}
\hline ano & local & Fato \\
\hline 2010 & UE & $\begin{array}{l}\text { MMCD biológico indicado, preferencialmente anti-TNF } \\
\text { (adalimumabe, certolizumabe pegol, etanercepte, infliximabe, } \\
\text { golimumabe) pela EULAR em associação a MMCD sintético, se } \\
\text { doença ativa e mau prognóstico após terapia combinada com } \\
\text { MMCD sintético, ou se doença ativa após } 2 \text { esquemas de } \\
\text { MMCD sintético. Se doença ativa após MMCD biológico anti- } \\
\text { TNF, qualquer outro MMCD biológico em associação com } \\
\text { MMCD sintético pode ser uma opção. }\end{array}$ \\
\hline 2011 & Brasil & Aprovação do certolizumabe pegol e golimumabe \\
\hline 2012 & EUA & $\begin{array}{l}\text { MMCD sintético anti-TNF (adalimumabe, certolizumabe pegol, } \\
\text { etanercepte, infliximabe, golimumabe) indicado pelo ACR até } 6 \\
\text { meses de início de doença como } 1 \text { a linha de tratamento em } \\
\text { associação a MTX se alta atividade da doença por } 6 \text { meses; se } \\
\text { alta atividade da doença por } 3 \text { meses, mau prognóstico, e } \\
\text { ausência de limitação de cobertura assistencial; se após } 6 \\
\text { meses de doença houver falha com MTX monoterapia e alta } \\
\text { atividade da doença, ou moderada atividade com mau } \\
\text { prognóstico; e qualquer MMCD biológico (incluindo abatacepte, } \\
\text { rituximabe e tocilizumabe) se alta atividade da doença após } \\
\text { tratamento com } 2 \text { esquemas de MMCD sintético ou MMCD } \\
\text { sintéticos combinados }\end{array}$ \\
\hline 2012 & EUA & Aprovação do tofacitinibe \\
\hline 2012 & Brasil & $\begin{array}{l}\text { Consenso SBR - indicação de uso de MMCD biológico } \\
\text { (infliximabe, etanercepte, adalimumabe, golimumabe, } \\
\text { certolizumabe pegol) se atividade da doença presente após } 2 \\
\text { esquemas de tratamento com MMCD sintético ou após } 1 \\
\text { esquema e muitos fatores de mau prognósticos; e demais } \\
\text { MMCD biológico (abatacepte, tocilizumabe, rituximabe) } \\
\text { indicados se presença de atividade de doença após tratamento } \\
\text { com anti-TNF }\end{array}$ \\
\hline 2013 & Brasil & $\begin{array}{l}\text { Incorporação de certolizumabe pegol, golimumabe, } \\
\text { abatacepte, rituximabe e tocilizumabe no PCDT do MS para } \\
\text { AR, sendo os anti-TNF indicados após } 2 \text { esquemas de } \\
\text { tratamento com MMCD sintético com atividade de doença } \\
\text { moderada ou alta, e os demais após tratamento com anti-TNF } \\
\text { e atividade de doença moderada a alta }\end{array}$ \\
\hline 2013 & UE & $\begin{array}{l}\text { MMCD biológico indicado (adalimumabe, certolizumabe pegol, } \\
\text { etanercepte, infliximabe, golimumabe, abatacepte, rituximabe } \\
\text { e tocilizumabe) pela EULAR em associação a MMCD sintético, } \\
\text { se doença ativa e mau prognóstico após terapia combinada } \\
\text { Com MMCD sintético, ou se doença ativa após } 2 \text { esquemas de } \\
\text { MMCD sintético. Tofacitinibe pode ser uma opção associado a } \\
\text { um MMCD sintético após tratamento com MMCD biológico e } \\
\text { presença de doença ativa. }\end{array}$ \\
\hline
\end{tabular}


Quadro 02: Linha do tempo com aprovações e indicação dos MMCD biológicos no Brasil e no mundo

continuação

\begin{tabular}{|c|c|c|}
\hline Ano & local & fato \\
\hline 2014 & Brasil & Aprovação do tofacitinibe \\
\hline 2015 & EUA & $\begin{array}{l}\text { MMCD biológico (adalimumabe, certolizumabe pegol, } \\
\text { etanercepte, infliximabe, golimumabe, abatacepte, rituximabe } \\
\text { e tocilizumabe) indicado pelo ACR até } 6 \text { meses de início de } \\
\text { doença como opção na } 2 \text { a linha de tratamento se atividade da } \\
\text { doença moderada a alta após } 1 \text { a linha; como opção combinada } \\
\text { com MMCD sintético se na doença estabelecida ( }>6 \mathrm{~m} \text { ) houver } \\
\text { moderada ou alta atividade - neste caso o tofacitinibe também } \\
\text { pode ser usado com outro MMCD sintético como opção }\end{array}$ \\
\hline 2015 & Brasil & $\begin{array}{l}\text { Consenso SBR - indicação de tofacitinibe em monoterapia ou } \\
\text { associado ao MTX como opção para doença em atividade } \\
\text { moderada a alta, após tratamento com } 2 \text { esquemas de MMCD } \\
\text { sintético e um MMCD biológico }\end{array}$ \\
\hline 2016 & RU & $\begin{array}{l}\text { MMCD biológico (adalimumabe, etanercepte, infliximabe, } \\
\text { certolizumabe pegol, golimumabe, tocilizumabe, abatacepte) } \\
\text { indicado preferencialmente em associação com MTX pelo NICE } \\
\text { para doença ativa após tratamento combinado com MMCD } \\
\text { sintético }\end{array}$ \\
\hline 2016 & UE & $\begin{array}{l}\text { MMCD biológico indicado (adalimumabe, certolizumabe pegol, } \\
\text { etanercepte, infliximabe, golimumabe, abatacepte, rituximabe } \\
\text { e tocilizumabe) pela EULAR em associação a MMCD sintético, } \\
\text { se doença ativa e mau prognóstico após terapia combinada } \\
\text { com MMCD sintético, ou se doença ativa após } 2 \text { esquemas de } \\
\text { MMCD sintético. Neste caso tofacitinibe também pode ser } \\
\text { indicado, com preferência para o MMCD biológico. }\end{array}$ \\
\hline $\begin{array}{c}2017 \\
/ \mathrm{fev}\end{array}$ & Brasil & $\begin{array}{l}\text { Indicação de incorporação no PCDT do MS para AR pela } \\
\text { CONITEC para doença com atividade moderada a alta, após } \\
\text { uso de MMCD sintético - aguardando publicação de novo PCDT } \\
\text { com orientações de uso }\end{array}$ \\
\hline & & $\begin{array}{l}\text { ção própria, com base nos protocolos brasileiros }{ }^{2,40,41} \\
55,58 \text {, europeus } 3,54,56,59,60 \text {, e britânicos } 46,63,64 \\
\text { ', sites } \\
\text { doras }{ }^{48,50,62} \text {, e Upchurch et al. }(2012)^{38}\end{array}$ \\
\hline
\end{tabular}

ACR: Colégio Americano de Reumatologia (American College of Rheumatology); AR: artrite reumatoide; EUA: Estados Unidos da América; EULAR: Liga Europeia contra o Reumatismo (European League Against Rheumatism); MMCD: medicamento modificador do curso da doença; MS: Ministério da Saúde; MTX: metotrexato; NICE: Instituto Nacional britânico para a Excelência da Saúde e do Cuidado e (National Institute for Health and Care Excellence); PCDT: Protocolo Clínico e Diretrizes Terapêuticas; RU: Reino Unido; SBR: Sociedade Brasileira de Reumatologia; UE: União Europeia 
Chama a atenção nos protocolos brasileiro e internacionais a referência à janela de oportunidade terapêutica de início com MMCD nos 12 primeiros meses após os primeiros sintomas da doença alterando significativamente o prognóstico do paciente.

Para cumprir esta meta agressiva de início de tratamento para uma doença de difícil diagnóstico, é necessária a participação ativa das equipes de AP, que devem estar treinadas para identificação dos sintomas relacionados, solicitação de exames confirmatórios e de avaliação de prognóstico, e encaminhamento para a atenção especializada em tempo hábil para confirmação diagnóstica e início precoce com MMCD.

Em documento da Organização Mundial da Saúde ${ }^{30}$, Mendes descreve a relevância do estabelecimento de parceria entre o paciente e a equipe de saúde primária, para que possa haver monitoramento regular da condição de saúde, e educação continuada sobre autocuidado, conforme capacidade de entendimento de cada usuário. A equipe de AP é a equipe mais próxima a este paciente, e que pode assumir esta responsabilidade, para o melhor manejo da doença junto a ele.

Além disso, dada a limitação de disponibilidade de reumatologistas no Brasil e no mundo, a meta de tempo desde os sintomas até o início com MMCD só pode ser atingida mediante participação ativa da equipe de tenção primária, rastreando, encaminhando e garantindo o acesso ao cuidado a este paciente. $15,24,25$ 


\subsection{SISTEMA DE SAÚDE NO BRASIL: SUS E SETOR PRIVADO}

O desenho do sistema de saúde brasileiro está estruturado com base em dois principais subsetores, o público e o privado, contemplando este tanto o serviço oferecido através de operadoras privadas de saúde quanto o gasto como desembolso direto com medicamentos, consultas, exames diagnósticos, e internações. Ambos os subsetores convivem em imbricadas e tensas relações. ${ }^{65,66} \mathrm{O}$ cidadão pode fazer uso do serviço de ambos os subsetores, a depender da facilidade de acesso e da sua capacidade de pagamento. 66

Pela natureza jurídica do prestador de serviço de saúde, $68 \%$ dos leitos do país são de propriedade privada (dados de 2005), porém podem ser contratados pelo subsetor público para complementar a oferta ao usuário do SUS, e de fato o são - $65 \%$ dos leitos privados são contratados e oferecidos pelo SUS. ${ }^{66}$ Relação semelhante de contratação de serviço privado para complementar a oferta do público se dá com os serviços diagnósticos. 66

Cerca de $41 \%$ dos valores gastos em saúde no país provém de verba pública (dados de 2008 ) $^{65}$, e apenas $22,8 \%$ da população brasileira tem acesso a planos de saúde privados. ${ }^{9,67}$ Ainda, parte da população com plano de saúde utiliza o serviço de saúde público: em 2003, 15,4\% da população que tinha plano de saúde e foi internada, internou em um leito oferecido pelo serviço público. ${ }^{66}$ 
A esta relação de entrelaçamento entre os subsistemas dá-se o nome de mix público-privado. Ela pode ocorrer desde a oferta, que pode eventualmente ser de um serviço público numa estrutura privada, ou de um serviço privado numa estrutura pública; passando pela utilização, quando ocorre o vai-e-vém dos usuários por entre os dois subsistemas em busca de cuidado; até o financiamento, com subsídios do Estado para o setor privado. 66

Considerando este mix, presente também no oferecimento de tratamentos especializados como 0 da $A R$, parece importante considerarmos as datas de incorporação dos MMCD's biológicos no rol de procedimentos e eventos em saúde da Agência Nacional de Saúde Suplementar, que regula o mercado de planos privados de saúde.

Os MMCD's biológicos infliximabe, tocilizumabe, abatacepte e rituximabe (apresentações de administração endovenosa) tornaram-se cobertura assistencial obrigatória para os planos de saúde em $2012^{68}$, e adalimumabe, etanercepte, certolizumabe pegol e golimumabe (via de administração subcutânea) foram contemplados no rol de $2014^{69}$.

Utilizando-se dos argumentos de universalidade e integralidade do Sistema Único de Saúde (SUS) descritos na Constituição Federal70, antes da incorporação dos MMCD's biológicos na RENAME, já havia a solicitação de cobertura destes medicamentos através de ações judiciais. ${ }^{71,72}$

O uso da via judicial para a obtenção do direito de cobertura pelo SUS pode ser considerado instrumento agravador das iniquidades no sistema de 
saúde, uma vez que a população com melhores condições socioeconômicas é a que mais demanda judicialmente esta cobertura. ${ }^{73}$

Não foram encontrados estudos comparando estas demandas antes e após a última grande incorporação dos MMCD's biológicos na RENAME em 2012.

Nas ações de escolha, prescrição, compra e adesão ao tratamento medicamentoso não podemos desconsiderar os diversos atores e interesses envolvidos, que passam inclusive pelo instrumento da judicialização. ${ }^{71-78}$

Na lógica comercial, medicamentos mais novos, menos conhecidos pelo profissional e usuário, e mais caros, costumam ter maior verba destinada à propaganda o que aumenta seu poder de influência sobre os atores envolvidos na decisão pela terapia.

Pela característica limitada do orçamento da saúde, bem como de todos os orçamentos públicos, os esforços de investimento devem ser bem direcionados para ações e programas de comprovada efetividade na melhoria das condições de saúde da população.

Neste contexto, faz-se relevante estudar e entender o caminho percorrido pelo paciente no sistema de saúde para o diagnóstico da doença, e para a prescrição e dispensação do MMCD biológico.

Para apoiar na elucidação e entendimento dos nós do sistema de saúde, e na discussão de alternativas para resolvê-los, é necessário 
entender o vai-e-vem do paciente nos diferentes serviços públicos e privados do sistema de saúde.

\subsection{ITINERÁRIO TERAPÊUTICO}

Kleinman em $1981^{79}$ descreveu o Itinerário Terapêutico como o caminho encontrado pelo paciente para a solução dos seus problemas de saúde, em um ou mais dos três subsistemas: profissional, informal (ou popular), e o folk (de especialistas não oficiais, como curandeiros e rezadores); considerando a dimensão subjetiva e cultural que interfere na utilização do sistema formal de saúde, a facilidade ou não de acesso a este sistema formal, e a capacidade de atendimento da demanda pelo mesmo.

Em 2009, Bellato e colaboradores ${ }^{80}$ definiram o IT como a trajetória de busca, produção e gerenciamento de cuidado em saúde, realizada por paciente e família, segundo lógica própria que dá a ele sustentabilidade na experiência de adoecer, e é tecida nas múltiplas redes de cuidado em saúde.

Neste trabalho foi dado destaque particular ao subsistema profissional de Kleinman, para discussão a respeito da implementação do PCDT de AR na região estudada, da articulação entre os diferentes níveis de cuidado, e do mix público-privado na cobertura da assistência.

$\mathrm{Na}$ composição do IT, duas lógicas diferentes coexistem gerando tensão uma à outra: a dos serviços de saúde e a dos pacientes e suas 
famílias. Ambas se correlacionam a todo momento, não podendo acontecer de forma independente. ${ }^{80}$ É possível evidenciar que essas trajetórias são afetadas pelo modo como o sistema de saúde produz e disponibiliza cuidado, dando respostas mais ou menos resolutivas, demonstrando assim a articulação entre os níveis de cuidado e a coordenação da AP no sistema de saúde. ${ }^{81}$

\section{JUSTIFICATIVA}

Considerando a relevância da doença na limitação de vida do paciente, sua prevalência, custo para a sociedade, dificuldade no diagnóstico, e os diversos interesses envolvidos na prescrição dos MMCD's biológicos, escolheu-se como objeto de pesquisa a investigação do caminho escolhido e percorrido pelo paciente em uso de tratamento de alto custo (MMCD biológico), logo após os primeiros sintomas de $A R$, na busca por

cuidado e controle dos seus sintomas, através dos subsistemas público e privado.

Além disso, a partir dos itinerários descritos, pôde-se checar a aplicação prática do PCDT do MS para o tratamento da AR. 


\section{OBJETIVOS}

\subsection{OBJETIVO GERAL}

Explorar as trajetórias percorridas na busca por cuidado por pacientes com AR em uso de MMCD biológico no município de São Paulo.

\subsection{OBJETIVOS SECUNDÁRIOS:}

* Identificar as dificuldades encontradas por estes usuários para obter diagnóstico, tratamento e monitoramento da AR conforme descritos no PCDT de AR do MS;

* Caracterizar os papéis da atenção primária e do atendimento especializado na trajetória destes pacientes;

* Caracterizar o mix público-privado no diagnóstico e tratamento da AR na trajetória destes pacientes. 


\section{METODOLOGIA E ASPECTOS ÉTICOS}

\subsection{METODOLOGIA}

A AR foi escolhida devido à sua alta prevalência e morbimortalidade, existência de protocolo de tratamento bem descrito pelo MS, disponibilidade do tratamento medicamentoso completo no SUS, e existência de diversos atores públicos e privados que contribuem no diagnóstico e escolha do tratamento.

Para alcançar os objetivos do trabalho, optou-se por estudo qualitativo, descritivo e exploratório, com entrevistas abertas, em profundidade, com pacientes com diagnóstico de artrite reumatoide que tinham recebido ao menos uma vez tratamento com MMCD biológico dispensado pelo SUS, para assegurar que tinham as características necessárias para a dispensação destes medicamentos.

Para mapear o percurso do paciente no sistema, compreender sua organização e oferta de cuidados, foi utilizado o conceito de Itinerário Terapêutico.

O estudo foi submetido ao Comitê de Ética em Pesquisa (CEP) da Faculdade de Saúde Pública da Universidade de São Paulo, e aprovado sob o número 60891116.6.0000.5421. (anexo I) 
Os pacientes foram convidados a relatar sua história com a doença desde os primeiros sintomas até o momento da entrevista, detalhando sua busca por cuidado, as investigações realizadas, e os tratamentos adotados. As entrevistas abertas semi estruturadas foram conduzidas de forma a abordar:

- sintomas iniciais de AR;

- tempo de atendimento até a primeira consulta médica;

- tempo, encaminhamentos e profissionais consultados desde a primeira consulta até o diagnóstico, com foco na equipe atual, cuidados prestados e frequência;

- tempo de diagnostico até o início do tratamento com MMCD e tratamentos utilizados anteriormente;

- tratamentos não medicamentosos utilizados para a AR;

- orientação recebida sobre a AR e o tratamento;

- interferência da AR nas atividades pessoais e laboral;

- usuário ou não do subsistema privado.

O número de pacientes necessário para a coleta dos dados foi estipulado pelo critério de saturação obtida para os subtemas acima descritos.

Conforme solicitação da Secretaria Estadual de Saúde do estado de São Paulo, que concedeu anuência para as entrevistas com os pacientes nas farmácias de medicamentos alto custo (anexo III), os resultados serão apresentados a esta Secretaria. 
Os itinerários terapêuticos foram comparados com o preconizado no PCDT, considerando a AP porta de entrada e coordenadora do cuidado. Foi discutido o mix público-privado existente na assistência a esta doença, e foram identificados e discutidos os nós e oportunidades de melhorias nos serviços e no sistema de saúde.

Para efeito comparativo, realizou-se levantamento bibliográfico nos bancos de dados PubMed, Scielo e BIREME, além das páginas eletrônicas das sociedades médicas de reumatologia europeia, canadense, norteamericana e brasileira, e do serviço de referência nacional britânico, a respeito das melhores práticas de diagnóstico, tratamento e monitoramento disponíveis para a AR. As diretrizes mais recentes disponíveis (de 2001 a 2017) foram lidas e compiladas em quadro de referência.

\subsection{LOCAL DE ESTUDO}

Definiu-se as farmácias de dispensação de medicamentos do componente especializado com maior movimento - Várzea do Carmo e Maria Zélia, como locais de coleta de dados junto aos pacientes. Previu-se que, por se tratarem de grandes dispensários, a possibilidade de encontro com pacientes com as mais diversas histórias e itinerários de busca por cuidado poderia ser mais assertiva. 
Ambas as farmácias são gerenciadas por equipes da Associação Paulista para o Desenvolvimento da Medicina (SPDM), organização social prestadora de serviço de saúde no estado de São Paulo. Assim, após aprovação do estudo pelo CEP, foi solicitada autorização da gerência de farmácia destas unidades para a aplicação das entrevistas.

Foram indicadas as farmacêuticas de referência para cada uma das farmácias dispensadoras. O projeto de pesquisa foi apresentado para cada uma delas e suas equipes, e foi solicitado apoio para identificação dos pacientes para as entrevistas.

Cada uma das farmácias possuía uma equipe de farmacêuticos, basicamente com a responsabilidade de orientar administrativamente os usuários sobre suas dificuldades específicas não solucionadas pelos atendentes, apoiar no fluxo de trabalho dos mesmos e gerenciar estoque. Não havia nas duas farmácias uma sala ou uma mesa destinada à orientação dos usuários sobre os medicamentos, o tratamento ou a doença pelo farmacêutico.

A identificação dos pacientes em cada um dos dispensários, com o diagnóstico de interesse e prescrição de MMCD biológico, contou com o apoio da equipe de atendimento, que através dos Laudos de Solicitação, Avaliação e Autorização de Medicamento do Componente Especializado da Assistência Farmacêutica (LME's) trazidos pelos usuários, sinalizava a presença de um usuário potencial para a entrevista.

Foram entrevistados 18 pacientes, porém apenas 17 foram incluídos nesta pesquisa. Um deles apresentava diagnóstico inicial de artrite juvenil, 
a busca por cuidado foi realizada pelos responsáveis pela criança à época, e eles não puderem estar representados durante a entrevista, sendo os dados assim desconsiderados para efeito do itinerário terapêutico.

Sempre que permitido, as entrevistas foram gravadas. Em seguida transcritas, e relidas exaustivamente para identificação dos trajetos percorridos pelos pacientes e falas mais representativas. Além disso foram feitas anotações relevantes em diário de campo para apoiar a análise dos dados.

As entrevistas foram realizadas após a aplicação do termo de consentimento livre e esclarecido. Ocorreram nos meses de fevereiro a abril de 2017, no próprio salão de atendimento das farmácias, em área afastada do grande fluxo de pessoas, para melhor escuta e preservação da privacidade dos pacientes.

\subsection{ASPECTOS ÉTICOS}

No desenvolvimento da pesquisa foram cumpridas todas as exigências éticas prescritas pela Resolução CNS 466/121 e suas complementares.

As entrevistas foram transcritas e houve o cuidado de retirar quaisquer palavras que pudessem identificar os entrevistados. Para preservar a identidade deles e resguardar as informações disponibilizadas em confiança ao entrevistador, no decorrer do estudo não foram citados 
nomes, cargo ou designação profissional ou institucional que possam levar à identificação direta dos participantes.

Não houve qualquer conflito de interesses na coleta e análise dos dados.

\section{RESULTADOS E DISCUSSÃO}

\subsection{CARACTERIZAÇÃO DOS ENTREVISTADOS}

Foram incluídos 17 pacientes. Seguem no quadro 03 os dados dos entrevistados.

Quadro 03: Dados demográficos dos usuários entrevistados

\begin{tabular}{|c|c|c|c|c|c|c|}
\hline $\begin{array}{l}\text { paci - } \\
\text { ente }\end{array}$ & sexo & $\begin{array}{c}\text { idade } \\
\text { na data } \\
\text { da } \\
\text { entre- } \\
\text { vista } \\
\text { (anos) }\end{array}$ & $\begin{array}{c}\text { idade no } \\
\text { diagnós- } \\
\text { tico de } \\
\text { AR } \\
\text { (anos) }\end{array}$ & $\begin{array}{l}\text { cor } \\
\text { auto } \\
\text { referida }\end{array}$ & profíssão & $\begin{array}{c}\text { para exames } \\
\text { e consultas, } \\
\text { usuário atual } \\
\text { do sub- } \\
\text { sistema } \\
\text { público, } \\
\text { privado, ou } \\
\text { mix dos dois }\end{array}$ \\
\hline $\mathbf{A}$ & fem & 50 & 45 & parda & $\begin{array}{c}\text { atendente } \\
\text { de loja - } \\
\text { aposentada }\end{array}$ & $\begin{array}{c}\text { privado } \\
\text { (operadora de } \\
\text { saúde) }\end{array}$ \\
\hline C & fem & 42 & $26-27$ & branca & $\begin{array}{l}\text { doméstica - } \\
\text { aposentada }\end{array}$ & público \\
\hline D & masc & 40 & $34-35$ & branca & $\begin{array}{l}\text { represen- } \\
\text { tante } \\
\text { comercial }\end{array}$ & $\begin{array}{c}\text { mix } \\
\text { (privado: } \\
\text { cartão cristâo) }\end{array}$ \\
\hline$E$ & fem & 46 & 30 & branca & NI & $\begin{array}{c}\text { privado } \\
\text { (operadora de } \\
\text { saúde) }\end{array}$ \\
\hline$F$ & fem & 56 & 52 & parda & NI & público \\
\hline
\end{tabular}


Quadro 03: Dados demográficos dos usuários entrevistados

continuação

\begin{tabular}{|c|c|c|c|c|c|c|}
\hline $\begin{array}{l}\text { paci - } \\
\text { ente }\end{array}$ & sexo & $\begin{array}{c}\text { idade } \\
\text { na data } \\
\text { da } \\
\text { entre- } \\
\text { vista } \\
\text { (anos) }\end{array}$ & $\begin{array}{c}\text { idade no } \\
\text { diagnós- } \\
\text { tico de } \\
\text { AR } \\
\text { (anos) }\end{array}$ & $\begin{array}{c}\text { cor } \\
\text { auto } \\
\text { referida }\end{array}$ & profissão & $\begin{array}{c}\text { para exames } \\
\text { e consultas, } \\
\text { usuário atual } \\
\text { do sub- } \\
\text { sístema } \\
\text { público, } \\
\text { privado, ou } \\
\text { mix dos dois }\end{array}$ \\
\hline G & fem & 50 & 43 & branca & NI & público \\
\hline $\mathbf{H}$ & fem & 69 & $50-53$ & branca & $\begin{array}{c}\text { NI - } \\
\text { aposentada }\end{array}$ & público \\
\hline $\mathbf{I}$ & fem & 66 & NI & asiática & $\begin{array}{c}\text { NI - } \\
\text { aposentada }\end{array}$ & $\begin{array}{c}\text { privado } \\
\text { (operadora de } \\
\text { saúde) }\end{array}$ \\
\hline $\mathbf{J}$ & fem & 45 & 37 & parda & enfermeira & $\begin{array}{l}\text { privado } \\
\text { (operadora de } \\
\text { saúde) }\end{array}$ \\
\hline $\mathbf{K}$ & fem & 60 & 53 & branca & professora & $\begin{array}{c}\text { privado } \\
\text { (operadora de } \\
\text { saúde) }\end{array}$ \\
\hline$L$ & fem & 46 & 35 & NI & NI & $\begin{array}{c}\text { privado } \\
\text { (operadora de } \\
\text { saúde) }\end{array}$ \\
\hline$M$ & fem & 65 & 56 & NI & NI & público \\
\hline $\mathbf{N}$ & masc & 66 & $55-56$ & branca & $\begin{array}{l}\text { autônomo } \\
\text { (dono de } \\
\text { mecânica) }\end{array}$ & público \\
\hline 0 & fem & 48 & 39 & parda & diarista & $\begin{array}{c}\text { privado } \\
\text { (operadora de } \\
\text { saúde) }\end{array}$ \\
\hline $\mathbf{P}$ & masc & 41 & 36 & branca & $\begin{array}{l}\text { coordenador } \\
\text { de } \\
\text { segurança }\end{array}$ & Público \\
\hline $\mathbf{Q}$ & fem & 43 & 38 & branca & $\begin{array}{l}\text { auxiliar de } \\
\text { escrita fiscal }\end{array}$ & $\begin{array}{c}\text { privado } \\
\text { (operadora de } \\
\text { saúde }+ \\
\text { desembolso } \\
\text { direto) }\end{array}$ \\
\hline $\mathbf{R}$ & fem & 69 & 52 & branca & doméstica & $\begin{array}{l}\quad \text { mix } \\
\text { (particular - } \\
\text { desembolso } \\
\text { direto) }\end{array}$ \\
\hline
\end{tabular}

Fonte: elaboração própria

fem: feminino; masc: masculino; NI: não informado 
Dos usuários entrevistados, $82 \%$ eram mulheres, de maioria branca, com idades entre 26 a 56 anos à época do diagnóstico. Apesar de se tratar de estudo qualitativo, e não ter sido utilizada qualquer técnica de aleatoriedade para escolha dos participantes, os dados confirmam o descrito na literatura a respeito da doença ser mais predominante em mulheres que em homens, em caucasianos, e ocorrer normalmente entre a $4^{\mathrm{a}}$ e a $6^{\mathrm{a}}$ décadas de vida. ${ }^{2,7}$

Sobre a atividade laboral, chama a atenção que 3 dos 12 que forneceram informação sobre a atividade laboral já estavam aposentados antes da idade indicada para aposentadoria no país. As pacientes A e C confirmaram a aposentadoria devido à doença. A paciente $H$ não esclareceu o motivo da aposentadoria.

\subsection{SINAIS DA AR INICIAL}

Apesar de classicamente todos os casos envolverem o acometimento da membrana sinovial, ao longo do tempo, a AR foi sendo melhor compreendida como uma patologia de apresentação heterogênea, e os critérios diagnósticos da ACR - largamente traduzidos e utilizados, foram atualizados de 1987 para 2010 contemplando esta heterogeneidade.

A forma mais ou menos agressiva, e mais ou menos clássica dos sintomas se apresentarem pode contribuir para a celeridade na busca pelo 
cuidado. Há extensa literatura ressaltando a necessidade de que esta busca ocorra prontamente para que haja também diagnóstico precoce e rápido início com MMCD. No entanto, devido à heterogeneidade dos sintomas, e a possibilidade de que sejam confundidos com outras doenças, há também em todo o mundo um protelamento frequente entre a apresentação destes primeiros sinais e sintomas e a busca por cuidados médicos. ${ }^{14-17,20,21}$

Nas entrevistas realizadas, chama a atenção que o caminho mais frequente para a busca de cuidado para os usuários do SUS não tenha sido o posto de saúde, mas sim a busca por serviços de emergência, onde foi normalmente atendido por um ortopedista.

Em estudo de 2014-2015 na Holanda realizado por Kraaijvanger e colaboradores $^{82}$, e posterior revisão sistemática do mesmo grupo de trabalho de $2016^{83}$, a comodidade de ter o clínico geral, o especialista, e a disponibilidade de exames no mesmo local, bem como a praticidade do atendimento sem necessidade prévia de marcação de consulta aparecem como motivos mais comuns para a busca do atendimento de emergência, ao invés da atenção primária, mesmo em condições não agudas. Lega e Mengoni em estudo de 2007 na Itália haviam também encontrado o uso do serviço em dias e horários mais convenientes, e o acesso a especialista e exames mais acurados como as principais razões da busca por serviços de emergência. ${ }^{84}$

Wong e Hall verificaram em estudo de 2013 na Austrália que experiências prévias negativas com clínicos gerais também impulsionam a busca por cuidado de emergência. ${ }^{85}$ 
Cinco dos nove pacientes usuários exclusivos do subsistema público relataram este caminho após os primeiros sintomas.

"Procurei a Santa Casa de Santo Amaro, aí engessaram o meu braço, que não tinha nada a ver... Ortopedista... Acharam que era porque eu trabalhava e doméstica e subia a descia escada. E eu falei não é isso... mas mesmo assim ele engessou... Não fez exame... nada, nada... Quando eu cheguei em casa já tirei. Por que eu sabia que não ia adiantar." [paciente C]

"Eu vim a saber o que eu tinha, tem mais ou menos uns 1011 anos. Na realidade eu sentia dores, e dores, e dores... bem antes... desde 94-95... Aí eu fui numa médica lá no Santa Marcelina... e ela me disse que era ácido úrico que eu tinha... (...) $\mathrm{Na}$ emergência... (...) Eu tomava... Tandrilax... tomava... esses para amenizar, né... Tipo assim... uma hora tomava um, uma hora tomava outro... eu achava que era coluna... sabe, você ia no médico e ele não Ihe dava uma... (...) A princípio era no joelho. Foi evoluindo, minhas mãos, tá vendo... ela... entortou... as minhas juntas..." [paciente $\mathrm{N}$ ]

"Faz uns 9 anos. Começou pelos meus punhos, com dores... Eu pensei que tida dado mal jeito nos pulsos... aí eu fui num ortopedista. Ele enfaixou... só que aí eu via que não estava melhorando, voltava de novo, e ele enfaixava.." [paciente O]

Nos serviços de emergência é comum estar disponível o especialista em traumatologia, e o paciente pode buscar neste serviço a solução para seu desconforto quando não consegue programar a ausência das suas atividades de trabalho durante o horário de expediente. Outro fato possivelmente relacionado é a ausência de conhecimento pelo paciente e sociedade em geral sobre as doenças reumáticas e a dificuldade de associálas aos seus sintomas, ou a possibilidade de confundi-los facilmente com sintomas de doenças traumático-ortopédicas.

Entre os usuários do subsistema privado, também houve uma busca pelo ortopedista. Apenas uma paciente relatou buscar diretamente um reumatologista. Possivelmente isto pode estar relacionado a ser o 
ortopedista um profissional mais disponível nos serviços de saúde relativamente aos reumatologistas. Conforme dado do DATASUS/CNES referentes a julho de 2017, havia pouco mais de 1 reumatologista para cada 10 ortopedistas no município de São Paulo. 86

Na literatura internacional, o caminho mais comum e mais estudado desde os primeiros sintomas até o diagnóstico é o do paciente buscando apoio na AP, que procede as primeiras investigações para diferenciar o problema se agudo ou crônico, e identifica um diagnóstico suspeito, para então encaminhar para o especialista. O especialista, de posse da investigação preliminar, pode confirmar ou não o diagnóstico, e realizar o correto direcionamento do paciente, iniciando o tratamento com MMCD's no caso de ser confirmada a AR. ${ }^{14-17,20,21}$

Os primeiros sintomas de AR de fato podem ser confundidos com problemas musculoesqueléticos. ${ }^{2,3,12} \mathrm{E}$ é relevante que o paciente suspeite de outra causa para participar e apoiar na investigação e escolha de tratamento para sua condição.

Nas entrevistas realizadas, o sintoma inicial mais presente foi a dor osteoarticular, normalmente em mãos, punhos e pés, que podem ser confundidas pelo leigo com sintomas de lesão de esforço repetido. A paciente J, por exemplo, cita na sua fala o tratamento com ortopedistas de suposto diagnóstico de tendinite por cerca de 5 anos, com antiinflamatórios:

"Eu passava num ortopedista, e eles falavam que era tendinite, o que eu tinha nos punhos. Aí eu acabei fazendo ultrassom e dava tendinopatia mesmo... Então eu usava 
medicações voltadas para tendinite... isso levou uns cinco anos... Voltaren, este tipo de medicação. Daí eu passava em vários ortopedistas. Eu trabalhava com maca, paciente pesado. Cada vez que eu saía, eu saía... pior... Levou bastante tempo para descobrir que era artrite reumatoide. Bastante. Inclusive meu punho direito atrofiou antes de eu descobrir. Demorou muito para ser feito o diagnóstico, então ele atrofiou, e eu perdi a cartilagem, tá osso com osso."

A usuária $\mathrm{K}$, mesmo já em acompanhamento com reumatologista, ficou tratando os sintomas como fibromialgia por um período, possivelmente pela doença se apresentar também nas pernas, não muito comum para a AR:

" Tinha dores muito intensas nas mãos, pés, cotovelos, pernas. Fiquei tomando remédio para fibromialgia, e a coisa piorando - não conseguia segurar um copo de água na mão."

Em pacientes com baixa atividade da doença, as dores podem aparecer tão sutilmente que não chegam a incapacitá-lo, e tampouco a o impelir a buscar ajuda. ${ }^{1} \mathrm{O}$ usuário $\mathrm{N}$ apresentou dores que iam e vinham por 13 anos, até que sentiu necessidade de buscar ajuda. Não chegou a ter qualquer prejuízo concreto nas suas atividades profissionais ou pessoais:

"Comecei tem uns 10-11 anos. Eu sentia dores, e dores, e dores... bem antes... desde $94-95 .$. no joelho... a princípio era no joelho."

Infelizmente, no entanto, muitos dos pacientes entrevistados descreveram sintomas incapacitantes provocados pela doença antes de terem conseguido descobrir a causa da incapacitação, tampouco iniciar o tratamento para a mesma. 
"Nós nas mãos, entravada, não podia fechar a mão, doía o corpo, todas as juntas do corpo. Foi ficando mal, mal, mal, mal, sinovite acometendo mãos, punhos e joelhos." [paciente A]

"Muita dor, mãos inchadas, não conseguia pegar um talher, não conseguia pentear o cabelo, não tinha força pra nada. Evoluiu muito rápido, o pé doía, não era capaz de calçar um tênis..." [paciente C]

"Muita dor no corpo e os membros começaram a travar. Um dia travava uma perna, outro dia travava o braço..." [paciente G]

"Mãos e punhos inchados, não conseguia por uma roupa no varal, não conseguia escovar os dentes, não conseguia fazer nada, parecia um pesadelo." [paciente $\mathrm{H}$ ]

Diante dos relatos citados, fica clara a necessidade de o paciente e os profissionais primeiramente acessados (AP e emergência) tenham mais conhecimento sobre as doenças reumáticas, para apoiar na busca mais assertiva por cuidado, e na abreviação do tempo primeiros sintomas-início com MMCD. Algumas das estratégias encontradas por Villeneuve e colaboradores em revisão sistemática recente ${ }^{15}$ : para aumentar conhecimento dos pacientes e/ou encurtar o tempo para busca de cuidados médicos: criação de páginas na internet sobre o assunto por associações de pacientes e de reumatologistas, e campanhas de triagem e de educação sobre doenças osteomusculares; e para melhorar identificação da doença na atenção primária: oficinas e programas educacionais para profissionais da atenção primária, e aproximação destes com reumatologistas de forma sistemática e frequente para troca de conhecimento. 


\subsection{BUSCA POR CUIDADO - DIAGNÓSTICO}

Por se tratar de doença crônico-degenerativa, quanto antes o paciente buscar cuidado médico, mais curto pode ser o tempo para diagnóstico e início do tratamento adequado, que pode mudar o curso da doença. 2,3,12 $\mathrm{A}$ redução do tempo entre os primeiros sintomas e o início do tratamento adequado, no entanto, é um desafio mundial. 2,3,12,18,24

Nos relatos sobre os primeiros sintomas dos entrevistados, a busca por cuidado, e os encaminhamentos recebidos, fica clara a necessidade de fortalecer o conhecimento dos profissionais dos serviços de AP e de emergência sobre doenças reumáticas, e de conhecer as dificuldades encontradas pelos mesmos durante a triagem e avaliação inicial de pacientes com acometimento nas articulações.

O conhecimento do público leigo sobre doenças reumáticas - paciente e seus conviveres - também ajudaria a abreviar o tempo para início com tratamento modificador da doença. ${ }^{87}$

Interessante e importante compreender melhor, em estudos futuros, os principais motivos que, conforme os relatos aqui descritos, levam o paciente de AR a buscar preferencialmente apoio no serviço de emergência ao invés de na sua equipe de AP.

Campos e colaboradores avaliaram o acesso à saúde primária em município do estado de São Paulo e encontraram a falta de médicos, a demora no atendimento, e a "super-regulação" do acesso à consulta médica aliada à impressão pessoal de que o seu problema de saúde seja urgente, 
como os principais problemas mobilizadores do usuário do serviço de AP, que o fazem migrar e buscar solução no atendimento de urgência. ${ }^{88}$

Objetivando abreviar o tempo para início do tratamento, Puchner e colaboradores $^{89}$ avaliaram a efetividade de um serviço rápido de triagem realizado em consultório, no estado de Alta Áustria, na Áustria, por reumatologistas, para pacientes com suspeita de artrite reumatoide ou espondiloartrite. O estudo coloca o conhecimento do paciente sobre a doença como componente fundamental para a rápida referência para o especialista.

Zafar e colaboradores ${ }^{90}$ discutiram algumas ações realizadas pela sociedade e pelo governo sauditas no período de 2006 a 2010 para minimizar o tempo decorrido entre o início dos sintomas e o diagnóstico e início de tratamento com MMCD, focando principalmente no esclarecimento à população sobre sintomas da doença permitindo-a que, suspeitando de $A R$, busque ajuda médica precoce para rápido controle e melhor prognóstico. Algumas das iniciativas descritas no estudo foram criação de grupos de suporte a paciente, execução de campanhas de esclarecimento à população com diversos eventos educativos espalhados pelo país, em shopping centers, feiras e eventos culturais, aproveitando inclusive o dia mundial de consciência sobre artrite, coberto anualmente pelos canais de rádio e televisão locais para ampliação da divulgação, e, uma ampla ação, em conjunto com uma associação de pacientes, de envio de material informativo sobre AR através das contas de luz e água. 
Revisão sistemática de 2013 conduzida por Villeneuve e colaboradores $^{15}$ selecionou estudos com ações que visaram a redução do tempo entre a apresentação dos primeiros sintomas e o início de uso de MMCD. Os autores dividem as oportunidades de intervenção para redução do tempo acima descrito em 4 esperas: 1- dos sintomas até a busca por cuidados médicos; 2- do primeiro médico (normalmente um clínico geral) até o encaminhamento para o reumatologista; 3 - do encaminhamento até a consulta com o especialista; 4- da primeira consulta com o especialista até o início com o MMCD. Veja figura 1.
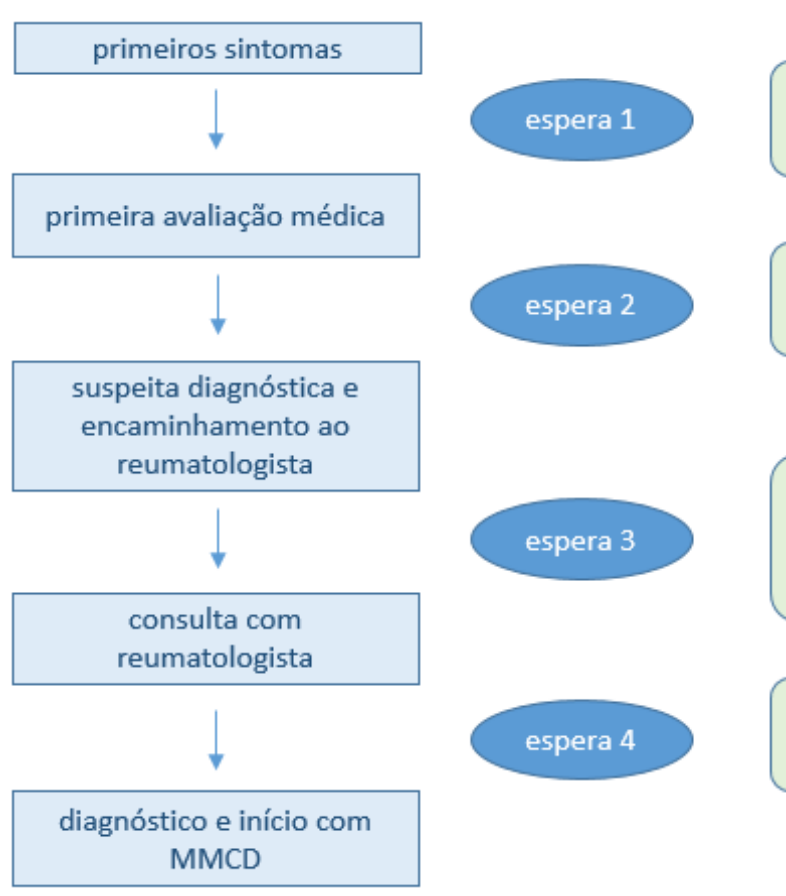
AP treinados (enfermeiros/farmacêuticos)

\section{espera 2}

ações/planos educacionais para médicos da AP, implantação de protocolos

\section{espera 3}

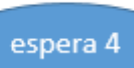

espera 4 formulários/cartas padronizadas com a suspeita diagnóstica de $A R$, clínicas reumatológicas de triagem, contatos telefônicos com especialista para apoio na triagem

ações/planos educacionais para reumatologistas, implantação de protocolos de cuidados

Figura 01: Fases de espera entre os primeiros sintomas de AR e o início com o MMCD, e ações que podem ser realizadas para minimizar o tempo das etapas

Fonte: adaptado de Villeneuve e colaboradores. ${ }^{15}$ 
Feuchtenberger e colaboradores ${ }^{25}$ descreveram a possibilidade de priorização mais adequada no encaminhamento dos pacientes com suspeita de doença reumática inflamatória feito pelo clínico geral/médico generalista, retriados através de um contato telefônico entre paciente e um reumatologista experiente. Os pacientes cujas características de doença inflamatória incluindo descrição e duração dos sintomas, e resultados de exames preliminares apontassem uma maior probabilidade de doença inflamatória foram priorizados na agenda, e os autores confirmaram que estes foram mais frequentemente diagnosticados com a suspeita diagnóstica de doença inflamatória que os que não foram priorizados a partir dos dados colhidos na ligação. Assim, o tempo médio entre o encaminhamento pelo clínico e a confirmação do diagnóstico da doença pôde ser encurtado.

Além das iniciativas descritas nos estudos acima, podemos pensar em disponibilizar ferramentas de autoavaliação de sintomas aos pacientes nos serviços de AP, preparar profissionais mais da ponta do sistema de saúde, como farmacêuticos de farmácias comunitárias, ou enfermeiros de saúde da família para reconhecimento de sinais e sintomas de AR de forma a auxiliar na triagem e encaminhamento precoce dos pacientes para a avaliação médica, e implantar protocolos de avaliação em serviços de saúde para auxiliar médicos especialistas e não especialistas na condução da investigação do problema musculoesquelético do paciente e, no caso dos não especialistas, auxiliar no encaminhamento adequado com cartas ou 
formulários que apoiem a priorização da agenda dos serviços de reumatologia.

Dentre os entrevistados no presente estudo, 3 deles declararam não ter procurado pronto cuidado médico após a apresentação dos sintomas. O motivo pode estar relacionado à falta de conhecimento sobre doenças reumáticas, especialmente a $A R$, à baixa severidade dos sintomas, que podiam ser resolvidos com medicamentos isentos de prescrição médica, e às experiências prévias buscando cuidado de saúde. ${ }^{87,91,92}$

Estudo realizado no Reino Unido $^{92}$ reunindo as principais publicações sobre motivações do paciente com AR na busca por cuidado reforça que quando os sintomas são mais leves, vagos ou transitórios, há maior dificuldade em identificá-los com doença estabelecida e buscar apoio. Os autores destacam que nestes casos a busca é normalmente relacionada à fase de acometimento de um maior número de articulações, quando há então a busca não por um diagnóstico, mas pelo alívio dos sintomas. Esta revisão identifica um conhecimento maior sobre doenças cardíacas e câncer, e que não há comumente a percepção de que sintomas articulares possam se relacionar com uma condição mais grave de saúde. Outros fatores relevantes são a distância do serviço de saúde e a expectativa negativa de que o profissional de saúde (sobretudo o clínico geral) não seja competente ou associe os sintomas ao estilo de vida da pessoa.

Os 3 pacientes referidos citaram não considerarem os sintomas relevantes para uma investigação mais profunda, e mencionaram também 
a tratativa dada pelos primeiros profissionais procurados como reforço para não considerarem os sintomas como de uma doença grave. Seguem relatos de $H, N$ e $R$, respectivamente:

"Não, não fui buscar [diagnóstico]... fiz bastante coisa, paguei massagem, paguei massagista para ver se era... eu nunca fui buscar..."

"Na realidade eu sentia dores, e dores, e dores... bem antes... desde 94-95... Aí eu fui numa médica da emergência, que me disse que era ácido úrico que eu tinha... Eu tomava... Tandrilax... tomava... esses para amenizar, né... Tipo assim... uma hora tomava um, uma hora tomava outro... eu achava que era coluna... sabe, você ia no médico e ele não lhe dava uma [solução]... Tipo assim, vou dispensar logo ele... tal..."

"Sempre o corpo era dolorido, né... Quando eu comecei com essa dor... que piorou que eu fui procurar a médica... Então, dor... aí eu não sabia o que era né... era dor no corpo inteiro, as juntas todas, sabe... aí mesmo assim eu trabalhava. À noite eu sentia dor... no corpo, nas pernas... mas de manhã eu tomava um vinho e continuava e ia trabalhar. Isso continuou bem quase um ano, e eu trabalhando, né... e as dores aumentando... aí quando não deu mais, aí eu inchava, de repente... isso aqui era tudo inchado, os pés... aí fui no médico, médico pensava que era ácido úrico, né... porque dava dor de repente, e inchava..."

$\mathrm{N}$ buscou cuidado médico diversas vezes durante mais de 10 anos. Todas as vezes em serviço de emergência público próximo à sua residência. Considerava (e considera até hoje) ter sempre recebido um bom atendimento neste serviço, mas devido possivelmente a seus sintomas que eram mais leves no início, não pôde ser diagnosticado com condição crônica. Nem as equipes de saúde, nem ele mesmo valorizou os sintomas nos primeiros anos. Com o tempo, a piora da sua condição e o aparecimento de comprometimento das articulações, foi enfim diagnosticado. O cuidado próximo e continuado pela AP poderia ter 
abreviado o tempo de seu diagnóstico. E o maior conhecimento sobre doenças reumáticas poderia tê-lo feito mais diretivo nas suas consultas médicas.

Este paciente se destacou dentre os demais devido ao longo período de apresentação de sintomas sem resolução, e ressalta-se que na sua entrevista menciona que dois de seus filhos trabalham na área da saúde. Assim, fica evidente a necessidade de ações e projetos educativos, para a população em geral para o reconhecimento de sinais e sintomas relacionados às doenças reumáticas.

É preciso, sobretudo, disponibilizar à população cuidado preventivo e monitoramento da sua condição de saúde, responsabilidades também da AP. E especialmente com relação à $A R$, que não tem um sintoma ou exame definidor para seu diagnóstico, é necessária a implantação de protocolos institucionais que apoiem a condução da investigação de queixas relacionadas ao sistema musculoesquelético.

R teve apresentação mais aguda dos sintomas. Relatou presença de dores contínuas, sobretudo pela noite, e inchaço nas pernas. Por motivo que não soube explicar, relacionado sobretudo à sua falta de entendimento sobre sua condição de saúde, demorou cerca de um ano para buscar avaliação médica. Foi ao posto de saúde próximo à sua casa, e atendida pelo clínico geral que de início suspeitou de gota. Não ficou claro se chegou a ser feito diagnóstico diferencial, mas a paciente foi encaminhada para o reumatologista. Descreveu como curto o tempo entre este 
encaminhamento e o agendamento da consulta com o especialista do sistema público. Este profissional, no entanto, não atendeu suas expectativas, tampouco pôde diagnosticar a AR. Por orientação de uma comadre foi a outro profissional, desta vez do sistema privado (pagamento de próprio bolso), quando foi identificada a AR. Paciente $R$ continua em acompanhamento com este médico, com quem está satisfeita. A necessidade de busca pelo cuidado no subsistema privado para receber o diagnóstico, e voltar ao público para recebimento do tratamento medicamentoso nos remete à fala dos farmacêuticos dos dispensários onde foram realizadas as entrevistas: "Onde estão os pacientes do sistema público? Estes possivelmente não chegam [ao diagnóstico/tratamento]."

De Cock e colaboradores ${ }^{18}$ avaliaram o tempo entre a apresentação de sintomas e o início com um MMCD entre 2009 e 2012 em alguns serviços belgas. Constataram, assim como nosso paciente $\mathrm{N}$, que quanto mais leves os sintomas, maiores eram os tempos de intervalo estudado entre as duas ocorrências. O tempo médio encontrado por eles foi de pouco menos de 6 meses, com a maior parte do tempo utilizada da apresentação dos sintomas até a busca do paciente pelos primeiros cuidados - cerca de 10 semanas.

Entre os entrevistados, além de $\mathrm{N}$ e $\mathrm{R}, \mathrm{H}$ também demorou a ir buscar atendimento, convivendo com os sintomas da doença por alguns anos antes de ser avaliada por um médico. 
Dois outros pacientes, J e L, apesar de passarem em consulta em diversos médicos particulares, ficaram também sem diagnóstico correto respectivamente por 5 anos, e período não especificado referido como de alguns anos. Os médicos consultados por L (ortopedistas) não chegaram a realizar o encaminhamento ao reumatologista, tendo sido ela mesma quem resolveu consultá-lo após longo período sem adequado controle dos sintomas. J descreveu ter tido outras complicações, agudas, após os primeiros sintomas de $A R$, o que desviou o foco da investigação e busca por cuidado para os sintomas desta doença.

Os tempos de espera para diagnóstico e início de tratamento nestes casos estão em consonância com os dados buscados retrospectivamente por Rodríguez-Polanco e colaboradores ${ }^{5}$, em serviços de saúde venezuelanos, nos anos de 2006 a 2007. Os pesquisadores encontraram tempos de espera de 40 meses para o diagnóstico e de 57 meses para o início com um MMCD. $O$ estudo considera que o paciente poderia ter tido acesso ao reumatologista como primeiro médico consultado. Entre os entrevistados, os fatores que mais contribuíram para demora foram atendimento prévio por clínico ou ortopedista, atendimento em serviços públicos e diagnóstico realizado antes do ano de 2000 .

Em conformidade com o gradual ganho de conhecimento esperado sobre a AR pelos profissionais com o passar do tempo e das publicações de protocolos nacionais e internacionais para diagnóstico e tratamento, parece haver entre os entrevistados uma sutil redução nos tempos de 
espera até o diagnóstico com o passar do tempo. Para confirmação desta suspeita seria necessário estudo com este foco especifico para a população brasileira. Veja quadro 04 com os tempos de cada paciente até o diagnóstico.

Com relação ao mix público-privado, apenas uma paciente referiu especificamente para o diagnóstico de AR ter passado por médicos particulares no início dos sintomas (desembolso direto), e, percebendo tratar-se de situação médica de mais longos resolução e monitoramento, acabou migrando para o cuidado oferecido pelo SUS.

Com relação à busca por profissionais e consultas no monitoramento de sua condição de saúde, outro paciente referiu intenso vai-e-vém entre os dois subsistemas para tratamento de sua condição de saúde. Descreveu possuir um cartão cristão, uma espécie de convênio com uma empresa que não se constitui como operadora de saúde, e oferece, mediante o pagamento do cartão, o direito a consultas médicas e com outros profissionais de saúde sem custo adicional, sem acesso a exames ou internação. Este paciente referiu ter acompanhamento no SUS e, sempre que precisava de uma consulta com mais agilidade do que a oferecida pelo sistema público, lançava mão das consultas com o referido cartão. Em seguida, se algum exame Ihe fosse prescrito, voltava a utilizar os serviços públicos, já que esta cobertura não the era disponibilizada pelo cartão cristão. Desta forma, encurtava o tempo de espera para o atendimento. 
Quadro 04: Datas estimadas de diagnóstico e tempos médios de espera dos primeiros sintomas até o diagnóstico

\begin{tabular}{|c|c|c|}
\hline paciente & $\begin{array}{l}\text { ano estimado } \\
\text { do } \\
\text { diagnóstico }\end{array}$ & $\begin{array}{c}\text { tempo dos primeiros } \\
\text { sintomas até o } \\
\text { diagnóstico }\end{array}$ \\
\hline $\mathbf{F}$ & 2013 & NI \\
\hline $\mathbf{P}$ & 2012 & menor que 3 meses \\
\hline $\mathbf{Q}$ & 2012 & de 3 a 12 meses \\
\hline D & $2011-2012$ & NI \\
\hline G & 2010 & de 3 a 12 meses \\
\hline $\mathbf{K}$ & 2010 & de 3 a 12 meses \\
\hline J & 2009 & $\begin{array}{l}\text { maior que } 12 \text { meses } \\
\text { (5 anos) }\end{array}$ \\
\hline $\mathbf{0}$ & 2008 & de 3 a 12 meses \\
\hline $\mathbf{N}$ & $2006-2007$ & $\begin{array}{l}\text { maior que } 12 \text { meses } \\
\text { (cerca de } 12 \text { anos) }\end{array}$ \\
\hline $\mathbf{A}$ & 2002 & menor que 3 meses \\
\hline C & $2001-2002$ & menor que 3 meses \\
\hline $\mathbf{E}$ & 2001 & não informado \\
\hline $\mathbf{R}$ & 2000 & $\begin{array}{l}\text { maior que } 12 \text { meses } \\
\text { (pouco mais de } 1 \text { ano) }\end{array}$ \\
\hline $\mathbf{H}$ & $1998-2001$ & $\begin{array}{l}\text { maior que } 12 \text { meses } \\
\text { (não especificado) }\end{array}$ \\
\hline $\mathbf{L}$ &.+-2006 & $\begin{array}{l}\text { maior que } 12 \text { meses } \\
\quad \text { (alguns anos) }\end{array}$ \\
\hline $\mathbf{M}$ &.+-2008 & de 3 a 12 meses \\
\hline $\mathbf{I}$ & NI & NI \\
\hline
\end{tabular}

Fonte: elaboração própria

NI: não informado

Outra paciente informou que quando não consegue consulta com sua médica atual no $A M E$, passa com sua antiga reumatologista em consulta particular, e a mesma Ihe faz um "desconto" no preço da consulta por desembolso direto, cobrando também o serviço à operadora de saúde da paciente.

Dois outros pacientes citaram consulta com profissionais exercendo suas profissões como caridade, com consultas gratuitas à população, ou 
cobrando apenas o material utilizado (neste caso as agulhas da acupuntura).

Estes são alguns exemplos de relatos dos entrevistados demonstrando que quando o paciente percebe a necessidade de apoio profissional para tratamento da sua condição de saúde, ele busca das mais diversas formas uma maneira de encontrar este apoio.

\subsection{EDUCAÇÃO SOBRE A DOENÇA}

Radford e colaboradores ${ }^{93}$ publicaram em 2008 um estudo sobre as principais necessidades percebidas pelos pacientes logo após o diagnóstico de $A R$, e as duas principais foram educação e suporte psicológico.

Estudos revelam o sofrimento experienciado pelo paciente após o diagnóstico, considerando tratar-se de doença crônica degenerativa e incapacitante. ${ }^{93,94} \mathrm{O}$ conhecimento sobre a doença e tratamento apoia o paciente no enfrentamento da fase inicial e o fortalece sua capacidade de autocuidado e de continuidade de suas atividades diárias. Idealmente este conhecimento deve vir de uma equipe qualificada. Mesmo recebendo orientações da equipe de saúde, o paciente buscará apoio em outras fontes, nem sempre confiáveis e nem sempre favoráveis e adequadas para o suporte ao tratamento, como a internet. 95 
Os protocolos de tratamento citam consistentemente a necessidade de promover a educação ao paciente sobre doença como um dos primeiros princípios necessários ao tratamento. A partir dela, o paciente pode perceber modos de lidar com cronicidade da AR, praticar o autocuidado de forma consciente, perceber, comunicar e criar alternativas para suas limitações, e poupar-se de maiores dores ou desconfortos ao perceber os primeiros sinais de crise. $2,3,95-103$

Entre os entrevistados, houve menção de educação realizada pela equipe por apenas 6 pacientes. Ela foi sempre realizada pelo médico prescritor, que usualmente foi descrito como o único profissional a acompanhar o paciente com AR. As orientações recebidas relacionaram-se principalmente à prática de atividade física e a cuidados na realização das atividades diárias. Houve apenas uma orientação a respeito da necessidade de equilíbrio emocional para lidar com a doença.

"Eu divido as tarefas de casa, tipo, hoje é quarta, hoje eu vou fazer um pouquinho da faxina, amanhã eu faço outro, e na $6^{a}$ eu faço outro. Por orientação do médico, eu fazia num dia só, e eu travava. Depois do meio dia eu travava que o dia acabava pra mim. Conversando com ele, ele pegou e me orientou a fazer isso, dividir, e procurar descansar." [paciente $\mathrm{C}$ ]

"Ela foi explicando o que acontecia dia a dia, pediu para eu não carregar peso, não levantar os braços, que eu podia só fazer caminhada com exercício de bicicleta... e assim, peso, esfregar, fazer movimentos repetitivos não podia... porque com certeza no outro dia ia doer" [paciente G]

"Orientou que eu tenho de fazer atividades de baixo impacto, tipo hidroginástica, natação, tudo de baixo impacto, não posso forçar a articulação. (...) Ela falava assim "Você precisa se acalmar, ter auto-controle..."[paciente J] 
Apesar do reconhecido benefício percebido na educação sobre AR, ela representa um desafio para os serviços e profissionais de saúde, e não raras vezes, a busca individual é a única ferramenta disponível para os pacientes. Algumas falas demonstram a dificuldade em se promover o conhecimento sobre a AR a partir dos prescritores.

"Orientação eu mesmo que tenho." [paciente A]

"Nada, nada. Eu tive que pesquisar sempre sozinha. Eu te disse, médico é assim" [paciente $\mathrm{K}$ ]

Uma das pacientes teve uma gestação durante o tratamento de AR. Optou por conta própria a descontinuar o tratamento, sem abordar o assunto com o médico.

"Eu parei com esse medicamento aí por conta própria... porque eu queria engravidar..." [paciente Q]

Nos relatos, sobretudo quando o paciente abordou o modo como recebeu orientação sobre a autoadministração do medicamento usado por via subcutânea, os laboratórios fabricantes foram citados. Alguns deles oferecem, conforme relatos, serviço de visita domiciliar para orientação sobre a administração do MMCD biológico. Estes laboratórios são acessados pelo paciente a partir de cadastro em programas de adesão realizado pelo médico. Há sítios de internet bem montados e com diversas informações sobre AR, patrocinados por estes laboratórios. Ao serem questionados, os entrevistados referiram ter recebido destes programas material sobre a doença, mas não se lembraram espontaneamente desta fonte. 
As únicas fontes de educação citadas foram o médico prescritor, o material do fabricante, e a busca feita pelo paciente na internet e em livros. Nenhum programa educacional sobre a doença foi citado. Ao serem questionados, nenhum paciente havia tido contato ou conhecimento sobre associação de pacientes portadores de AR.

Diversos estudos revelam o impacto psicológico e o potencial limitante da doença. 4,7,32,93,94 Sem conhecimento, este impacto cresce sobremaneira, já que o paciente desconhece técnicas para preservação de energia e proteção de articulações, o autocuidado fica portanto mais limitado e a possibilidade de controle dos sintomas na crise reduzido sem o apoio médico. Além das limitações físicas, o paciente com doença crônica incapacitante sem conhecimento tem dificuldade para manter o equilíbrio emocional e continuar participando ativamente da sociedade, sentindo-se muitas vezes marginalizado, e sob forte risco de manifestar desordens psiquiátricas como depressão. $93,94,104,105$

É preciso conscientização das equipes de saúde a respeito da importância em se criar espaços nas consultas e fora delas dedicados à educação sobre AR. A construção de materiais de apoio para entrega ao paciente e seus familiares pode ajudar. Mas sobretudo é preciso que se pense e se implemente, ainda que de forma experimental, modos efetivos de dar a este paciente a chance de participar de forma consciente do seu cuidado, reconhecer ativamente suas limitações, expressá-las no seu meio de convívio, e particpar da escolha da sua terapia, medicamentosa e não medicamentosa. 


\subsection{TRATAMENTO NÃO MEDICAMENTOSO INSTITUÍDO}

Os protocolos europeu (2016) e britânico (2015) indicam o tratamento não medicamentoso como aliados aos MMCD.3,106 O PCDT brasileiro (2015), apesar de citar logo no início da seção específica sobre o tema que as evidências científicas são escassas, descreve cada uma delas, e respalda as iniciativas envolvendo atividade física e apoio psicológico ao paciente. ${ }^{2}$

Segundo o protocolo britânico citado, o paciente deve ter acesso ao time multiprofissional, constituído por fisioterapeuta, terapeuta ocupacional, psicólogo e podólogo. Deve haver um profissional que coordene o cuidado, por exemplo um enfermeiro especialista, e o paciente deve poder ser avaliado periodicamente a respeito do impacto da AR na sua vida e o suporte disponível para manejo da doença.

Os protocolos de tratamento americano (2015) e canadense (2012) atêm-se apenas aos MMCD e corticoides, deixando de fora as terapias não farmacológicas. ${ }^{12,45}$ Protocolos anteriores destes dois países (EUA 2002 e Canadá 2001), no entanto, descreviam as medidas não farmacológicas, como fisioterapia e/ou terapia ocupacional, como base do tratamento inicial. 52,53 Não fica claro o motivo das medidas não farmacológicas terem deixado de integrar estes protocolos.

Dentre os entrevistados, 11 informaram não ter atualmente qualquer apoio ou monitoramento profissional para a AR além do reumatologista que 
o acompanha e prescreve os medicamentos. Esta é uma representação do baixo apoio dado a estas práticas no PCDT brasileiro, e do modelo de atenção à saúde ainda hegemônico.

Apenas 5 citaram ter recebido orientação ou encaminhamento para tratamento não medicamentoso pelo médico. Outros 7 buscaram por conta própria fisioterapia, acupuntura, e outras terapias complementares ao MMCD. Cinco pacientes não chegaram a receber qualquer tratamento além dos medicamentos.

Apenas 4 citaram a prática de atividades físicas. Destes, 1 interrompeu devido a limitações físicas (dores), e não chegou a receber orientação ou incentivo para retomar.

"Eu fazia, mas eu parei, porque a osteoporose doía muito a minha perna... eu tava fazendo caminhada, aí eu parei... aí não faço não... eu já faço muita coisa na minha casa, já faço o suficiente... [paciente $\mathrm{H}$ ]

Dos 3 que declararam realizar atividade física, apenas 1 citou ter sido orientada pelo médico a respeito.

Dois receberam encaminhamento para fisioterapia, apesar de não terem iniciado ainda com as sessões - um recebeu prescrição da fisioterapia junto com a programação para cirurgia corretiva. Uma das pacientes chegou a perguntar à médica a respeito do possível benefício da fisioterapia, e foi orientada a declinar desta alternativa de tratamento. 
"Quando eu tava em crise eu perguntei para ela se o fisioterapeuta poderia estar me ajudando e ela falou que acreditava que não, que não poderia tá ajudando muito. [paciente J]

Três entrevistados passaram por sessões de acupuntura, tendo 2 deles buscado por conta própria e pago por desembolso direto.

O terceiro relatou ter passado por sessões sem ter percebido benefício, optando por não dar continuidade devido à característica intermitente do tratamento oferecido pelo SUS.

"Fiz fisioterapia, e acupuntura por 2 vezes, esse tipo de tratamento não surtiu efeito... Acupuntura é um pouco mais demorado, às vezes, por causa da fila de espera. Às vezes você fica dois meses, por causa de uma fila de espera. Então, acupuntura, pelo conhecimento que eu tenho, é um tipo de tratamento que você tem de fazer a longo prazo. Você fazer dez sessões, não surte nenhum efeito. Eu parei porque assim, você começa, faz dez sessões, aí tem que voltar com o médico, você não consegue fazer assim fazer dez, na outra semana continuar fazer de novo mais dez... não, você tem que retornar pro médico fazer uma nova solicitação, quer dizer, passar pelo médico são quatro meses de espera... Fazer dez sessões, uma por semana, e já interromper, pro meu caso, não senti muita melhora. Então quando a médica falava "Você quer fazer acupuntura?", eu já dizia que não precisava. [paciente D]

Dentre as demais estratégias não medicamentosas, houve um relato de encaminhamento para nutricionista para orientação de dieta para reduzir reações adversas dos medicamentos; um relato de preocupação com controle de peso para não sobrecarregar articulações; um encaminhamento para grupo de apoio para pacientes com dor crônica, não levado adiante pela paciente por dificuldade de conciliação com horário do trabalho; e um 
relato de orientação para poupar energia e articulações feita próprio médico:

"Eu divido as tarefas de casa, tipo, hoje é quarta, hoje eu vou fazer um pouquinho da faxina, amanhã eu faço outro, e na $6^{a}$ eu faço outro. Por orientação do médico... eu fazia num dia só, e eu travava. Depois do meio dia eu travava que o dia acabava pra mim. Conversando com ele, ele pegou e me orientou a fazer isso, dividir, e procurar descansar. [paciente $\mathrm{C}$ ]

Revisões sistemáticas sobre cuidados não médicos para AR foram realizadas por Bearne e colaboradores em $2015^{96}$ e por Badamgarav e colaboradores em $2001^{97}$, e não sistemática por Vliet Vlieland e Hazes ${ }^{98}$ em 1997. Todas verificaram que existe uma importante carência de estudos bem desenhados que possam embasar com mais segurança a indicação de medidas não farmacológicas como suporte adicional necessário ao paciente de AR.

\subsection{FARMACOTERAPIA INSTITUÍDA}

Nesta seção trataremos em alguns momentos os MMCD's sintéticos apenas como medicamentos sintéticos, ou sintéticos, e os MMCD's biológicos como biológicos. Destaca-se que ambos são considerados como medicamentos que mudam o prognóstico da doença, e os sintéticos e não devem ser confundidos com outros medicamentos, também sintéticos, como corticoides ou anti-inflamatórios não esteroides, usados como 
adjuvantes no tratamento. Esta denominação abreviada será utilizada aqui apenas para facilitar a leitura e o entendimento do texto.

O PDCT de 2015 orienta o início com os MMCD's sintéticos logo após diagnóstico, tão logo quanto possível. Após 2 esquemas terapêuticos em doses otimizadas com estes medicamentos em mono ou politerapia, se paciente mantém atividade da doença de moderada a alta, deve-se iniciar uso de um biológico. ${ }^{2}$ Recomendações da CRA de 2012 indicam também os biológicos após 2 esquemas com os sintéticos, exceto se contraindicação a estes e presença de mau prognóstico. ${ }^{57}$

A liga europeia (EULAR) e o instituto de excelência clínica do Reino Unido (NICE), em suas recomendações de 2016, orientam o início de tratamento com biológico após falha com um esquema de tratamento com MMCD's sintéticos e presença de mau prognóstico. ${ }^{3,46} \mathrm{O}$ colégio americano, em protocolo de 2015 também recomenda uso de biológico se doença com atividade moderada a alta após um esquema de tratamento com os medicamentos sintéticos. ${ }^{12}$

Em 2002, e de novo em 2006, o tratamento com biológico foi indicado no protocolo do MS brasileiro, após 3 esquemas com MMCD's sintéticos. Em 2006 os biológicos também foram indicados em caso de contraindicação ao MTX. Em 2002 apenas o infliximabe estava disponível na RENAME, e em 2006 foram incorporados também adalimumabe e etanercepte. ${ }^{40,41}$

Os pacientes entrevistados, na sua maioria, tiveram início com MMCD sintético logo após o diagnóstico, conforme preconizado no PCDT. Paciente 
E foi prescrita com esta classe de medicamentos, porém optou por não utilizar, com receio de suas possíveis reações adversas:

"Começou no dedo indicador, e aí eu procurei até médico homeopata. Fiquei dois anos tratando com homeopatia, e não resolveu nada. Ele falou que era artrite, mas a gente sempre soube que a medicação pra artrite era meio pesada, não tinha muita coisa, né, falta de conhecimento da minha parte."

Pacientes $A, G$ e $R$, por motivo não esclarecido, acabaram não sendo prescritos com um MMCD sintético após o diagnóstico. A e R foram diagnosticados antes a publicação do primeiro protocolo do MS - 2002 e 2000, respectivamente. G queixou-se da capacitação técnica do médico que a diagnosticou, buscando outro profissional em seguida que iniciou com o medicamento correto.

Dentre os pacientes que conseguiram descrever o histórico de seus esquemas terapêuticos, metade deles passou por todas as linhas indicadas no PCDT vigente à época - C, E, G, J, N e P. Outros 4 não cumpriram a sequência proposta no protocolo para início com o biológico, apesar de terem utilizado medicamentos orais por alguns anos: MMCD's sintéticos no caso dos pacientes $\mathrm{D}, \mathrm{H}$ e Q, e apenas corticoide pelo paciente $\mathrm{R}$. Para estes pacientes, não ficou claro se havia contraindicação aos demais MMCD's sintéticos sugeridos no protocolo ou se o prescritor optou por ir direto para o biológico devido à atividade da doença ou presença de mau prognóstico.

De todos os pacientes pesquisados, apenas 2 relataram início precoce com os medicamentos biológicos. Paciente $\mathrm{K}$ logo após o diagnóstico já foi 
prescrita com infliximabe e MTX em associação, e informou desde o início receber os medicamentos pelo SUS. Apesar de ter sido questionado, não foram fornecidos maiores detalhes de como o medicamento pôde ser retirado sem que os esquemas terapêuticos preconizados com os MMCD's sintéticos, menos custosos, fossem testados. A paciente $\mathrm{O}$ relatou ter utilizado leflunomida por 1 mês, sem sucesso terapêutico. Em seguida solicitou à sua médica que mudasse o tratamento, e foi atendida. Conforme o protocolo, são necessários 3 meses de doses otimizadas para avaliar efetividade dos MMCD's sintéticos. No quadro 05 estão descritos os esquemas terapêuticos de todos os entrevistados.

A responsabilidade pelo financiamento e aquisição de leflunomida e todos os biológicos é do Ministério da Saúde, conforme Portaria GM/MS no 1.554, de 30 de julho de $2013^{107}$, e, conforme depoimento dos entrevistados, não tem sofrido com desabastecimento. Nenhum deles relatou falta por mais de 1 mês do produto nos dispensários do componente especializado. Ao contrário do que relataram com os demais medicamentos utilizados, como por exemplo o MTX, do qual foi informada falta frequente. Apesar de o desenho do estudo incluir apenas pacientes dispensados com seus medicamentos biológicos pelo SUS, destacamos o fato de que 10 dos 17 pacientes entrevistados referiram possuir plano de saúde privado. No entanto, nenhum deles buscou cobertura dos seus medicamentos através da sua operadora de saúde, o que seria permitido pelo menos desde 2014, 
quando todos os MMCDb disponíveis no SUS passaram a integrar também o rol de procedimentos da ANS. ${ }^{42}$

Também, não se conhece ação do suS para devolver a responsabilidade às operadoras de saúde pelo pagamento destes medicamentos para os pacientes dos seus planos.

Todos os pacientes que relataram possuir plano de saúde privado descreveram em maior ou menor intensidade o vai e vem entre os subsistemas público e privado, com o intuito de facilitar seu acesso ao tratamento, e encurtar os tempos de espera para exames ou consultas.

Este mesmo trânsito entre os subsistemas foi descrito por Conill e colaboradores $^{108}$, em estudo sobre a trajetória de beneficiários do subsistema suplementar brasileiro, sobretudo para coberturas de medicamentos de alto custo, internações, urgências, e cuidados de profissionais não médicos. 
Quadro 05: Datas estimadas de diagnóstico, início com MMCD sintético e biológico, e esquemas terapêuticos utilizados antes dos biológicos

\begin{tabular}{|c|c|c|c|c|}
\hline $\begin{array}{l}\text { Paci- } \\
\text { ente }\end{array}$ & $\begin{array}{l}\text { ano } \\
\text { estimado } \\
\text { do } \\
\text { diagnóstico }\end{array}$ & $\begin{array}{l}\text { primeiros esquemas de } \\
\text { tratamento }\end{array}$ & $\begin{array}{l}\text { ano } \\
\text { estimado } \\
\text { do início } \\
\text { com } \\
\text { MMCD } \\
\text { sintético }\end{array}$ & $\begin{array}{l}\text { ano } \\
\text { estimado } \\
\text { do início } \\
\text { com } \\
\text { MMCD } \\
\text { biológico }\end{array}$ \\
\hline $\mathbf{A}$ & 2002 & $\begin{array}{c}\text { corticoides e AINE's por cerca } \\
\text { de } 7 \text { anos }\end{array}$ & 2009 & 2009 \\
\hline C & $2001-2002$ & $\begin{array}{c}\text { imobilização com gesso => } \\
\text { MTX, cloroquina e } \\
\text { sintomáticos, em diferentes } \\
\text { esquemas => leflunomida, } \\
\text { MTX e sintomáticos } \\
=>\text { biológico }\end{array}$ & 2001-2002 & $\begin{array}{l}2003- \\
2004\end{array}$ \\
\hline D & 2011-2012 & $\begin{array}{c}\text { tratamento para artrose } \\
\text { (medicamentos não descritos) } \\
=>\text { MTX em diferentes doses } \\
=>\text { biológico }\end{array}$ & 2011-2012 & 2015 \\
\hline $\mathbf{E}$ & 2001 & $\begin{array}{c}\text { diclofenaco }=>\text { homeopatia } \\
=>\text { diversos medicamentos } \\
\text { incluindo MTX, sulfassalazina } \\
\text { e ciclofosfamida }=> \\
\text { leflunomida }=>\text { biológico }\end{array}$ & NI & 2009 \\
\hline $\mathbf{F}$ & 2013 & NI & NI & 2012 \\
\hline $\mathbf{G}$ & 2010 & $\begin{array}{c}\text { analgésico injetável no PS } \\
=>\mathrm{MTX}+ \\
\text { prednisona+AINE+sintomático } \\
=>\mathrm{MTX}+\text { cloroquina }+ \\
\text { sintomáticos }=>\text { leflunomida } \\
=>\text { biológico }\end{array}$ & $\begin{array}{l}\text { após } 2-3 \\
\text { meses do } \\
\text { diagnóstico }\end{array}$ & $\begin{array}{l}2010- \\
2011\end{array}$ \\
\hline H & $1998-2001$ & MTX => biológico & NI & 2011 \\
\hline $\mathbf{I}$ & NI & $\begin{array}{c}\text { sintomáticos }=>\mathrm{MTX} \\
=>\text { biológico }\end{array}$ & $\begin{array}{c}\text { NI, } \\
\text { prescrita } \\
\text { logo após } \\
\text { diagnóstico, } \\
\text { não usou } \\
\text { por medo } \\
\text { de } \\
\text { possíveis } \\
\text { reações } \\
\text { adversas }\end{array}$ & 2009 \\
\hline J & 2009 & $\begin{array}{c}\text { AINE's para tendinite }=> \\
\text { cloroquina }=>\mathrm{MTX}+ \\
\text { AINE+corticoide+sintomáticos } \\
=>\text { biológico }\end{array}$ & 2009 & 2012 \\
\hline $\mathbf{K}$ & 2010 & infliximabe (biológico) + MTX & 2010 & 2010 \\
\hline
\end{tabular}


Quadro 05: Datas estimadas de diagnóstico, início com MMCD sintético e biológico, e esquemas terapêuticos utilizados antes dos biológicos

continuação

\begin{tabular}{|c|c|c|c|c|}
\hline paciente & $\begin{array}{c}\text { ano } \\
\text { estimado } \\
\text { do } \\
\text { diagnóstico }\end{array}$ & $\begin{array}{l}\text { primeiros esquemas de } \\
\text { tratamento }\end{array}$ & $\begin{array}{l}\text { ano } \\
\text { estimado } \\
\text { do início } \\
\text { com } \\
\text { MMCDs }\end{array}$ & $\begin{array}{l}\text { ano } \\
\text { estimado } \\
\text { do início } \\
\text { com } \\
\text { MMCDb }\end{array}$ \\
\hline $\mathbf{L}$ &.+-2006 & diversos esquemas VO NI & NI & 2007 \\
\hline M &.+-2008 & esquema VO NI & NI & 2014 \\
\hline $\mathbf{N}$ & $2006-2007$ & $\begin{array}{c}\text { leflunomida }+ \text { AINE }+ \\
\text { sintomáticos }=> \\
\text { medicamento manipulado } \\
\text { não informado }=> \\
\text { leflunomida }+ \text { outra fórmula } \\
\text { com MTX }+ \text { corticoide por } \\
\text { conta própria }=>\text { biológico }\end{array}$ & $2006-2007$ & 2017 \\
\hline $\mathbf{0}$ & 2008 & leflunomida $=>$ biológico & 2008 & 2008 \\
\hline $\mathbf{P}$ & 2012 & $\begin{array}{c}\text { corticoide }=>\text { leflunomida }+ \\
\text { corticoide }+ \text { MTX } \\
=>\text { biológico }+ \text { leflunomida }+ \\
\text { MTX }+ \text { corticoide }\end{array}$ & 2012 & 2015 \\
\hline $\mathbf{Q}$ & 2012 & $\begin{array}{c}\text { corticoide }+ \text { hidroxicloroquina } \\
=>\text { MTX }+ \text { corticoide }+ \\
\text { biológico }\end{array}$ & 2012 & 2014 \\
\hline $\mathbf{R}$ & 2000 & $\begin{array}{l}\text { corticoide VO e EV SN } \\
=>\text { corticoide + biológico }\end{array}$ & não usou & 2006 \\
\hline
\end{tabular}

Fonte: elaboração própria

AINE: anti-inflamatório não esteroide; EV: endovenoso; MMCD: medicamento modificador do curso da doença; MTX: metotrexato; NI: não informado; SN: se necessário; VO: via oral.

Nas figuras 2 e 3 podemos verificar este mix através dos itinerários terapêuticos dos pacientes $\mathrm{A}$ e $\mathrm{C}$. A tem plano de saúde privado, e utiliza o SUS para seu tratamento com medicamento biológico. C iniciou a busca por cuidados através de médico particular (desembolso direto), e migrou para o SUS por não conseguir sustentar o pagamento dos serviços.

Para os pacientes com plano de saúde, algumas vezes o sistema público parece mais resolutivo. Este é um depoimento do paciente $D$ acerca 
das escolhas que realiza na busca por cuidados, percorrendo caminho com mix bem demarcado entre o público e o privado:

"Eu passo com um dermatologista porque eu tenho vitiligo, passo com um otorrino... aqui acho que são esses três. O gastro, a endoscopia eu fiz aqui pelo SUS mas não consegui o gastro aqui, fiz pelo cartão cristão, mas consegui fazer a endoscopia aqui, nutricionista acabei fazendo fora... (...) Clínico assim, se eu tiver que passar por um clínico eu passo no cartão cristão, que é perto de casa, ou se for uma emergência, no AMA, prefeitura, posto de saúde. Pros tratamentos das doenças, dou preferência por aqui [AME]. (...) Quer dizer, se eu passo por um médico e ele pede exame de sangue, eu já faço aqui a coleta. Se eu tiver que fazer uma ressonância, eu faço aqui, se eu tiver que fazer um raio $X$, eu também faço aqui. Exame de vista, eu também fiz aqui. Acabam sendo completos os serviços oferecidos. Mais por essa razão. Numa emergência, eu passo pelo cartão. Mas por exemplo se o médico pedir um exame de sangue no cartão cristão, eu tenho de pagar pelos exames. $\mathrm{E}$ aí eu dou preferência por aqui. $\mathrm{O}$ exame que $\mathrm{O}$ médico pediu sairia mais de duzentos reais. Pelo cartão. Então eu prefiro até esperar um pouco mais se eu tenho esse tempo, e passar por aqui, porque eu tenho todo o serviço aqui. Até uma internação, se eu tiver que passar, a pedido do médico aqui, ele encaminharia. Pelo cartão cristão, eu não teria esse encaminhamento. Teria de fazer por conta. O sistema de saúde para mim tem funcionado." 


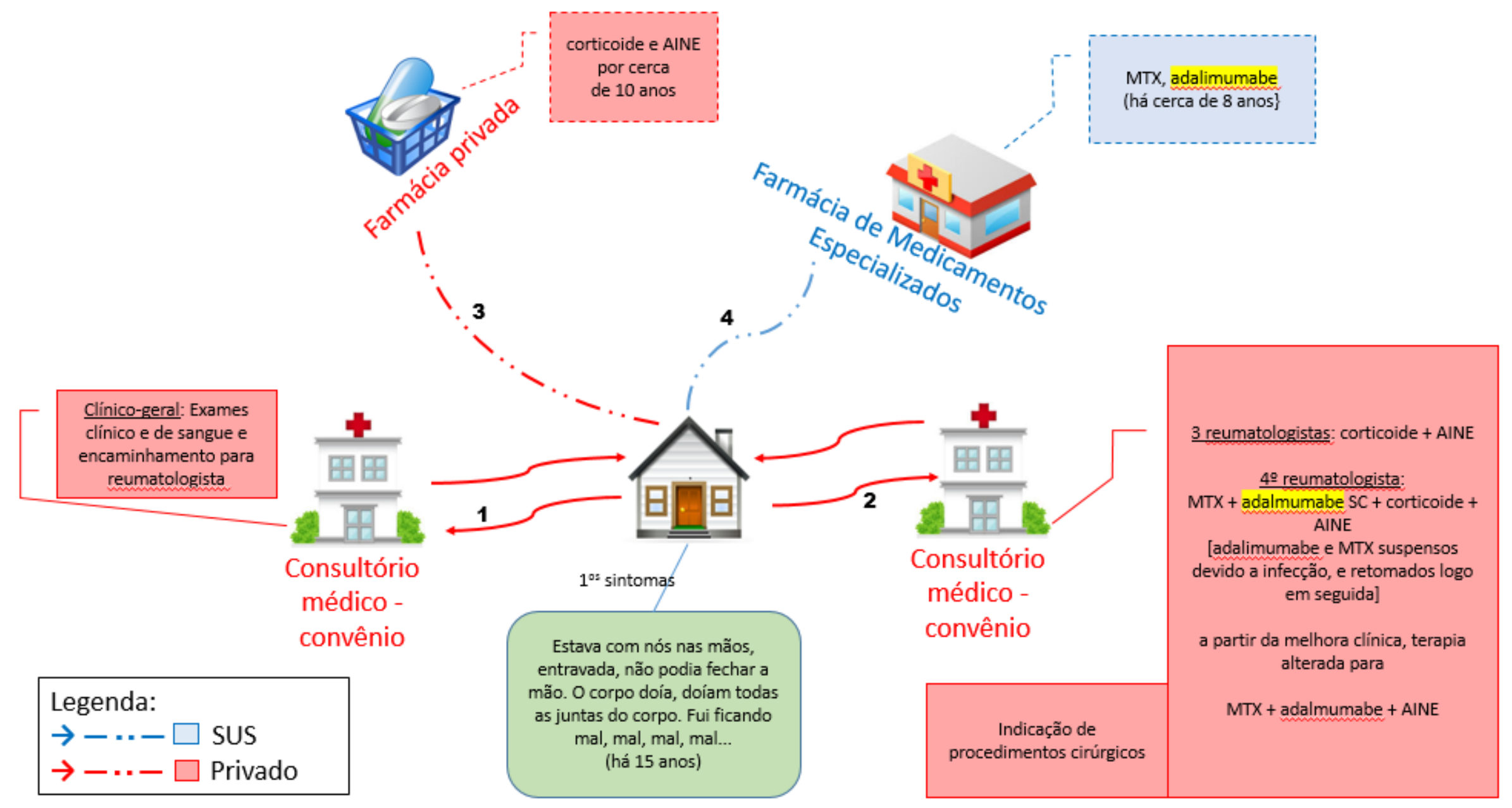

Figura 02: Itinerário terapêutico da paciente A

Fonte: elaboração própria

AINE: anti-inflamatório não esteroide; MTX: metotrexato; SC: subcutâneo. 


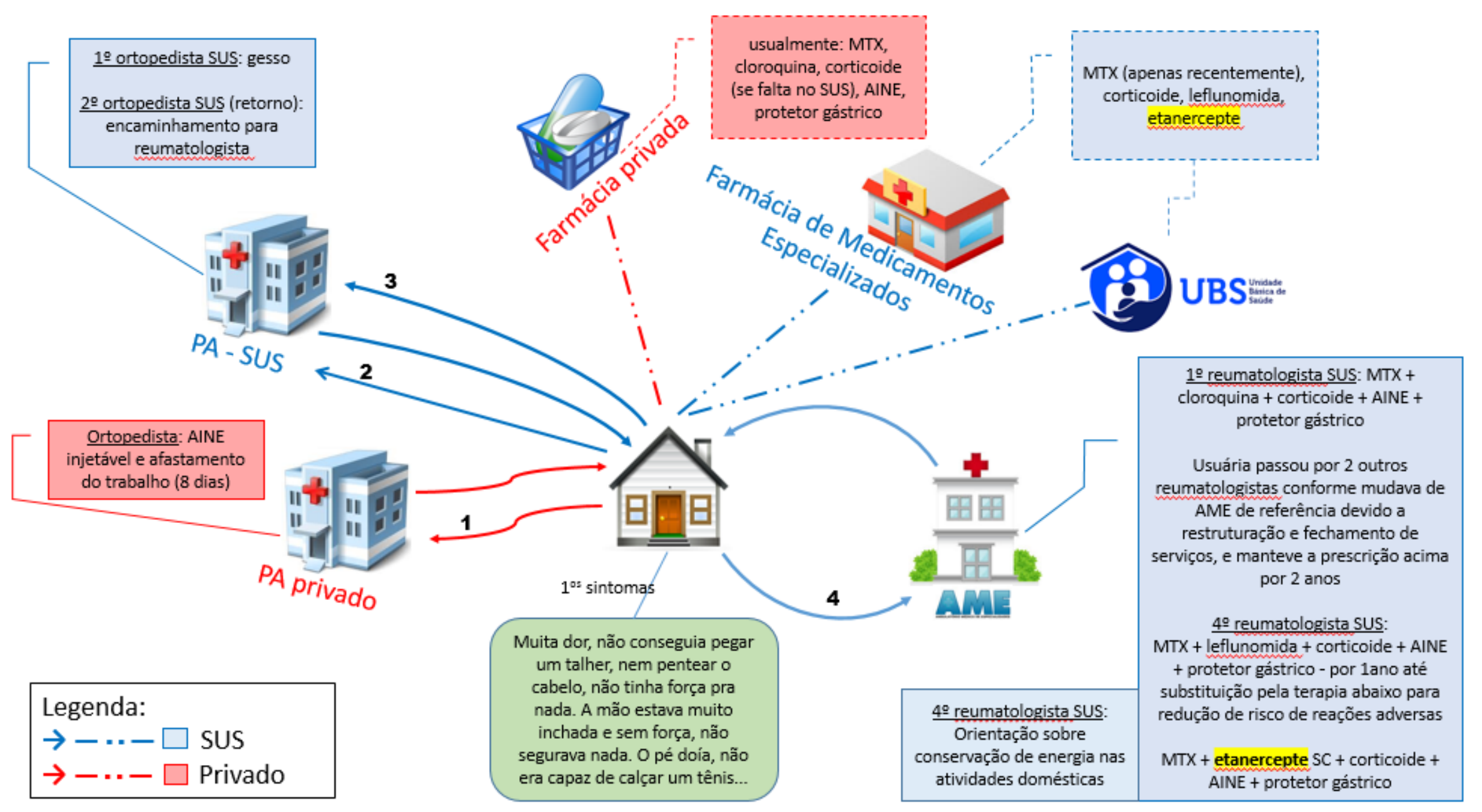

Figura 03: Itinerário terapêutico da paciente

Fonte: elaboração própria

AINE: anti-inflamatório não esteroide; MTX: metotrexato; SC: subcutâneo; UBS: unidade básica de saúde. 
Nos relatos dos entrevistados, alguns outros atores do sistema privado apareceram constantemente. Dois com grande frequência foram os enfermeiros, funcionários dos fabricantes dos medicamentos biológicos, que foram às casas dos pacientes dispensados pelo SUS para ensiná-los a administrar os medicamentos biológicos via subcutânea, e os centros de infusão, também privados, porém com custo de serviço igualmente pago pelas indústrias farmacêuticas.

Conforme fala dos profissionais dos dispensários, e com base na alocação de recursos entre os subsistemas público e privado66, as dificuldades já discutidas para acesso a especialista e diagnóstico correto certamente são mais percebidas pelos usuários do subsistema público. Considerando a estrutura disponível num e noutro, quando um usuário de plano de saúde privado se consulta no subsistema público, ou faz uso dos medicamentos por ele dispensados, o recurso destinado a este subsistema é ainda mais dividido, o que reduz o gasto per capita em saúde para o sistema público, e agrava as dificuldades encontradas pelos usuários exclusivos do SUS. Apesar do seu caráter de acesso universal, é preciso que haja no SUS uma melhor regulação que possa discutir e propor ações resolutivas para estes gastos desproporcionais, que prejudicam o acesso à saúde pela parcela menos beneficiada economicamente - justamente aquela que deveria receber maiores investimentos se quisermos proporcionar equidade à nossa sociedade através da saúde. 


\subsection{AFASTAMENTOS LABORAIS}

O desconforto físico a que os pacientes têm de se adaptar mesmo fora das crises, e a limitação laboral e de realização das atividades diárias causada pela doença não controlada aparecem com frequência nos depoimentos.

"Trabalhava na época e precisei sair, porque não dava. Tinha dia que eu conseguia levantar da cama e tinha dia que eu não conseguia." [paciente G]

"Não me afastou porque eu tive força de vontade. Se eu não tivesse força de vontade eu estava paralítica na cama..." [paciente Q]

Detaille e colaboradores, em estudo realizado na Holanda104, verificaram que o fator mais relevante para o paciente com AR continuar trabalhando foi o apoio do gestor, com aceitação, conhecimento e suporte do mesmo com relação a limitações físicas. Nas entrevistas, este apoio não é mencionado. Os pacientes relatam, ao contrário, falta de compreensão dos colaboradores de trabalho com relação à sua doença:

"Consegui conduzir minhas atividades, mas assim... mas com dificuldade, ouvindo piadinhas... vamos dizer assim... porque quando eu andava ou sentava, ou levantava... aí aquela expressão de dor ficava aparente, né... aí alguns me chamavam de velho... dessas coisas assim, entendeu... porque era muita dor... Foi um constrangimento grande, muito grande." [paciente P]

Em segundo lugar no estudo holandês como fator relevante para a continuidade das atividades laborais aparece o autocuidado e a capacidade de manejar os desafios impostos pela doença, como uso da correta terapia 
medicamentosa, conhecimento sobre AR e limitações próprias, e a busca por uma vida saudável incluindo prática de atividade física.

Nossos entrevistados relataram estar neste momento sendo beneficiados de uma boa prescrição medicamentosa, com adequado controle da doença. Entretanto este não foi o histórico de doença mais frequente, com muitos deles tendo sintomas persistentes e limitantes por longos períodos, sobretudo no início da AR.

Com relação à capacidade de manejar os desafios impostos, dois citam a persistência como aliada. Nenhum, no entanto, informou qualquer suporte de psicólogo ou terapeuta ocupacional, que pudesse apoiar na construção de um repertório individual para enfrentamento dos altos e baixos da doença.

Outro fator relevante na continuidade do trabalho, segundo Detaille e colaboradores, é a possibilidade de adaptação de equipamentos como cadeira e teclado e a flexibilização dos horários. Dois pacientes mencionaram ter tido no ambiente de trabalho esta adaptação. Nas falas de ambas também aparece o esforço individual para a continuidade das atividades realizadas.

"No [trabalho na instituição] particular eu tinha restrição. (...) Às vezes puxa um pouquinho, às vezes eu sinto, às vezes vou na doutora, e outras vezes q eu sinto a articulação inchar muito e me debilita um pouco, daí eu passo na doutora e ela faz uma punção." [paciente J]

"No meu serviço eles foram legais comigo, eles deixavam eu chegar atrasada, né, porque eu tinha que andar bem devagarinho... Até hoje... eu não poso pegar peso com a mão..." [paciente Q] 
Coincidentemente, estas duas pacientes trabalhavam com atividades especializadas, com algum grau de exigência intelectual. Os afastamentos descritos pelos demais pacientes foram de atividades que exigiam maior esforço físico, como tarefas domésticas.

Um dos entrevistados, trabalhador autônomo, fez um importante destaque sobre a limitação da capacidade de adaptação no trabalho, que compete com a necessidade de continuidade do acompanhamento médico:

"A consulta médica é no horário comercial de $2^{\mathrm{a}}$ a $6^{\mathrm{a}}$, você tem que reservar um período para isso, acaba interferindo... Como eu sou autônomo, eu consigo até conciliar. Mas atrapalha." [paciente D]

Este paciente, atendido pelo SUS, coincidentemente descreveu o mais rico repertório de encaminhamentos para profissionais não médicos recebido dentre os entrevistados, incluindo acupunturista e nutricionista. Hoje não está mais em seguimento com estes profissionais. Conforme seu relato, não havia tempo disponível para todos os acompanhamentos, e optou pelos profissionais que avaliou como mais relevantes, ficando apenas com o médico para apoio com a AR. Para os profissionais autônomos, a necessidade de se conhecer e se reinventar parece ainda maior diante das limitações da AR. No caso deste paciente, que descreveu um controle adequado dos sintomas, a recusa ao suporte dos demais profissionais pôde ser feita. Em situações de maior atividade da doença provavelmente não haveria a chance de escolha, e o caso poderia ter um desfecho de afastamento temporário ou definitivo. 
Diversos estudos dedicam-se a avaliar a incidência dos afastamentos laborais e os custos sociais relacionados. ex: ${ }^{109-111}$ Sokka e colaboradores ${ }^{105}$ avaliaram afastamentos em 32 países, comparando-os com o índice de incapacidade do questionário de avaliação em saúde, a época do diagnóstico (antes ou depois da disponibilidade de MMCD biológicos no mercado), e o produto interno bruto (PIB) do país. Como esperado, quanto maiores os valores para o índice de incapacidade, maiores as frequências de afastamento. Um resultado intrigante no estudo foi a ausência de relação entre a data de diagnóstico e os afastamentos nos países estudados, o que os autores relativizam com a questão da indisponibilidade dos melhores tratamentos devido à baixa cobertura sobretudo nos países com menores PIB's.

Apesar de 5 dos nossos entrevistados terem declarado interrupção definitiva das atividades laborais e 1 temporária devido à limitação causada pela $A R$, eles revelaram baixo conhecimento com relação a seus direitos sociais - de suporte da previdência social em afastamentos definitivos e direitos sociais como transporte gratuito após comprovação da limitação física.

Apenas uma paciente revela ter recebido orientação sobre direitos sociais e a preocupação de seu médico em apoiá-la na busca pelos mesmos:

"Eu fui no médico particular no começo, depois da Santa Casa, o médico me dispensou na hora por oito dias... mas aí, tratamento é caro, né? Eu tive que ir pro SUS mesmo. Daí em seguida a minha patroa me dispensou, que eu não era registrada, aí eu fiquei danada. Aí esse médico viu minha situação e falou assim "Você trabalha?". Na primeira consulta com ele. Aí eu falei não, doutor, eu estou desempregada. Aí ele falou "Olha, esquece o mercado de trabalho que você não tem condição de voltar mais. 
Você já tem algum beneficio?" Falei também não. Eu não sabia, eu era tão assim, eu não sabia de nada, já tinha passado em outros médicos, aqui... ele foi o único que me orientou... Eu corri atrás e consegui. Estou aposentada, graças a deus e a ele. As pessoas não acreditam que eu consegui por causa da dificuldade que tá, né? Mas graças a deus eu consegui, coloquei na justiça, fiz tudo que ele me orientou, e deu certo tudo da forma que ele me orientou." [paciente C]

No estudo de Sokka, outro dado relevante foi pessoas com maiores índices de incapacidade em países com PIB's menores estarem trabalhando em comparação com pessoas afastadas com menor índice de incapacidade em países com maior desenvolvimento econômico.

O tema do afastamento laboral merece mais estudos da comunidade científica. Tanto sob o ponto de vista econômico, para melhor entendimento do tratamento não medicamentoso e suporte necessário ao paciente de AR para preservá-lo nas suas funções laborais, quanto do ponto de vista social, para identificação e tratativa dos fatores não orgânicos que permitem ao paciente continuar adequadamente inserido na sociedade e contribuindo para o seu desenvolvimento humano e econômico.

\section{ACHADOS A SEREM MELHOR EXPLORADOS EM OUTROS ESTUDOS}

Nas entrevistas apareceram atores não previstos, que merecem ter seu papel no processo melhor estudado, bem como seus interesses e sua capacidade de contribuir ou não para a saúde do usuário e do sistema. 
Alguns exemplos destes atores: programas de adesão ao medicamento das indústrias farmacêuticas fabricantes dos MMCD biológicos, clínicas privadas para infusão dos medicamentos endovenosos, e consultório médico com encaminhamento para escritório de advocacia com finalidade de judicializar o medicamento.

Quase todos os pacientes em uso de MMCD biológico referiram ter recebido algum apoio dos laboratórios fabricantes, sendo referida comumente a disponibilização por eles de bolsa térmica com gelox, como apoio para a manutenção do medicamento em cadeia fria, preservando suas características físico-químicas e efetividade. Além da bolsa, houve referência a envio pelos laboratórios de material impresso com orientação sobre a doença, visita de profissional de saúde dos programas de adesão ao paciente dos laboratórios para ensinar a autoadministração dos medicamentos por via subcutânea, ligações destes laboratórios para coleta de dados sobre o status clínico do paciente, e oferecimento de medicamento no caso de falta.

O usuário não se mostra capaz de realizar a distinção entre o serviço privado de infusão em clínicas especializadas oferecido pelos laboratórios e o SUS. Além disso, também não se mostra capaz de perceber a ausência de contrapartida nas ligações para coleta de informações sobre seu status clínico. Em todas as falas houve o reconhecimento do laboratório como parceiro no sistema, e gratidão do usuário pelo apoio fornecido.

Durante as entrevistas, as clínicas foram relacionadas aos programas de adesão. Mencionou-se a necessidade de ligação prévia no laboratório 
para autorizar a realização da infusão do MMCD biológico, aparentemente revelando que o serviço de infusão é um benefício oferecido pelo programa de adesão do laboratório ao paciente usuário do medicamento biológico. Conforme as entrevistas, o médico do paciente procede o cadastro do paciente no programa e o laboratório passa então a contatar este paciente.

Foi solicitada aprovação pelo Comitê de Ética para que fossem realizadas entrevistas adicionais com representantes das clínicas de infusão, para melhor esclarecimento do tema. A aprovação para as mesmas foi dada recentemente e ainda não foi possível a sua realização. O tema será trabalhado em futuros estudos.

Sobre o encaminhamento para a judicialização, em 17 entrevistas realizadas, 1 usuário citou já ter usado esta via. Não foi informado o motivo exato da judicialização. O usuário não chegou a conhecer o advogado responsável, pois todo o trâmite foi feito através do médico, que decidiu em nome do paciente por este caminho. Chama a atenção o fato de que o usuário nega ter pago qualquer valor pelo serviço do advogado. Atualmente, devido à disponibilidade integral dos medicamentos biológicos pelo SUS, não se faz mais necessária a judicialização destes medicamentos para pacientes com AR. ${ }^{2}$

Parece haver todo o interesse dos laboratórios farmacêuticos em dar continuidade e garantir o uso do tratamento prescrito para os pacientes encaminhados no sistema. Poderia ser avaliada uma parceria entre o sistema público e a iniciativa privada neste caso para benefício da sociedade. Valeria à pena ao Estado conhecer bem e regular estas 
iniciativas, fazer bom uso daquelas que trazem benefício para a população, e restringir as demais, que possam representar abuso ou risco para os usuários.

\section{LIMITAÇÕES DO ESTUDO}

A distância entre a data dos primeiros sintomas e a entrevista limitam a coleta pormenorizada da história dos pacientes. Em estudos futuros, para análise mais profunda de tempo de espera e motivadores, um desenho prospectivo abordando pacientes em serviços com atendimento de reumatologistas pode ser mais efetivo neste aspecto.

A dificuldade dos usuários com as nomenclaturas técnicas de exames e medicamentos também foi um fator limitante.

As iniquidades do sistema, como referido pelos profissionais dos dispensários, restringem a chegada do paciente com baixa e moderada atividade da doença ao diagnóstico e tratamento adequados. Assim, o recorte encontrado aqui talvez não possa ser considerado representativo destes pacientes no que diz respeito a tratamentos não farmacológicos, afastamentos laborais e outras características de apresentação, cuidado com a doença e questões sociais do portador de AR.

Ainda, vale citar que a pesquisadora que aplicou as entrevistas, não tendo uma formação em humanas e experienciando pela primeira vez a participação em um estudo qualitativo, encontra-se em construção contínua 
do seu olhar para as humanidades e seguramente tem oportunidades de melhoria na condução de futuras entrevistas.

\section{CONSIDERAÇÕES FINAIS}

As principais dificuldades encontradas nos itinerários terapêuticos foram a iniciativa da busca por resolução dos sintomas, de modo geral interpretados pelos pacientes como agudos e passageiros, exceto nos casos de apresentação mais agressiva da doença; e a disponibilidade do profissional adequado e qualificado para investigação dos sintomas e encaminhamento do paciente, bem como de estrutura que propiciasse a continuidade do cuidado, poupando as idas e vindas do paciente na busca por diagnóstico.

Raras vezes o médico generalista foi consultado no início da apresentação dos sintomas, e a AP não pôde contribuir muito no rastreio e investigação inicial dos pacientes. Foi frequente a busca de ajuda nos serviços de emergência e por seguidas vezes entre aqueles do subsistema público exclusivo, e deles os pacientes foram por fim encaminhados até chegar ao reumatologista.

Ficou clara a necessidade de conscientização da sociedade sobre a importância e as características das doenças reumáticas. Da mesma maneira, evidenciou-se a oportunidade de melhor preparo dos médicos 
generalistas e ortopedistas sobre o mesmo assunto, para abreviar o tempo desde os primeiros sintomas até o início com MMCD, contribuindo para melhor prognostico da AR, e menor impacto da doença para a sociedade.

No subsistema privado também houve despreparo dos profissionais para investigar os sintomas e conduzir o paciente para diagnóstico correto. Houve situações de vai-e-vém entre o público e o privado bem marcadas nas trajetórias dos pacientes, com o intuito sobretudo de abreviar os tempos de espera para o cuidado.

Chamou a atenção no mix público-privado principalmente a questão dos pacientes com planos de saúde não buscarem cobertura para os medicamentos de alto custo junto a suas operadoras, e de também não haver ação do SUS para esta devolução de responsabilidade.

Outros atores da iniciativa privada apareceram nos discursos e merecem ser melhor explorados em estudos futuros, com destaque para o papel das indústrias farmacêuticas e seus programas de adesão e apoio ao paciente, e os centros de infusão de medicamentos.

Sobre o tratamento, muitos pacientes demoraram a iniciar com MMCD, sobretudo devido ao diagnóstico demorado. Após o mesmo, houve o uso efetivo do recurso medicamentoso, tendo quase todos os pacientes passado pelas fases de uso dos MMCD's sintéticos como primeira alternativa. 
A educação sobre a doença e demais tratamentos não medicamentosos, no entanto, infelizmente foram descritos como suboferecidos aos pacientes de $A R$, e constituem alguns dos principais desafios ao sistema de saúde para o cuidado com esta doença.

O uso do itinerário terapêutico foi muito promissor como ferramenta para explorar as dificuldades encontradas no sistema através do olhar do paciente. Algumas extrapolações podem ser feitas a partir dos depoimentos colhidos neste estudo para começarmos a repensar o oferecimento de cuidado para pacientes com AR e outras doenças crônicas. Estudos mais aprofundados para cada um dos subtemas abordados seriam, no entanto, de enorme valia para respaldar a necessidade de mudança e endereçar os esforços de melhoria no sistema.

\section{REFERÊNCIAS}

1. SMOLEN, J.S.; ALETAHA, D.; MCINNES, I.B. Rheumatoid arthritis. Lancet, v.388, p.2023-38, 2016.

2. BRASIL, Ministério da Saúde. Portaria SAS/MS no 996, de 30 de setembro de 2015. Aprova o Protocolo Clínico e Diretrizes Terapêuticas da Artrite Reumatoide. Disponível em: < http://portalarquivos.saude.gov.br/images/pdf/2016/marco/08/pcdt -Artrite-Reumat--ide---Portaria-SAS-996-PCDT-AR-30-09-2015.pdf> Acesso em: 23 julho 2017.

3. COMBE, B. et al. 2016 update of the EULAR recommendations for the management of early arthritis. Annals of the Rheumatic Diseases, v.76, n.06, p.948-59, Junho 2017. 
4. MOTA, L.M.H.; LAURINDO, I.M.M.; SANTOS NETO, L.L. Artrite reumatoide inicial - conceitos. Revista da Associação Médica Brasileira, v.56, n.02, 2010.

5. RODRÍGUEZ-POLANCO, E. et al. Lag time between onset of symptoms and diagnosis in Venezuelan patients with rheumatoid arthritis. Rheumatolology International, v.31, n.05, p.657-65, maio 2011.

6. SANGHA, O. Epidemiology of rheumatic diseases. Rheumatology, v.39, supl.02, p.3-12, 2000.

7. WONG, R. et al. Prevalence of Arthritis and Rheumatic Diseases around the World. A Growing Burden and Implications for Health Care Needs. Division of Health Care and Outcomes Research, Arthritis Community Research \& Evaluation Unit (ACREU), Toronto Western Research Institute. 2010. 110 p.

8. SENNA E.R. et al. Prevalence of Rheumatic Diseases in Brazil: A Study Using the COPCORD Approach. The Journal of Rheumatology, v.31, n.3, p.594-7, 2004.

9. IBGE. Instituto Brasileiro de Geografia e Estatística. Projeção da população no Brasil - 23/07/2017. Disponível em: <http://www.ibge.gov.br/apps/populacao/projecao/> Acesso em: 23 julho 2017.

10. FIRESTEIN, G.S.; MCINNES, I.B. Immunopathogenesis of Rheumatoid Arthritis. Immunity, v.46, n.02, p.183-96, 2017.

11. MOURA, M.C et al. Perfil dos pacientes com manifestações extra-articulares de artrite reumatoide de um serviço ambulatorial em Curitiba, Sul do Brasil. Revista Brasileira de Reumatologia, v.52, n.05, p. 679-94, 2012.

12. SINGH, J.A. et al. 2015 American College of Rheumatology Guideline for the Treatment of Rheumatoid Arthritis. Arthritis \& Rheumatology, v.68, n.01, p.1-26, janeiro 2016.

13. ALETAHA, D. et al. 2010 Rheumatoid arthritis classification criteria: an American College of Rheumatology/European League Against Rheumatism collaborative initiative. Annals of the Rheumatic Diseases, v.69, p. 1580-8, 2010.

14. MOTA, L.M.H. et al. Rheumatoid arthritis in Latin America: the importance of an early diagnosis. Clinical Rheumatology, v.34, supl.01, p.29-44, 2015. 
15. VILLENEUVE, $\mathrm{E}$. et al. A systematic literature review of strategies promoting early referral and reducing delays in the diagnosis and management of inflammatory arthritis. Annals of Rheumatic Diseases, v.72, p. 13-22, 2013.

16. RAZA, K. et al. Delays in assessment of patients with rheumatoid arthritis: variations across Europe. Annals of Rheumatic Diseases, v.70, p.1822-25, 2011.

17. FAUTREL, B. et al. Early referral to the rheumatologist for early arthritis patients: evidence for suboptimal care. Results from the ESPOIR cohort. Rheumatology, v.49, p.147-55, 2010.

18. DE COCK, D. et al. A detailed analysis of treatment delay from the onset of symptoms in early rheumatoid arthritis patients. Scandinavian Journal of Rheumatology, v.43, n.01, p.1-8, 2014.

19. de THURAH, A. et al. Time to methotrexate treatment in patients with rheumatoid arthritis referred to hospital. Scandinavian Journal of Rheumatology, v.39, n.01, p.19-25, 2010.

20. KUMAR, K. et al. Delay in presentation to primary care physicians is the main reason why patients with rheumatoid arthritis are seen late by rheumatologists. Rheumatology, v.46, p.1438-40, 2007.

21. SUTER, L.G.; FRAENKEL, L.; HOLMBOE, E.S. What Factors Account for Referral Delays for Patients With Suspected Rheumatoid Arthritis? Arthritis \& Rheumatism, v.55, n.02, p.300-5, abril 2006.

22. HAZLEWOOD, G.S. et al. Improving Appropriate Access to Care With Central Referral and Triage in Rheumatology. Arthritis Care \& Research, v.68, n.10, p. 1547-53, outubro 2016.

23. van NIES, J.A. et al. Improved early identification of arthritis: evaluating the efficacy of Early Arthritis Recognition Clinics. Annals of Rheumatic Diseases, v.72, n.08, p.1295-301, Agosto 2013.

24. SEGURA, B.T.; BUSTABAD, S. Una nueva forma de comunicación entre reumatología y atención primaria: la consulta virtual. Reumatología Clínica, v.12, n.01, p.11-14, 2016.

25. FEUCHTENBERGER, M. et al. Rate of Proven Rheumatic Diseases in a Large Collective of Referrals to an Outpatient Rheumatology Clinic Under Routine Conditions. Clinical Medicine Insights: Arthritis and Musculoskeletal Disorders, v.09, p.181-7, outubro 2016. 
26. CUMMINS, L.L.; VANGAVETI, V.; ROBERTS, L.J. Rheumatoid Arthritis Referrals and Rheumatologist Scarcity: A Prioritization Tool. Arthritis Care \& Research, v.67, n.03, março 2015, p.326-331.

27. MULLER, S. et al. An algorithm to identify rheumatoid arthritis in primary care: a Clinical Practice Research Datalink study. BMJ Open, v.05, n.12, dezembro 2015. Disponível em < https://www.ncbi.nlm.nih.gov/pmc/articles/PMC4691776/>. Acesso em: 29 julho 2017.

28. VILLAVERDEA, V. et al. Características de una unidad de artritis precoz que mejoran la eficiencia de la derivación: encuesta a las unidades SERAP. Reumatología Clínica, v.07, n.04, p. 236-40, 2011.

29. MEYFROIDT, $S$. et al. A general practice perspective on early rheumatoid arthritis management: A qualitative study from Flanders. European Journal of General Practice, v.21, n.04, p.231-7, 2015.

30. MENDES, E.V. O Cuidado das Condições Crônicas na Atenção Primária à Saúde: O Imperativo da Consolidação da Estratégia da Saúde da Família. Brasília: Organização PanAmericana da Saúde, 2012, 512p.

31. AHLSTRAND, I. et al. Pain and daily activities in rheumatoid arthritis. Disability \& Rehabilitation, v.34, n.15, p. 1245-53, 2012.

32. BOONEN, A.; SEVERENS, J.L. The burden of illness of rheumatoid arthritis. Clinical Rheumatology, v.30, supl.01, p.S3S8, 2011.

33. BUENDGENS, F.B. et al. Estudo de custo-análise do tratamento da artrite reumatoide grave em um município do Sul do Brasil. Cadernos de Saúde Pública, v.29.supl.01, p.S81-91, 2013.

34. CMED - Câmara de Regulação do Mercado de Medicamentos, Secretaria Executiva. ANVISA. Preços Máximos de Medicamentos por Princípio Ativo - atualizada em 17/06/2016. Disponível em: <http://portal.anvisa.gov.br/documents/374947/2829072/LISTA+C ONFORMIDADE_2016-06-17.pdf/0a9406d6-2fe9-4c4c-ba19f7831e3ace3e> Acesso em: 20 junho 2016.

35. SES/SP - Secretaria de Estado da Saúde/São Paulo. Relação Estadual de Medicamentos do Componente Especializado da Assistência Farmacêutica. Disponível em: <http://www.saude.sp.gov.br/ses/perfil/gestor/assistenciafarmaceutica/medicamentos-dos-componentes-da-assistenciafarmaceutica/medicamentos-do-componente-especializado-da- 
assistencia-farmaceutica/relacao-estadual-de-medicamentos-docomponente-especializado-da-assistencia-farmaceutica> Acesso em: 20 junho 2016.

36. ANVISA - Agência Nacional de Vigilância Sanitária, Ministério da Saúde. Bulário Eletrônico. Disponível em: <http://www.anvisa.gov.br/datavisa/fila_bula/index.asp > Acesso em: 20 junho 2016.

37. de ALMEIDA, P.H.T.Q. et al. Terapia ocupacional na artrite reumatoide: o que o reumatologista precisa saber? Revista Brasileira de Reumatologia, v.55, n.03, p.272-80, 2015.

38. UPCHURCH, K.S.; KAY, J. Evolution of treatment for rheumatoid arthritis. Rheumatology, v.51, p.vi28-vi36, 2012.

39. Janssen-Cilag Farmacêutica - SAC Genéricos. Forwarded user message from www.janssen.com - Subject: www_janssen_com_brasil : TrackerId : 194303 [mensagem eletrônica]. Mensagem recebida por sil_coimbra@yahoo.com.br em 22 setembro de 2015.

40. BRASIL. Ministério da Saúde. Portaria SAS/MS no 865 de 08 de novembro de 2002. Protocolo Clínico e Diretrizes Terapêuticas da Artrite Reumatoide.

41. BRASIL. Ministério da Saúde. Portaria SCT/MS no 66 de 01 de novembro de 2006. Protocolo Clínico e Diretrizes Terapêuticas da Artrite Reumatoide. Disponível em <bvsms.saude.gov.br/bvs/saudelegis/sctie/2006/prt0066_01_11_2 006.html> Acesso em: 12 agosto 2015.

42. BRASIL. Ministério da Saúde. Secretaria de Ciência, Tecnologia e Insumos Estratégicos. Departamento de Assistência Farmacêutica e Insumos Estratégicos. Relação Nacional de Medicamentos Essenciais: RENAME 2014 - 9. ed. rev. e atual. Brasília: Ministério da Saúde, 2015. 230 p.

43. HAZLEWOOD, G. S. et al. Methotrexate monotherapy and methotrexate combination therapy with traditional and biologic disease modifying antirheumatic drugs for rheumatoid arthritis: abridged Cochrane systematic review and network metaanalysis. The BMJ, 353, i1777, 2016.

44. STEVENSON, M. et al. Adalimumab, etanercept, infliximab, certolizumab pegol, golimumab, tocilizumab and abatacept for the treatment of rheumatoid arthritis not previously treated with disease- 
modifying antirheumatic drugs and after the failure of conventional disease-modifying antirheumatic drugs only: systematic review and economic evaluation. Health Technolology Assessment, v.20, n.35, abril 2016.

45. BYKERK, V.P. et al. Canadian Rheumatology Association Recommendations for Pharmacological Management of Rheumatoid Arthritis with Traditional and Biologic Disease-modifying Antirheumatic Drugs. The Journal of Rheumatology, v.39, n.08, p.1559-1582, 2012.

46. National Institute for Health and Care Excellence. NHS. Adalimumab, etanercept, inflfliximab, certolizumab pegol, golimumab, tocilizumab and abatacept for rheumatoid arthritis not previously treated with DMARDs or after conventional DMARDs only have failed. NICE. Janeiro 2016. 82p.

47. BRASIL. Ministério da Saúde. Portaria SAS/MS no 710 de 27 de junho de 2013. Aprova o Protocolo Clínico e Diretrizes Terapêuticas da Artrite Reumatoide. Disponível em < http://bvsms.saude.gov.br/bvs/saudelegis/sas/2013/prt0710_27_0 6_2013.html> Acesso em 28 fevereiro 2016

48. FDA - U.S. Food and Drug Administration. FDA Approved Drug Products. Disponível em < https://www.accessdata.fda.gov/scripts/cder/daf/index.cfm?event= overview. process\&applno=203214> Acesso em 20 agosto 2017.

49. MINISTÉRIO DA SAÚDE. Secretaria de Ciência, Tecnologia e Insumos Estratégicos - Comissão Nacional de Incorporação de Tecnologias (CONITEC). Tofacitinibe para o tratamento de pacientes adultos com artrite reumatoide ativa moderada a grave com resposta inadequada a um ou mais medicamentos modificadores do curso da doença - relatório de recomendação n 241. Brasília: janeiro 2017, 79p.

50. ANVISA - Agência Nacional de Vigilância Sanitária, Ministério da Saúde. Consulta Produtos - Medicamentos. Disponível em: < https://consultas.anvisa.gov.br/\#/medicamentos/> Acesso em: 20 agosto 2017.

51. MOTA, L.M.H. et al. Posicionamento sobre o uso de tofacitinibe no algoritmo do Consenso 2012 da Sociedade Brasileira de Reumatologia para o tratamento da artrite reumatoide. Revista Brasileira de Reumatologia, v.55, n.06, p.512-21, 2015. 
52. WOLFE, $F$. et al. Consensus recommendations for the assessment and treatment of rheumatoid arthritis. The Journal of Rheumatology, v.28, n.06, p.1423-30, 2001.

53. American College of Rheumatology Subcommittee on Rheumatoid Arthritis Guidelines. Guidelines for the Management of Rheumatoid Arthritis - 2002 Update. Arthritis \& Rheumatism, v.46, n.02, 328-46, 2002.

54. COMBE, B. et al. EULAR recommendations for the management of early arthritis: report of a task force of the European Standing Committee for International Clinical Studies Including Therapeutics (ESCISIT). Annals of the Rheumatic Diseases, v.66, n.01, p.3445, 2007.

55. SAAG, K.G. et al. American College of Rheumatology 2008 recommendations for the use of nonbiologic and biologic diseasemodifying antirheumatic drugs in rheumatoid arthritis. Arthritis \& Rheumatism, v.59, n.06, p.762-84, 2008.

56. SMOLEN, J.S. et al. EULAR recommendations for the management of rheumatoid arthritis with synthetic and biological disease-modifying antirheumatic drugs. Annals of the Rheumatic Diseases, v.69, n.06, p.964-75, 2010.

57. BYKERK, V.P. et al. Canadian Rheumatology Association Recommendations for Pharmacological Management of Rheumatoid Arthritis with Traditional and Biologic Disease-modifying Antirheumatic Drugs. The Journal of Rheumatology, v.39, n.08, p.1559-82, 2012.

58. SINGH, J.A. et al. 2012 Update of the 2008 American College of Rheumatology Recommendations for the Use of Disease-Modifying Antirheumatic Drugs and Biologic Agents in the Treatment of Rheumatoid Arthritis. Arthritis Care \& Research, v.64, n.05, p.62539, maio 2012.

59. SMOLEN, J.S. et al. EULAR recommendations for the management of rheumatoid arthritis with synthetic and biological disease-modifying antirheumatic drugs: 2013 update. Annals of the Rheumatic Diseases, v.73, n.03, p.492-509, 2013.

60. SMOLEN, J.S. et al. EULAR recommendations for the management of rheumatoid arthritis with synthetic and biological 
disease-modifying antirheumatic drugs: 2016 update. Annals of the Rheumatic Diseases, v.76, n.06, p.960-77, junho 2017.

61. FURST, D.E. et al. Updated consensus statement on tumour necrosis factor blocking agents for the treatment of rheumatoid arthritis (May 2000). Annals of the Rheumatic Diseases, v.59, sup.01, p.i1-2, 2000.

62. EMA - European Medicine Agency. Science Medicines Health. Disponível em < www.ema.europa.eu>. Acesso em 02 julho 2015.

63. The National Collaborating Centre for Chronic Conditions NICE/NHS. Rheumatoid Arthritis. National clinical guideline for management and treatment in adults. Royal College of Physicians. London: 2009. 275p.

64. National Institute for Health and Care Excellence. NHS. Adalimumab, etanercept, inflfliximab, rituximab and abatacept for the treatment of rheumatoid arthritis after the failure of a TNF inhibitor. NICE. Agosto 2010. 66p.

65. PAIM, J. et al. The Brazilian health system: history, advances, and challenges. Lancet, v.377, n.9779, p.1778-97, maio 2011.

66. SANTOS, I.S.; UGÁ, M.A.D.; PORTO, S.M. O mix público-privado no Sistema de Saúde Brasileiro: financiamento, oferta e utilização de serviços de saúde. Ciência \& Saúde Coletiva, v.13, n.5, p.14311440, 2008.

67. ANS - Agência Nacional de Saúde Suplementar. Informações em saúde Suplementar, Tabnet, Beneficiários - dados de setembro de 2017. Disponível em <http://www.ans.gov.br/perfil-dosetor/dados-e-indicadores-do-setor> Acesso em 01 fevereiro 2018.

68. ANS - AGÊNCIA NACIONAL DE SAÚDE SUPLEMENTAR. Resolução Normativa no 211, de 11 de janeiro de 2010. Atualiza o Rol de Procedimentos e Eventos em Saúde que constitui a referência básica para cobertura assistencial mínima nos planos privados de assistência à saúde e dá outras providências. Disponível em: <http://www.ans.gov.br/component/legislacao/?view=legislacao\&ta $\mathrm{sk}=$ TextoLei\&format $=$ raw\&id $=\mathrm{MTgOMA}==\#$ anexo $>$. Acesso em: 28 fevereiro 2016.

69. ANS - AGÊNCIA NACIONAL DE SAÚDE SUPLEMENTAR. Resolução Normativa no 338, de 21 de outubro de 2013. Atualiza o Rol de Procedimentos e Eventos em Saúde que constitui a referência básica para cobertura assistencial mínima nos planos privados de 
assistência à saúde e dá outras providências. Disponível em: <http://www.ans.gov.br/component/legislacao/?view=legislacao\&ta $\mathrm{sk}=$ TextoLei\&format $=$ raw\&id $=\mathrm{MjU} \mathrm{MMQ}==>$. Acesso em: 28 fevereiro 2016.

70. BRASIL. Constituição Federal, 1998, artigo 194.

71. CAMPOS NETO, O.H. et al. Médicos, advogados e indústria farmacêutica na judicialização da saúde em Minas Gerais, Brasil. Revista de Saúde Pública, v.46, n.5, p.784-90, 2012.

72. SOARES, J.C.R.S.; DEPRÁ, A.S. Ligações perigosas: indústria farmacêutica, associações de pacientes e as batalhas judiciais por acesso a medicamentos. Physis, v.22, n.1, p. 311-329, 2012.

73. CHIEFFI, A.L.; BARATA, R.C. Judicialização da política pública de assistência farmacêutica e eqüidade. Cadernos de Saúde Pública, v.25, n.8, p.1839-49, agosto 2009.

74. CHIEFFI, A.L.; BARATA, R.C. Ações judiciais: estratégia da indústria farmacêutica para introdução de novos medicamentos. Revista de Saúde Pública, v.44, n.3, p.421-9, 2010.

75. NASCIMENTO, A. Propaganda de medicamentos: como conciliar uso racional e a permanente necessidade de expandir mercado? Trabalho, Educação e Saúde, Rio De Janeiro, v.05, n.02, julho 2007.

76. MOLINER, J. et al. [Is it pertinent to investigate the relations between physicians and the drug industry.] Revista de Calidad Asistencial, v.24, n.02, p.72-79, abril 2009.

77. YEH, J.S. et al. Association of Industry Payments to Physicians With the Prescribing of Brand-name Statins in Massachusetts. JAMA Internal Medicine, v.176, n.06, p.763-68, junho 2016.

78. ALHAMOUD, H.A. et al. Author Self-disclosure Compared with Pharmaceutical Company Reporting of Physician Payments. American Journal of Medicine, v.129, n.01, p.59-63, janeiro 2016.

79. KLEINMAN, A. Culture, Health Care Systems and Clinical Reality. In: Patients and Healers in the Context of Culture: An Exploration of the Borderland Between Anthropology, Medicine, and Psychiatry. University of California Press, 1981. p.24-70. 
80. BELLATO, R. et al. Itinerários terapêuticos de famílias e redes para o cuidado na condição crônica: alguns pressupostos. In: PINHEIRO, R.; MARTINS, P.H. Avaliação em Saúde na Perspectiva do Usuário. Rio de Janeiro: CEPESC/IMS-UERJ, 2009. p.187-94.

81. BELLATO, R.; ARAUJO, L.F.S.; CASTRO, P. O itinerário terapêutico como uma tecnologia avaliativa da integralidade em saúde. In: Pinheiro, R.; SILVA JÚNIOR, A.G.; MATTOS, R.A. Atenção básica e integralidade: contribuições para estudos de práticas avaliativas em saúde. $1^{\text {a }}$ ed. Rio de Janeiro: CEPESC/IMS-UERJ, 2008. p.167-85.

82. KRAAIJVANGER, N.; van LEEUWEN, H.; RIJPSMA, D. et al. Motives for self-referral to the emergency department: a systematic review of the literature. BMC Health Services Research, v.16, n.685, 2016.

83. KRAAIJVANGER, N.; RIJPSMA, D.; WILLINK, L. et al. Why patients self-refer to the Emergency Department: A qualitative interview study. Journal of Evaluation in Clinical Practice, v. 23, n.03, p.593-8, 2017.

84. LEGA, F.; MENGONI, A. Why non-urgent patients choose emergency over primary care services? Empirical evidence and managerial implications. Health Policy, v.88, n.2-3, p.326-338, 2008.

85. WONG, C.Y.; HALL, J. Does patients' experience of general practice affect the use of emergency departments? Evidence from Australia. Health Policy, Dezembro 2017.

86. DATASUS. Informações de Saúde (TABNET). Rede Assistencial. Disponível em http://tabnet.datasus.gov.br/cgi/deftohtm.exe?cnes/cnv/proc02sp.d ef> Acesso em 20 Ago 2017.

87. SIMONS, G. et al. Qualitative Exploration of Illness Perceptions of Rheumatoid Arthritis in the General Public. Musculoskeletal Care, v.15, n.01, p.13-22, 2017.

88. CAMPOS, R.T.O. et al. Avaliação da qualidade do acesso na atenção primária de uma grande cidade brasileira na perspectiva dos usuários. Saúde debate, v.38, n.esp, p.252-264, 2014.

89. PUCHNER, R. et al. Efficacy and Outcome of Rapid Access Rheumatology Consultation: An Office-based Pilot Cohort Study. Journal of Rheumatology, v.43, n.06, p.1130-5, 2016. 
90. ZAFAR, S. et al. Efforts to increase public awareness may result in more timely diagnosis of rheumatoid arthritis. Journal of Clinical Rheumatology, v.18, n.06, p.279-82, 2012.

91. SHEPPARD, J. et al. 'I just thought it was normal aches and pains': a qualitative study of decision-making processes in patients with early rheumatoid arthritis. Rheumatology, v. 47, p.1577-82, 2008.

92. STACK, R.J. et al. Delays in help seeking at the onset of the symptoms of rheumatoid arthritis: a systematic synthesis of qualitative literature. Annals of Rheumatic Diseases, v.71, p. 4937, 2012.

93. RADFORD, S. et al. 'It's quite hard to grasp the enormity of it': perceived needs of people upon diagnosis of rheumatoid arthritis. Musculoskeletal Care, v.6, n.03, p.155-67, 2008.

94. DILDY, S.P. Suffering in people with rheumatoid arthritis. Applied Nursing Research, v.09, n.04, p.177-83, 1996.

95. HAYWOOD, H.; ADAMS, J. Patients' Experiences of Rheumatoid Arthritis Education: A Short Report. Musculoskeletal Care, v.09, n.02, p.113-9, 2011.

96. BEARNE, L.M. et al. Multidisciplinary team care for people with rheumatoid arthritis: a systematic review and meta-analysis. Rheumatology International, v.36, n.03, p.311-24, 2016.

97. BADAMGARAV, $\mathrm{E}$. et al. Effects of disease management programs on functional status of patients with rheumatoid arthritis. Arthritis \& Rheumatism, v.49, n.03, p. 377-87, 2003.

98. VLIET VLIELAND, T.P.; HAZES, J.M. Efficacy of multidisciplinary team care programs in rheumatoid arthritis. Seminars in Arthritis and Rheumatism, v.27, n.02, p.110-22, 1997.

99. MÄKELÄINEN, P. et al. Rheumatoid arthritis patient education: RA patients' experience. Journal of Clinical Nursing, v.18, n.14, p.2058-65, 2009.

100. JENNINGS, F. et al. Brazil Patient Knowledge Questionnaire (PKQ) and evaluation of disease-specific knowledge in patients with rheumatoid arthritis. Clinical and Experimental Rheumatology, v.24, n.05, p.521-8, 2006. 
101. KHALIL, Z. et al. Patients' knowledge on Rheumatoid Arthritis A study at a tertiary care hospital. Journal of Pakistan Medical Association, v.67, n.02, p.256-60, 2017.

102. PYTEL, A.; WRZOSEK, Z. Estimation of patient knowledge on rheumatoid arthritis in the range of their own disease - preliminary study. Advances in Clinical and Experimental Medicine, v.21, n.03, p.434-51, 2012.

103. ELLARD, D.R. et al. Piloting education days for patients with early rheumatoid arthritis and their partners: a multidisciplinary approach. Musculoskeletal Care, v.07, n.01, p.17-30, 2009.

104. DETAILLE, S.I.; HAAFKENS, J.A.; van DIJK, F.J. What employees with rheumatoid arthritis, diabetes mellitus and hearing loss need to cope at work. Scandinavian Journal of Work, Environment \& Health, v.29, n.02, p.134-42, 2003.

105. SOKKA, T. et al. Work disability remains a major problem in rheumatoid arthritis in the 2000s: data from 32 countries in the QUEST-RA study. Arthritis Research and Therapy, v.12, n.02, 2010.

106. NICE - National Institute for Health and Care Excellence. Rheumatoid arthritis in adults: management. Clinical guideline. 2009. 18p.

107. BRASIL, Ministério da Saúde. Portaria GM/MS no 1.554, de 30 de julho de 2013. Dispõe sobre as regras de financiamento e execução do Componente Especializado da Assistência Farmacêutica no âmbito do Sistema Único de Saúde. Disponível em <http://portalarquivos.saude.gov.br/images/pdf/2014/abril/02/ptgm-ms-1554-2013-alterada-1996-2013.pdf> Acesso em: 20 agosto 2017.

108. CONILL, E.M. et al. O mix público-privado na utilização de serviços de saúde: um estudo dos itinerários terapêuticos de beneficiários do segmento de saúde suplementar brasileiro. Ciência \& Saúde Coletiva, v.13, n.5, p.1501-10, 2008.

109. GEUSKENS, G.A.; BURDORF, A.; HAZES, J.M.W. Consequences of rheumatoid arthritis for performance of social roles - a literature review. The Journal of Rheumatology, v.34, n.06, p.1248-60, 2007. 
110. MIRANDA, L.C. et al. Finding Rheumatoid Arthritis Impact on Life (FRAIL Study): economic burden. Acta Reumatológica Portuguesa, v.37, n.02, p.134-42, 2012.

111. TANG, K. et al. Measures of work disability and productivity: Rheumatoid Arthritis Specific Work Productivity Survey (WPS-RA), Workplace Activity Limitations Scale (WALS), Work Instability Scale for Rheumatoid Arthritis (RA-WIS), Work Limitations Questionnaire (WLQ), and Work Productivity and Activity Impairment Questionnaire (WPAI). Arthritis Care \& Research, v.63, supl.11, p. S337-49, 2011. 


\section{ANEXOS}

\section{Anexo I - Termo de Consentimento Livre e Esclarecido}

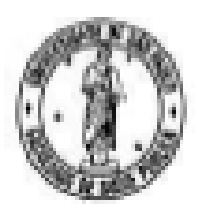

Unlvercldade de sso Paulo

Faouldade de saude Publlos

Av. Dr. Arnaldo, 716 - CEP 01248-904 - sSo Paulo - Bracll

TERMO DE CONSENTIMENTO LIVRE E

ESCLARECIDO

Titulo do Projeto: Itinerario terapeutico de pacientes com artite reumatolde en uso de medicamentos modilicadores do curso da doença blologicos

Pesqulsador Responsavel: Sllvia Colmbra de Ollvelra

Voce esta sendo convidado a particlpar do projeto de pesqulsa de mestrado itinerario terapéutico de paclentes com artilte reumatolde em uso de medicamentos modificadores do curso da doença.

O objetivo da pesquisa e identificar, descrever e anallsar o caminho percornido por voce e outros pacientes desde 06 primeiros sintomas de artrite reumatolde, a passagem pelos serviços de saude, ate o dlagnostico da doença e o tratamento especincamente com o medicamento blologico. Com estas trajetorlas, poderemos identuncar a estrutura de culdados disponivel na cidade de sto Paulo a partir dos olnos do paclente, reconhecer e descrever as difculdades encontradas, $e$ apresenta-las aos gestores. Desta forma um dos beneficios posslvels desta pesquisa e contribulr com Informaçbes para a melhoria do slstema de saude apos a devolutiva para os gestores.

Durante a realizaçăo das entrevistas, ha o risco de voce se sentir desconfortavel com a lembrança da sua doença. Voce tera a Ilberdade de năo responder a alguma pergunta e de desistir da entrevista a qualquer momento, sem qualquer prejulzo.

Os dados serăo util zados excluslvamente para fim desta pesquisa. Todas as Informaçbes fornecidas serăo tratadas confldendaimente, e sua identidade sera preservada.

Nåo ha despesas, nem compensaçăo financeira pela partipaçăo na pesquisa.

Voce tem o direlto de receber uma via deste termo de consentimento lwre e esciarecido. Caso deseje, voce podera ser atualizado sobre os resultados parcials da pesqulsa.

Em qualquer etapa da pesquisa, voce podera ter acesso aos profissionals responsavels para esclarecer dumdas. O investigador princlpal e a aluna de mestrado Silvia Colmbra de Olvelra, orlentada pela professora doutora Aylene Bousquat, que podem ser encontradas no endereço Av. Dr. Arnaldo, 715, Cerquelra Ce6ar - CEP 01246-904, Săo Paulo, SP - Telefone: (11) 3061-7796/ 7784.

Se tiver alguma dúvida etica ou queira notifcar acontecimento náo previsto na pesquisa, entre em contato com o Comlte de Etica em Pesquisa da Faculdade de Saúde Publica da Universidade 
de Săo Paulo, no endereço Av. Dr. Arnaldo, 715, Cerquelra Cesar - CEP 01246-904, Săo Paúo, SP - Telefone: (11) 3051-7779 - e- mal: ceepofisp.usp.or.

Acredto ter sido suficientemente informado a respeito das informaçbes que II ou que foram Idas para mim, descrevendo o estudo Itinerario terapéutico de paclentes com artitite reumatolde em uso de medicamentos modincadores do curso da doença biologicos

Eu olscur com o pesquisador (a) RG sobre a minha declsăo em partcipar nesse estudo. Ficaram claros para mim quais s50 os objetvos do estudo, os procedmentos a serem realizados, seus desconfortos e niscos, as garantlas de contdencialdade e de esclarecimentos pemanentes. Flcou claro tambem que minha participaçăo e isenta de despes3s. Concordo voluntarlamente em participar deste estudo e poderel reirar o meu consentmento a qualquer momento, antes ou durante o mesmo, sem penaldades ou prejulzo ou perda de qualquer beneficio que eu possa ter adquirido, ou no meu atendimento no serviço de saude que frequento.

Assinatura do paclentelrepresentante lega:

Data $I$ I

Assinatura da testemunha

Data $f, l$

para casos de paclentes anafrabetos, seml-anaifabetos ou portadores de deflcencla auditiva ou visua.

(Somente para o responsavel do projeto)

Deciaro que oottve de forma apropriada e voluntaria o Consentlmento LIvre e Esclarecido deste paclente ou representante legal para a partclpaçato neste estudo.

Assinatura do responsavel pelo estudo

Data $/$ I 


\title{
Anexo II - Aprovação do estudo pelo CEP-FSP/USP
}

\author{
FACULDADE DE SAÚDE \\ PÚBLICA DA UNIVERSIDADE \\ DE SÃo PAULO
}

\section{PARECER CONSUBSTANCIADO DO CEP}

\section{DADOS DO PROJETO DE PESQUISA}

Titulo da Pesqulsa: Itinerario terapeutico de paclentes com artrite reumatolde em uso de medlcamentos modilicadores do curso da doença blologlcos

Pesqulsador: Sivia Colmbra de Olvelra

Area Tematica:

Versa: 1

CAAE: 60691116.6.0000.5421

Inatttulçąo Proponente: Faculdade de Saude Publlca da Universldade de S50 Paulo - FSP/USP

Patrocinador Principal: Financlamento Proprio

\section{DADOS DO PARECER}

Nümero do Parecer: 1.811 .367

Apresentaça do Projeto:

Estudo qual tatvo, descritivo e exploratorio sobre as trajetorias percorndas pelo usuanto do Sistema Único de Saude para acessar tratamento especiallzado para artrite reumatoide (AR) com medlcamento modincador do curso da doença blologlco (MMCDo). A metodologla envolve a aplicaçăo de entrevistas en profundldade a portadores de AR que tenham recebido tratamento com MMCDo dispensado pelo sistema pubilco na cidade de săo Paulo. As entrevistas serăo aplicadas em dlspensarios publicos de medicamentos do componente especiallzado. Seråo entrevistados cerca de 15 sujeitos, apos apllcaçăo de TCLE. Serấo Identifcados e descritos 05 itinerarios Terapeuticos (IT), Isto e, a trajetoria na busca de culdado, s0b o olhar de cada usuario, desde 05 primeiros sintomas da doença, dlagnostlco e utllizaçấ do MMCDb. Alem dos IT, o estudo pretende caractertzar e discutir $\infty$ papels e a articulaç5̆o entre a atençto primaria e 0 atendimento especialzado, bem como o mbx publico-privado de serviços utllizados nestas trajetorias.

\section{Objettvo da Pesqulsa:}

Identincar, descrever e analsar as trajetorias percorridas pelos usuarios do Sistema Único de Saude para acessar os MMCDo na reglấo de saude do municlpio de saude de săo Paulo. 


\section{FACULDADE DE SAÚDE PÚBLICA DA UNIVERSIDADE DE SÃo PAULO}

Cortinuacle do Pencer 1 bis $x$ t

Avallaçăo dos Rlscos $\theta$ Beneficios:

Riscos minimos: durante a reallzaçă das entrevistas, ha o risco do sujelto se sentir desconfortavel com a lembrança da sua doença.

Beneficios: Identftcaçăo da estutura de culdados disponilvel na cidade de Salo Paulo a partir dos olhos do paclente, reconhecimento e descriçăo das difnculdades encontradas, e apresentaçăo das mesmas aos gestores, o que pode contribulr para melhorar o serviço de saude dlsponlvel.

Comentarios $\theta$ Consideraçes sobre a Peequlsa:

Pesquisa relevante com metodologla adequada.

Consideraçes sobre $\propto$ Termos de apresentsça obrigatorla:

Pesquisadora apresenta TCLE adequado e carta de anuencla assinada pela Coordenadorla de Clencla, Tecnologla e insumos Estrateglcos de Saude da Secretarla de Estado da Saude de Săo Paulo.

Conclusరes ou Pendanclas $\theta$ Lista de inadequaç๐es:

Aprovado.

Consideraçes Finals a criterio do CEP:

Este parecer fol elaborado baseado nos documentos ababo relaclonados:

\begin{tabular}{|c|c|c|c|c|}
\hline Tipo Documento & Arqulvo & Postagem & Aufior & Situaçaso \\
\hline $\begin{array}{l}\text { Triromaçoes Basacas } \\
\text { do Proleto }\end{array}$ & $\begin{array}{l}\text { PE_INFOFIVACCOES_BASICAS_DO_P } \\
\text { ROJETO } 804311 . \mathrm{pd}\end{array}$ & $\begin{array}{c}10 / 10 / 2016 \\
12: 52-22\end{array}$ & & Acelto \\
\hline Folha de Rosto & folha_de_rosto_FSP.pdif & $\begin{array}{c}10 / 10 / 2016 \\
12: 51: 36\end{array}$ & $\begin{array}{l}\text { Silvia Coimbra de } \\
\text { Olvelra }\end{array}$ & Acelto \\
\hline $\begin{array}{l}\text { TCLE/Termos de } \\
\text { Assentimento I } \\
\text { Justificativa de } \\
\text { Ausencla }\end{array}$ & TCLE_projeto.pa' & $\begin{array}{c}10 / 10 / 2016 \\
07: 54: 11\end{array}$ & $\begin{array}{l}\text { Sivia Combra de } \\
\text { Olvelra }\end{array}$ & Acelto \\
\hline Crçamento & projeto_previsao_de_custos.pd & $\begin{array}{c}10 / 10 / 2016 \\
07: 50: 41\end{array}$ & $\begin{array}{l}\text { Slva Combra de } \\
\text { Olvelra }\end{array}$ & Acelto \\
\hline Outros & resposta_anuenda_SES.po' & $\begin{array}{c}10 / 10 / 2016 \\
07: 49: 42\end{array}$ & $\begin{array}{l}\text { Slvia Coimbra de } \\
\text { Olvelra }\end{array}$ & Acelto \\
\hline Cronograma & projeto_cronograma.pd & $\begin{array}{l}10 / 10 / 2016 \\
07: 48: 17\end{array}$ & $\begin{array}{l}\text { Slva combra de } \\
\text { Olvelra }\end{array}$ & Acelto \\
\hline $\begin{array}{l}\text { Projeto Detalhado / } \\
\text { Erochura }\end{array}$ & projeto_detalhado_10out2016.pd' & $\begin{array}{c}10 / 10 / 2016 \\
07: 48: 04\end{array}$ & $\begin{array}{l}\text { Silvia Coimora de } \\
\text { Olvelra }\end{array}$ & Acelto \\
\hline
\end{tabular}

Enderego: Av. Doutsr Amatde, 715

Bairre: Carqueina Cesa

CEP: 01 248004

UF: SP

Mu-icipia: SAOPALLO

Telefone: (11) $8061 \cdot \pi / 7$ )

Fax: (11)3061- 770

E-mail: coepchp usp br

Fipincis at in 
FACULDADE DE SAÚDE PÚBLICA DA UNIVERSIDADE DE SÃO PAULO

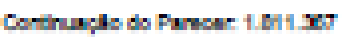

\begin{tabular}{|c|c|c|c|c|}
\hline |rivestgador & projetio_detalhado_100utzol6.pd' & $\begin{array}{l}10 / 70 / 2016 \\
07: 48: 04\end{array}$ & $\begin{array}{l}\text { Slvia Combra de } \\
\text { Olvelra }\end{array}$ & Acelto \\
\hline
\end{tabular}

SItusçaso do Parecer:

Aprovado

Necesstta Apreclsça da CONEP:

Năo

SAO PAULO, 08 de Novembro de 2016

Assinado por:

Marla Regina Alves Cardoso

(Coordenador) 


\title{
Anexo III - Anuência da SES/SP para entrevistas com pacientes
}

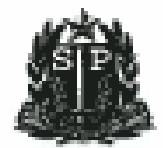

\author{
SECRETARIA DE ESTADO DA SAÚdE DE SÃO PAULO \\ COORDENADORIA DE CIÉNCIA, TECNOLOGIA E \\ INSUMOS ESTRATEGICOS DE SAUDE \\ Grupo de Asestencia Farmaceutes
}

intormaça CCTIES n'9. 236/2016

Intereseado: Mestrands Slva Coimbra de Oiverra a Professora Deutoera Ayinene Bousquat

Referência: S SRAD no $155706 / 2016$

Assunto: Projelo de pesquisa ftnerano teraptutpo da pacientes com act-te reumatode em uso de medcamentos modficadores do curso da dcenpa boilcgnos.

Em virtude do desenvommento do projeto de pesquisa ftunerano terapAutico da pacientes com artrite reumalove em uso de medcamerhos modficadores do curso da doença bolbg cos", a mestranda Stvia Combra de O mera e a Protessora

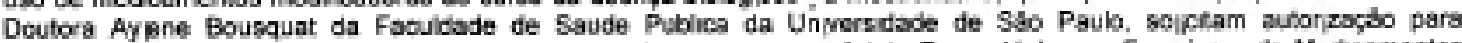
rearzacho de entrenstas a pacientes em uso de medicamentos para Avinte Reumeteide nas Fanmácras de Medicamentes Especralzados (FME) Maria Zela ou Varzea do Carmo, bem come documentaça relacionada ao tema pera aprofundamento

Quarto à solichisays, sformamos

- As diretrags papa atençato a saude as paciente com Adrte Reeumatoide no ambato do SUS conagam no Protocos Clinico e

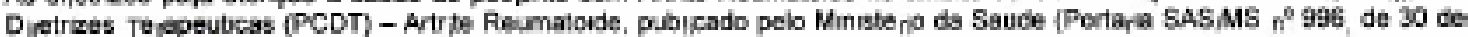
setembre de 2015)

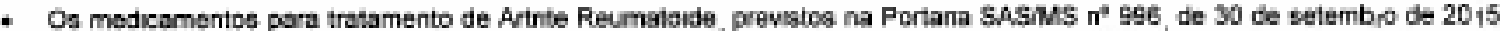

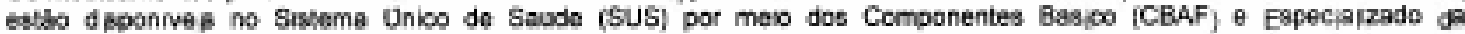
Assistenca Farmacbutica (CEAF) - Ouadro 01

Quadjo 01 - Modicamentos papa o tratamento de Artrite Reumaterde disporives no SUS

\begin{tabular}{|c|c|c|}
\hline Medramento & $\begin{array}{l}\text { Componente } \\
\text { da Asxbstons a } \\
\text { Farmateutice }\end{array}$ & Crupo de Finanelaments \\
\hline aturaospte $250 \mathrm{mg}$ metive ifpst rabss-empalaj & \multirow{16}{*}{ CEAF } & \multirow{9}{*}{ 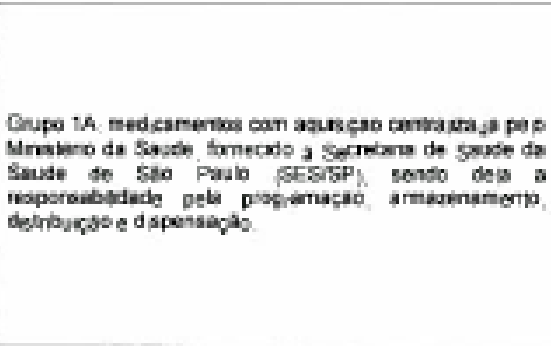 } \\
\hline 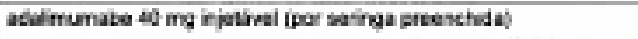 & & \\
\hline 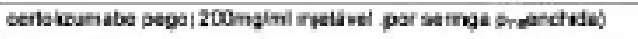 & & \\
\hline etareroept: $25 \mathrm{mg}$ nerdwel ipor frasc jansoa) & & \\
\hline 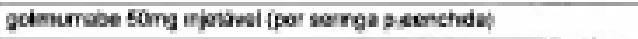 & & \\
\hline 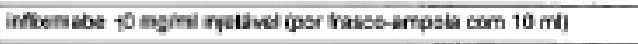 & & \\
\hline Iefnemada 20 mg (par eongrmado) & & \\
\hline 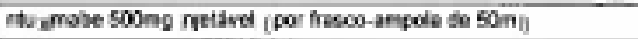 & & \\
\hline 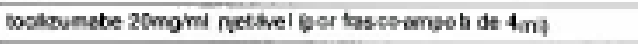 & & \\
\hline azatopern a $50 \mathrm{mp}$ poe comormads) & & \multirow{7}{*}{ 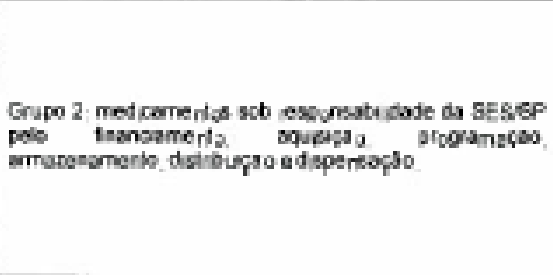 } \\
\hline 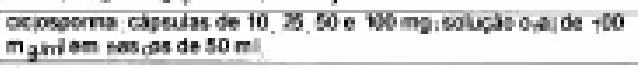 & & \\
\hline dior auns $100 \mathrm{~m}$, por comporm do) & & \\
\hline 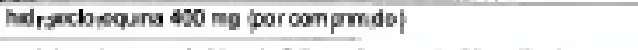 & & \\
\hline 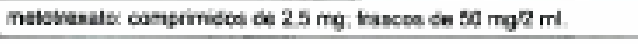 & & \\
\hline naprantna: compimides de $250 \mathrm{~m}$; eu te $509 \mathrm{mg}$ & & \\
\hline sulassdazina 560 my (par comprinicn) & & \\
\hline pedisone. comptimifos de 5 os $25 \mathrm{mg}$ & \multirow{3}{*}{ CQNF / CEAF } & \multirow{3}{*}{ 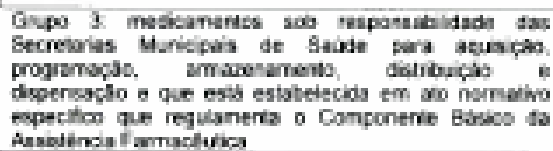 } \\
\hline prednisobens sobuçbo eral te 1 e $3 \mathrm{mg} \mathrm{mi}$. & & \\
\hline 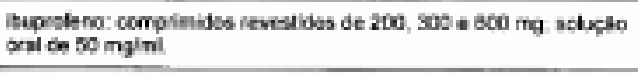 & & \\
\hline
\end{tabular}

ALM $/ K L^{2}$ 


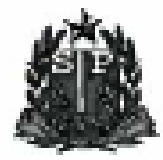

\author{
SECRETARIA dE ESTADO DA SAÚdE dE são PAULo \\ COORDENADORIA DE CIÉNCIA, TECNOLOGIA E \\ INSUNOS ESTRATEGICOS DE SAUDE \\ Grupo de Assistancia Farmacbutica
}

- O acesso ass medcamentos do CBAF se da em ámbato murucpal sendo recomendada a consulta a Secretarta Muncipal de Saude para Efermapoes pertinentes.

- O acesso sos medcamentos do CEAF ccerre em Fambcas de Medcamentos Eepecisizades (FME) da Secretaria de Estado da Saúde de S8o Paula, em conformudade com as regras previstas na Portana GMMMS ne 1,654/2013, a qual dispo sobre o financiamento e a execuç,o do CEAF no smbilo do Sistema Unuco de Sacide bem como acs.

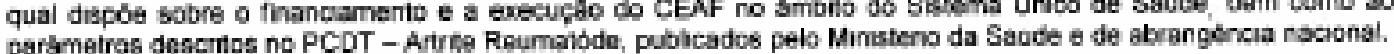

- De acordo com a Portana GMMS ñ2 1 564/2013, a execuç80 do CEAF ervolve as segumes etapas.

1. Solichachy corresponde ao plehto por medicamentos, pelo paciente ou seu responsalvel,

- Avaliaçaco corresponde a gndise técnica, de caráter decumental da solvataçăo e de renovaçấo do continuidade de tratamento:

Autorracho. corresponda ao perecer de cartiter adminstrativo que agrova ou nato o procedimento relerente a solvitaçaso ou rencvapas da conbnuidade do tratsmento greviamente avalıda

Dispensaça consiste no ato de fornecer medicamento(s) previamemte autorugdo|s)

Renovaçáo da confinudade do tratamento corresponde ao pletto pela conbnudade do tratamento. pelo

pacreme ou seu responsavel com penodicidade trimestral

- As FME Marra Zeita e Varzea do Camo saso unidades de referênea para medicementos do Componerne Especialzzado do Assisténcis Farmacéubca (CEAF) a pec,entes res,dentes no munierpio de Sto Paulo.

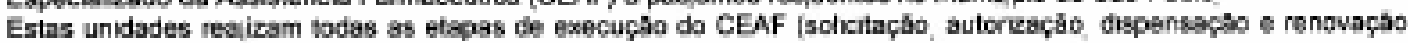
da contruadade do tratamento)

- Considarada a legisłaçáo santbria vigente, as FME Maria zélia e Varzea do Carmo reas zam a dispensaçbo dos modicamentos para Artrite Reumatode por meio de:

- Avendimento presencisl de pacientes;

- Entregs em domicilia para pacientes aderentes ae Programa.

- O Grupe de Assistencla FarmachuticanCCTIES nalo possui objeçbes com relaçbo à conduçăo das entreviatas junto aos pacientes no ámbito do projelo de pesquisa "ltenerasio beraptulico da pecientes com artrite reumstade em uso de medicamentos modficadores de curso da doença biologicos' contudo, soivith. se

1. Apresentaça do parecer do Comne de Ébca da Faculdade de Saúde Piblea ta Univeradade de SAa Paulo para prosseguimento $e$ anuencia conclusiva da conducto da pesquisa. uma vaz que dewem ser seguados cas preceitos éthcos de pesquisa $\mathrm{em}$ saide:

2 Apresentaço dos resultados do projeto de pescuisa a Secretan a de Estado da Sacde de SBo Paulo quando concluibo

- Com relaça ao materal complementar solkctado apresontamos as informaçbes que dispomos para letura e ennquecimento da discussdo do trabalho

1. Dados de faturamento dos medicamentos que integram o Grupo $1 \mathrm{~A}$

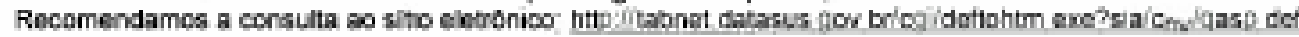

Neste endereco a possivel consultar o consume reaizado e aprovado pelo Mnisteno da Sacide para os medicamentos no ambito do CEAF, bem como os valores erwolvidos

Sugenmos utizar os seguimes fitros

- Linha Procodmento

- Coluna Acoimès processamento

- Conteúdo Qted Aprovada / Valor aprovade

- Periodos dieponiveis Jareiro al Dezembro/2015

- Grupo procedimento 06 Medicamentos

- Subgrupo proc : DeO4 Companente Especialzado da Assisienca Farmaceutica 
A Figura 1 apresenta 0 print screen do contecide nsualzado em http//tabnet.datasus.gov.br/cgV/deftohtm exe?sia/cnv/qusp del, cam os fltros sugendas

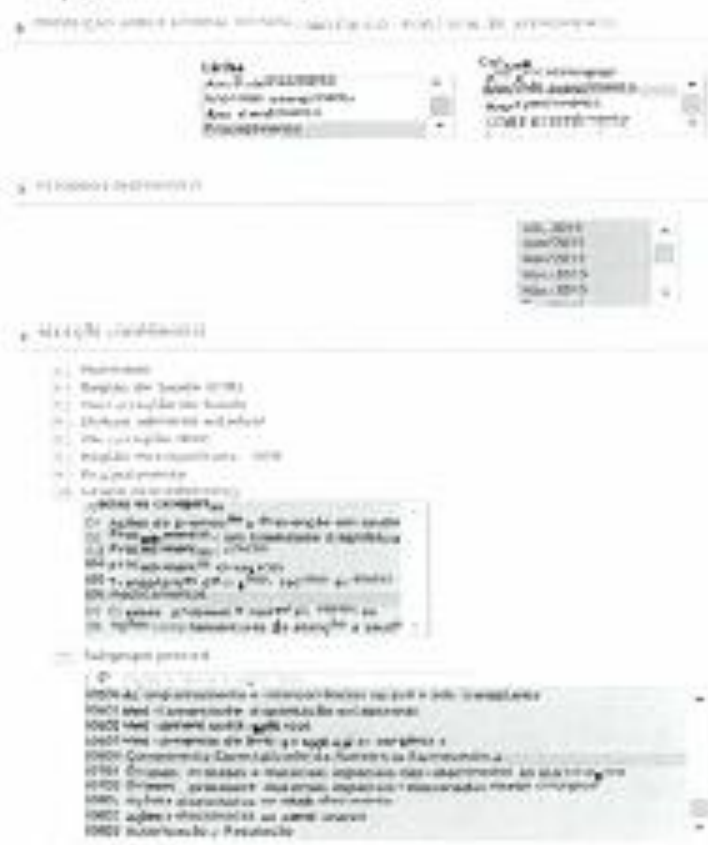

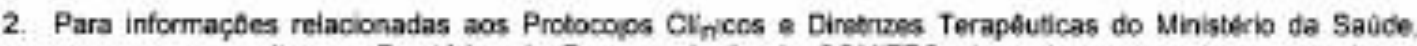
sugermos consulta aco Rezatórios de Recomendaçaso da CONITEC dsponivers no ende,joço eqetronico hittplloontec gav brirelaloriog-de-recomendacao.de-contec

Propoe-sa encaminhamento deste ao Gabinete do Coordenador ca CCTIES, pafa conhecmente e autorzaça de encaminhamento deste parecer as interessado se juigar pert nente

SSo Paula, 14 de sotemben de 2016

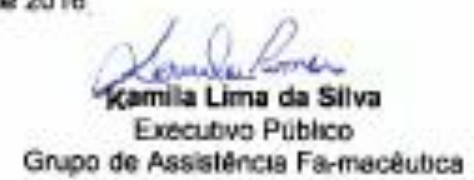

Ciente e de acondo.

Encarrinhe se conforme peuposto.

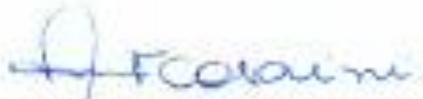

Alexandra Mariano Fidencio Casarini

Drefor Técnico de Sacide 11

Grupyue Assissencra Farmactutica 


\section{SECRETARIA DE ESTADO DA SAÙDE \\ COORDENADORIA DE CIENCIA, TECNOLOGIA E \\ INSUMOS ESTRATÉGICOS DE SAÜDE \\ Gabinete do Coordenador}

Despacho CCTIES $n^{\circ}$ 5.882/2016

Interessado: Mestranda Siva Cojmber de Otwejra e Protescora Dautora Aylene Bousquat

Refertncia: SISFAD no 158,7062018

Assunto. Projeto de pesquisa "Itonerano terapeutico da pacientes com artite reumatoide em uso de medcamerhos modificadores do curso da doença biơogicos"

Ciente e de acordo com a manifestaçẩo do Grupo de Assistencia FarmaceutcalCCTIES, por mejo da jiformaçaó CCTIES na g.236/2016. encaminhe-se ab interessado, conforme propcsto

São Paulo, 19 de selembro de 2016

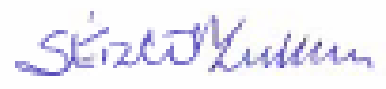

Sérgio Swain Müller

Cocrdenader de Saúde

Coordenadoria de Ciencia. Tecnologia $e$

Insumos Estrategoos de SaĹde - SESISP 